\title{
MULTIFACTOR SYSTEMATIC RISK ANALYSIS BASED ON TIME-VARYING SIGNAL PROCESSING MODELS
}

by

\author{
LUAN VO \\ Bachelor of Electrical Engineering, \\ Vietnam National University of Technology, 2007.
}

\author{
A thesis \\ presented to Ryerson University \\ in partial fulfillment of the \\ requirement for the degree of \\ Master of Applied Science \\ in the Program of
}

Electrical and Computer Engineering.

Toronto, Ontario, Canada, 2012

(C) LUAN VO, 2012 


\section{AUTHOR'S DECLARATION}

I hereby declare that I am the sole author of this thesis. This is a true copy of the thesis, including any required final revisions, as accepted by my examiners.

I authorize Ryerson University to lend this thesis to other institutions or individuals for the purpose of scholarly research.

I further authorize Ryerson University to reproduce this thesis by photocopying or by other means, in total or in part, at the request of other institutions or individuals for the purpose of scholarly research.

I understand that my thesis may be made electronically available to the public. 


\title{
Multifactor Systematic Risk Analysis Based on Time-varying Signal Processing Models
}

\author{
Master of Applied Science 2012 \\ LUAN VO \\ Electrical and Computer Engineering \\ Ryerson University
}

\begin{abstract}
This thesis applies the time-varying signal processing models to track the multifactor systematic risk in the Fama-French model. The mean reverting, random walk and random coefficient models are used to analyze the time-varying multifactor beta based on the multivariate Kalman filter algorithm. The sudden changes in the mutifactor beta are captured by the piecewise constant model. Our case studies explain the impacts of economic events on the sudden changes in betas for both individual stocks and industrial portfolios.

We propose a new time-varying beta model based on a piecewise mean reverting process to express the effects of different types of events on the multifactor beta. The tracking of the piecewise mean reverting beta, using the modified multivariate Kalman filter with the maximum log likelihood estimator, outperforms the traditional piecewise constant and random walk models as demonstrated in our simulations. The empirical tests indicate that the new model effectively captures the different changes in beta depending on the type of event.
\end{abstract}




\section{Acknowledgments}

I am heartily thankful to my supervisor, Dr Xiao-Ping Zhang, whose expertise, guidance, and support have enabled me to complete my thesis. His patience and advice have made writing this enjoyable.

I would like to thank Dr. K. Umapathy who provided great knowledge on Digital Signal Processing and Intelligent Systems which allowed me to apply it in this thesis.

I offer my regards to my thesis defense committee. I appreciate your time and contributions.

I am indebted to many of my colleagues in the CASPAL lab, Triloke, Tim, Arsalan, and Junfeng who were always willing to discuss and support me on solving technical problems that have made this thesis possible.

Lastly, I owe my deepest gratitude to my family for their encouragement and support in completing my Master's study. A special thanks to my parents and my fiance, Cathy, for always being there for me. 


\section{Contents}

1 Introduction $\quad 1$

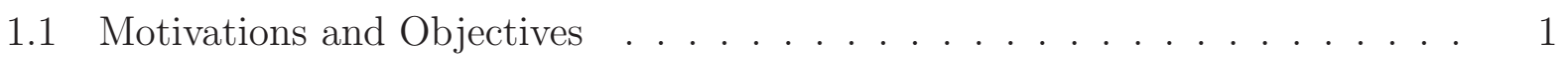

1.2 Background . . . . . . . . . . . . . . . . . . . 3

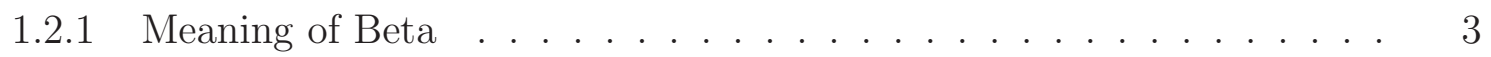

1.2 .2 Beta Estimation . . . . . . . . . . . . . . . 3

1.2.3 Time-varying Beta Models . . . . . . . . . . . . . . 4

1.2.4 The Capital Asset Pricing Model (CAPM) . . . . . . . . . . . 6

1.2.5 The Fama-French Model . . . . . . . . . . . . . . . . 7

1.2.6 CAPM versus Fama-French Model . . . . . . . . . . . . . 8

1.2.7 Methodologies . . . . . . . . . . . . . . . 9

1.3 Contributions ............................... 10

1.4 Organization of Thesis . . . . . . . . . . . . . . . . . . . 11

2 Constant Multi-factor Beta Analysis 13

2.1 Introduction . . . . . . . . . . . . . . . . . . . . 13

2.2 Multifactor Systematic Risk Analysis Review . . . . . . . . . . . . . . 14

2.3 Multi-factor Risk OLS Estimation . . . . . . . . . . . . . . 15

2.3.1 OLS Estimation for Single Factor CAPM . . . . . . . . . . . 15

2.3.2 OLS Estimation for Fama-French Three Factors Model . . . . . . . . 16

2.4 Empirical Tests . . . . . . . . . . . . . . . . . . 17

2.4.1 Leave-one-out Method . . . . . . . . . . . . . . 17

2.4 Data Sources . . . . . . . . . . . . . . . 17

2.4.3 Empirical Test Procedure . . . . . . . . . . . . . . . . . 18 
2.4.4 Estimation Performance Criteria . . . . . . . . . . . . 18

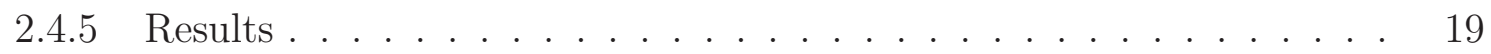

2.5 Summary . . . . . . . . . . . . . . . . . . . . . 23

3 Multi-factor Time-varying Beta Analysis 24

3.1 Introduction . . . . . . . . . . . . . . . . . . . . . . . . . 24

3.2 Time-varying Multi-factor Beta Analysis using Kalman Filter . . . . . . . . 25

3.3 Empirical Tests . . . . . . . . . . . . . . . . . . . . . . . . 30

3.3.1 Empirical Tests Module .................. 30

3.3.2 Estimation Performance Criteria . . . . . . . . . . . . . . 30

3.3.3 Data Sources . . . . . . . . . . . . . . . . 33

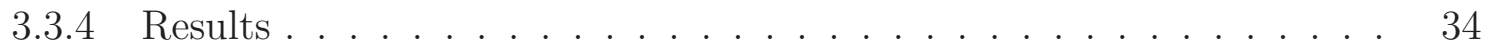

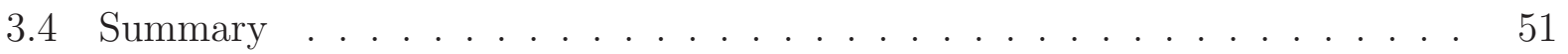

4 Apply Piecewise Constant Multi-factor Beta Model on Event Study 52

4.1 Introduction . . . . . . . . . . . . . . . . . . . 52

4.2 Apply PCM and Fama-French Model to Detect Events using Kalman Filter . 53

4.2.1 Piecewise Constant Model (PCM) . . . . . . . . . . . . 53

4.2.2 Detect a Jump Using the Modified Kalman Filter Review . . . . . . . 54

4.2.3 Event-study Based on the Kalman Filter . . . . . . . . . . . . . . . . 55

4.3 Empirical Tests . . . . . . . . . . . . . . . . . 57

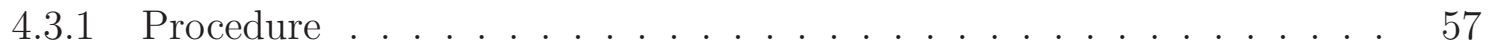

4.3 .2 Data Sources . . . . . . . . . . . . . . . 57

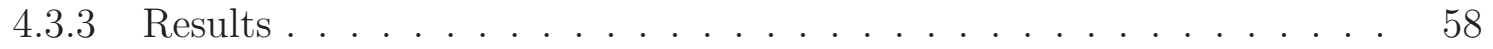

4.3 .4 Event-study Cases . . . . . . . . . . . . . . . . 59

4.4 Summary . . . . . . . . . . . . . . . . . . . . 73

5 Piecewise Mean Reverting Multi-factor Beta Model 75

5.1 Introduction . . . . . . . . . . . . . . . . . . . 75

5.2 Piecewise Mean Reverting Model . . . . . . . . . . . . . . . . . 76

5.3 Modified Kalman Filter Algorithm for PMR Beta Tracking . . . . . . . . . . 77 
5.4 Simulations . . . . . . . . . . . . . . . . . . . 78

5.5 Empirical Tests . . . . . . . . . . . . . . . . . . . . . 82

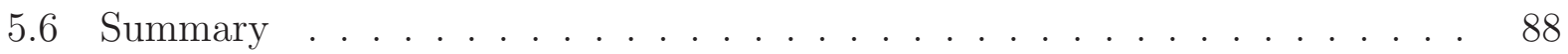

6 Conclusion and Future Works $\quad 89$

$\begin{array}{ll}\text { Bibliography } & 93\end{array}$

$\begin{array}{lr}\text { Vita } & 100\end{array}$ 


\section{List of Figures}

2.15 years rolling betas of AAPL $\ldots \ldots \ldots \ldots . \ldots \ldots \ldots$

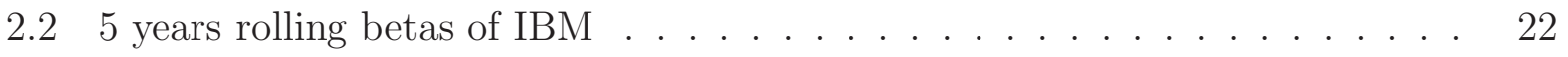

2.35 years rolling betas of $\mathrm{GE} \ldots \ldots \ldots \ldots \ldots$

3.1 Time-varying multi-factor beta of industry I (a) . . . . . . . . . . . 41

3.2 Time-varying multi-factor beta of industry I (b) . . . . . . . . . . . . 42

3.3 Time-varying multi-factor beta of industry II (a) . . . . . . . . . . . . 43

3.4 Time-varying multi-factor beta of industry II (b) . . . . . . . . . . . 44

3.5 Time-varying multi-factor beta of of AAPL (a) . . . . . . . . . . . 45

3.6 Time-varying multi-factor beta of AAPL (b) . . . . . . . . . . . . . 46

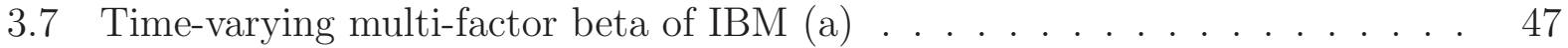

3.8 Time-varying multi-factor beta of IBM (b) . . . . . . . . . . . . . . . . 48

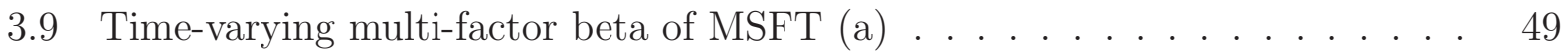

3.10 Time-varying multi-factor beta of MSFT (b) . . . . . . . . . . . 50

4.1 FF-PC: abnormal changes in multifactor systematic risk of AAPL . . . . . 60

4.2 FF-PC: abnormal changes in multifactor systematic risk of IBM . . . . . . 62

4.3 FF-PC: abnormal changes in multifactor systematic risk of GE . . . . . . . 64

4.4 FF-PC: abnormal changes in multifactor systematic risk of oil portfolio . . . 66

4.5 FF-PC: abnormal changes in multifactor systematic risk of banking portfolio 69

4.6 FF-PC: abnormal changes in multifactor systematic risk of real estate portfolio 71

5.1 A simulated sample of PMRM . . . . . . . . . . . . . . . . . 77

5.2 An example of PMR multi-factor beta tracking for $\beta \ldots \ldots$

5.3 An example of PMR multi-factor beta tracking for $\beta_{S M B}$ and $\beta_{H M L} \ldots . .80$ 
5.4 Effect of noise in the observation model on the PMR beta tracking . . . . . . 81

5.5 Effect of noise in the state model on the PMR $\beta$ tracking $\ldots . . . . . .82$

5.6 Effect of noise in the state model on the PMR $\beta_{S M B}$ and $\beta_{H M L}$ tracking . . 82

5.7 PMR multi-factor $\beta$ tracking of $\mathrm{CSCO} \ldots \ldots . \ldots . \ldots . \ldots$

5.8 PMR multi-factor $\beta$ tracking of RIMM . . . . . . . . . . . . . . 85

5.9 PMR multi-factor $\beta$ tracking of MSFT . . . . . . . . . . . . 85

5.10 PMR multi-factor $\beta$ tracking of automobile industrial portfolio. . . . . . . 87 


\section{List of Tables}

1.1 Meaning of beta . . . . . . . . . . . . . . . . . . 3

2.1 Leave-one-out test results for S\&P500: daily data . . . . . . . . . . . . . 19

2.2 Leave-one-out test results for S\&P500: monthly data . . . . . . . . . . . 20

2.3 Leave-one-out test results for 48 portfolios: daily data . . . . . . . . . . . . . 20

2.4 Leave-one-out test results for 48 portfolios: monthly Data . . . . . . . . . . . 21

3.1 Historical Stocks' Data for the Empirical Tests . . . . . . . . . . . . . . . . 33

3.2 Historical Empirical Tests Stocks' Market Cap in April 2012 . . . . . . . . . 34

3.3 Historical Industrial Portfolios' Data for the Empirical Tests . . . . . . . . . 34

3.4 Time-varying beta analysis in CAPM: empirical tests results of RW,RC and MR models for the individual stocks . . . . . . . . . . . . . 36

3.5 Time-varying beta analysis in CAPM: empirical tests results of RW,RC and MR models for the industrial portfolios . . . . . . . . . . . . . . . 37

3.6 Time-varying betas analysis in Fama-French model: empirical tests results of RW,RC and MR models for the individual stocks . . . . . . . . . . . 39

3.7 Time-varying betas analysis in Fama-French model: empirical tests results of $\mathrm{RW}, \mathrm{RC}$ and MR models for the industrial portfolios . . . . . . . . . . 40

4.1 Industrial portfolios for the empirical tests of the PC beta model . . . . . 58

4.2 CAPM-PC vs FF-PC criteria for individual stocks . . . . . . . . . . . . 59

4.3 CAPM-PC vs FF-PC criteria for portfolios . . . . . . . . . . . . . 59

$5.1 \quad$ FF-PMR test results for individual stocks . . . . . . . . . . . . . . 83

5.2 FF-PMR test results for portfolios . . . . . . . . . . . . . . . . 83 


\title{
List of Abbreviations
}

\author{
AIC - Akaike Information Criteria \\ BIC - Bayesian Information Criteria \\ CAPM - Capital Asset Pricing Model \\ FFM - Fama-French Model \\ MRM - Mean Reverting Model \\ OLS - Ordinary Least Squares \\ PCM - Piecewise Constant Model \\ PMRM - Piecewise Mean Reverting Model \\ RCM - Random Coefficient Model \\ RWM - Random Walk Model
}




\section{Chapter 1}

\section{Introduction}

\subsection{Motivations and Objectives}

The most well-known measure of risk of an investment is beta which presents the systematic risk and cannot be eliminated through diversification. In the Capital Asset Pricing Model (CAPM), the market beta is a single factor used broadly in practice. However, empirical tests show that market anomalies such as size and value effects cannot be explained by the CAPM [6], [3]. Thus, the market beta in CAPM is not sufficient enough to measure systematic risk. The multifactor beta in the Fama-French model (FFM) that includes market beta, size beta and value beta is more appropriate to measure the systematic risk [3].

The Ordinary Least Squares (OLS) regression, which assumes beta is constant during a certain period of time, is the most popular method used to estimate betas in both the CAPM [17], [40], [32] and FFM [2], [3], [25]. The downfall of this method is data frequencies and time intervals cannot be determined to achieve the best beta estimation. As a result, multiple time-varying beta models are being investigated along with the CAPM [44], [45], [40], [41]. Blume found that betas tend to regress towards the mean [44], [45]. Sunder and Simonds suggest that the Random Walk (RW) model is the most suitable model for the US market over long time periods [40], [41]. Ohlson and Rosenberg show improvements in beta estimation using the Mean Reverting (MR) model [39]. Shyam concludes the nonstationarity of market risk using the Random Coefficient (RC) model for individual stocks [40]. Brooks also suggests the RC model as the best fit model to describe the systematic risk of both individual stocks and portfolios [17]. Current research broadly attempts to test the 
validity of the time-varying models and the best-fit beta model in the single factor CAPM [40] [41] [42] [53]. However, when multifactor models are studied, only the traditional OLS regression is applied to estimate the multifactor beta [67], [36], [27]. Papers have not yet analyzed the time-varying multifactor beta in the Fama-French three-factor model. Thus, further research needs to be done to determine the time-varying characteristic of betas in the Fama-French model.

In event studies based on beta in the CAPM, Lockwood and Kadiyala develop an approach that allows different systematic risk parameters before, during, and after events. Using monthly returns, they found that the endpoints of event periods differ across firms [55]. Bar-Yosef and Brown imply that systematic risk first rises and then falls around stock splits. They confirm this for both rising and falling markets. Scholes shows the issue of stationary is somewhat mitigated by estimating parameters using returns before and after the event [57]. However, their approach do not allow for changes in beta during the event period. Ken and Ramon propose a new procedure permitting measures of systematic risk to change during the event period. The procedure explicitly identify unique event periods for each firm which is asymmetrical [58]. No papers have addressed the event studies based on time-varying multifactor beta.

The objective of this thesis is to analyze the systematic risk in the time-varying matter, based on the Fama-French three factors model and detect new applications of multifactor beta on event studies. It is different from previous literatures which focus only on the single factor CAPM. The traditional constant multifactor beta analysis is performed using multiple rolling windows and data frequencies to confirm the instability of beta. By applying signal processing knowledge and the financial facts, we attempt to prove the significance of the timevarying betas in the Fama-French model and the relationship between the sudden changes in the multifactor beta and important events. The time-varying multifactor beta is analyzed using multiple stochastic models (RW, RC and MR) along with the market models (CAPM and FFM). The multivariate Kalman filter is used to track the time-varying multifactor beta. The abnormal changes in betas are detected using the Piecewise Constant (PC) multifactor model. The significant change points then support event studies in determining the effects of macro and micro economic events on multifactor systematic risk. We propose a new Piecewise 
Mean Reverting (PMR) multifactor beta model to alternatively express the behavior of the market risk in regards to different types of events. The model allows beta to change following a reverting process during an event period.

\subsection{Background}

\subsubsection{Meaning of Beta}

Beta is a number that describes the relationship between an investment return and the overall market return. A high beta implies a dramatic growth in stock price when the market (index) price is up and a dramatic fall when the market price goes down [8]. It shows a high correlation between the stock return and the market return that it belongs to. In contrast, a small beta indicates the low correlation between the stock return and the market return. Table 1.1 summarizes the meaning of beta in finance theory. The beta depends on two important factors: the relative volatility of a security return as compared to the market return and the correlation of the security return to the market return.

Table 1.1: Meaning of beta

\begin{tabular}{|l|l|}
\hline beta & Meaning of beta \\
\hline beta $<0$ & The stock return tends to move in inverse to the market return. \\
\hline beta $=0$ & $\begin{array}{l}\text { The stock return and the market return move independently. } \\
\text { Their correlation equals to } 0 .\end{array}$ \\
\hline $0<$ beta $<1$ & $\begin{array}{l}\text { The stock return is less volatile than the market return. } \\
\text { They have low correlation. }\end{array}$ \\
\hline beta $=1$ & \begin{tabular}{l} 
The stock return has the same volatility as the market return. \\
\hline beta $>1$
\end{tabular} \\
\hline
\end{tabular}

\subsubsection{Beta Estimation}

An asset exhibits both systematic and unsystematic risk (or idiosyncratic risk). The portion of its volatility, which is considered systematic is measured by the degree to which its return varies relative to those of the overall market [44]. Beta measures the degree of co-movement 
between the asset return and the market portfolio return. In other words, beta quantifies the systematic risk of an asset:

$$
\beta=\frac{\operatorname{cov}\left(\mathbf{r}, \mathbf{r}_{I}\right)}{\sigma_{\mathbf{r}_{I}}^{2}}
$$

where $\mathbf{r}$ is the return of the asset, $\mathbf{r}_{I}$ is the return of the market, $\sigma_{\mathbf{r}_{I}}^{2}$ is the variance of the return of the market, and $\operatorname{cov}\left(\mathbf{r}, \mathbf{r}_{I}\right)$ is the covariance between the return of the market and the return of the asset [19]. A measure of risk can also be used in a model to describe the relationship between systematic risk and expected return, such as the CAPM. In this single factor model, beta is used to measure the systematic risk of an individual asset or a portfolio. The CAPM model, a corner-stone of modern finance, states that the risk premium of an individual asset is equal to its beta multiplied by the risk premium on the market portfolio.

In practice, beta is calculated using historical return for both the asset and the market. The market return is chosen from a set of indexes, such as the S\&P 500, NYSE, AMEX, NASDAQ, and etc. These historical data can be imported directly to software packages, for example MS Excel, and used to perform a regression method to estimate beta. It is also a useful parameter for evaluating the performance of the stock return. Based on the relationship between a stock and its market, beta can provide investors with a prediction on the movement of the stock return compared to its market return [67].

To obtain the right application of beta, we need to consider the variance of the beta based on different factors of the estimation. The value of estimated beta can be different depending on different time frames, time intervals, market indexes and dividends. For example, the beta of a historical time frame of one year will be different from thirty years time frame analysis [18] [19]. Monthly, weekly, and daily are the different frequencies of asset return and market return which also affect the beta calculation. Similarly, looking at a stock return in different markets or the exclusion of dividends will result in different beta values [66].

\subsubsection{Time-varying Beta Models}

The RW, RC and MR models are the most popular time-varying models used in previous

studies. When these models are used to analyze the beta in a single factor model (e.g Sharp Diagonal or CAPM), they demonstrate a great improvement in beta estimation as compared 
to the traditional OLS regression method [16], [14], [40], [41], [39].

\section{Random Coefficient Model (RCM)}

The coefficients in RCM consist of two parts: a mean or a fixed part $(\bar{\beta})$, and a variance or a random part $\left(\zeta_{t}\right)$. The random part is represented by a Gaussian noise with zero mean and $\sigma_{\zeta}^{2}$ variance. The beta in the model is represented as:

$$
\beta_{t}=\bar{\beta}+\zeta_{t}, \quad \zeta_{t} \sim N\left(0, \sigma_{\zeta}^{2}\right)
$$

The details and explanations of the RCM can be found in [48], [33] and [34].

\section{Random Walk Model (RWM)}

A Random Walk (RW) is a mathematical formalization of a trajectory that consists of taking successive random steps [1]. For financial data, a "random walk theory" became very popular after Burton Malkiel wrote "A Random Walk Down Wall Street" in 1973. Fama also determines the "random walks" in stock market prices [23]. In this thesis, we will look at the pure RWM which is formulated as:

$$
\beta_{t}=\beta_{t-1}+\zeta_{t}, \quad \zeta_{t} \sim N\left(0, \sigma_{\zeta}^{2}\right)
$$

where $\zeta_{t}$ represents the disturbance following a normal distribution with zero mean and $\sigma_{\zeta}^{2}$ variance.

\section{Mean Reverting Model (MRM)}

Mean Reverting (MR) model is applied to the financial time series data to determine the mean reversion of the stock price. Similar to the operational principal of the violin string analogy, the idea of the MR model states that the only way to measure mean reversion is when the variances of asset prices in financial markets get plucked away from their non-event levels [49]. The idea is formulated for beta in the following equation:

$$
\beta_{t}=\bar{\beta}+\phi\left(\beta_{t-1}-\bar{\beta}\right)+\zeta_{t}, \quad \zeta_{t} \sim N\left(0, \sigma_{\zeta}^{2}\right)
$$

The greater the mean-reverting parameter $\phi$ value is, the greater the pull back is to the

equilibrium level $\bar{\beta}$. Mean reversion in beta is justified by the theoretical models in [50] 
and [51]. These models imply that beta reverts to its long-term mean over a period of time consistent with the business cycle. These results are confirmed empirically in [52]. The evidence of time-varying betas with a slow mean-reverting component is also found in [53].

\subsubsection{The Capital Asset Pricing Model (CAPM)}

The CAPM was introduced by W. Sharpe and J. Lintner (resulting in a Nobel Prize for Sharpe in 1990). It has become the most well-known model in the asset pricing theory. According to CAPM [46], the expected excess return (expected return minus the risk free rate) on an asset is given by :

$$
E[\mathbf{r}]-\mathbf{r}_{f}=\beta .\left(E\left[\mathbf{r}_{I}\right]-\mathbf{r}_{f}\right),
$$

where $\mathrm{E}[$.$] is the expected value, \mathbf{r}$ is the return of an asset, $\mathbf{r}_{f}$ is the risk-free return, $\mathbf{r}_{I}$ is the return on the market portfolio, $\beta$ is the systematic risk of an asset related to the market portfolio. An estimate for $\beta$, therefore, is typically obtained by running the following time series regression:

$$
r_{t}-r_{f, t}=\alpha+\beta \cdot\left(r_{I, t}-r_{f, t}\right)+\epsilon_{t}, \quad \epsilon_{t} \sim N\left(0, \sigma_{\epsilon}^{2}\right),
$$

where $\left\{r_{t}-r_{f, t}\right\}$ is the excess return of an asset, $\left\{r_{I, t}-r_{f, t}\right\}$ is the excess return of a market, $\epsilon_{t}$ is the error term which is assumed to follow a normal distribution with zero mean and $\sigma_{\epsilon}^{2}$ variance.

In recent research, researchers work with portfolios rather than individual stocks using the CAPM model [57] [45], [47]. If $x_{i p}$ (with $\left.i=1,2, \ldots, N\right)$ are the weights of assets in portfolio $p$, the portfolio's expected return $\left(E\left[\mathbf{r}_{p}\right]\right)$ and the portfolio beta $\left(\beta_{p}\right)$ are related to the expected return and beta of assets as:

$$
E\left[\mathbf{r}_{p}\right]=\sum_{i=1}^{N} x_{i p} E\left[\mathbf{r}_{i}\right], \quad \beta_{p}=\sum_{i=1}^{N} x_{i p} \beta_{i} .
$$

Thus, the CAPM relation between expected return and beta in (1.5) holds when asset $i$ is a portfolio, as well as when $i$ is an individual security [24]. 


\subsubsection{The Fama-French Model}

CAPM has always been the most dominant model in stock market analysis. However, many research papers indicate that the model fails to explain the cross section of expected return [6], [3]. Based on empirical tests, Fama and French prove that the one factor model is not sufficient to catch all the market behaviors. Estimates of beta for individual assets are imprecise and creates measurement error when used to explain average return. According to their research, estimates of beta for a diversified portfolio not only reduces the critical errors in the variables but also shrinks the range of betas and statistical power [3]. In order to reduce this drawback, the sorting procedure was introduced for empirical test such as the first portfolio contains securities with lowest betas and then up to the last portfolio with the highest betas.

They also demonstrate the evidence of the empirical failures in the CAPM such that much of the variation in expected return is unrelated to the market beta. They confirm the importance in size, earnings-price, debt-equity, and book-to-market ratios to the explanation of expected stock return provided by the market return [6]. These are the basic foundation and evidences to search for another model more suitable and accurate to explain the relationship between the market return and the asset return.

Fama and French introduced the three-factor model for the expected return in belief that this model outperforms the CAPM model for portfolios based on their empirical tests [6],[3]. The model is as follow:

$$
E[\mathbf{r}]-\mathbf{r}_{f}=\beta \cdot\left(E\left[\mathbf{r}_{I}\right]-\mathbf{r}_{f}\right)+\beta_{S M B} \cdot E[S M B]+\beta_{H M L} \cdot E[H M L],
$$

where $\mathrm{E}[$.$] is the expected premiums, \beta, \beta_{S M B}, \beta_{H M L}$ are the slopes of the time series regression of a portfolio:

$$
r_{t}-r_{f, t}=\alpha+\beta \cdot\left(r_{I, t}-r_{f, t}\right)+\beta_{S M B} \cdot S M B_{t}+\beta_{H M L} \cdot H M L_{t}+\epsilon_{t} .
$$

The $S M B$ and $H M L$ factors are defined in [3] as follow:

- $S M B$ (Small Minus Big) is the average return on three small portfolios minus the average return on three big portfolios: 


$$
\begin{aligned}
S M B & =1 / 3(\text { Small Value }+ \text { Small Neutral }+ \text { Small Growth }) \\
& -1 / 3(\text { Big Value }+ \text { Big Neutral + Big Growth }) .
\end{aligned}
$$

- $H M L$ (High Minus Low) is the average return on two value portfolios minus the average return on two growth portfolios:

$$
H M L=1 / 2(\text { Small Value }+ \text { Big Value })-1 / 2(\text { Small Growth + Big Growth }) .
$$

\subsubsection{CAPM versus Fama-French Model}

CAPM is known as a single factor model in which the systematic risk (beta) is the only factor. Fama and French argue that "many of the CAPM average-return anomalies are related and they are captured by the three factors model" (known as the Fama-French model) [6]. In the Fama-French model, two more factors are added in the CAPM based on the empirical tests. It is evident that the Fama-French model gives more attention to the size and bookto-market values as compared to the CAPM since they believe these factors affect the risk measurement.

The Fama-French model is able to capture most of the cross sectional variation in the average stock return [6]. The HML and SMB factors are explained as follow:

- Slopes on HML proxy and book-to-market equity are relative distress:

+ Weak firms with persistently low earnings tend to have positive slopes on HML.

+ Strong firms with persistently high earnings tend to have negative slopes on HML.

- Evidence that there is a covariation in return related to relative distress that is not captured by the market return and is compensated in average return. HML and SMB captures these.

- Stocks with low long term past return (losers) tend to have positive SMB and HML slopes and higher average return. Conversely, long term winners tend to be strong stocks that have negative slopes on HML and low future return. 


\subsubsection{Methodologies}

\section{Ordinary Least Squares Method (OLS)}

OLS is a well-known method in statistic. This method allows for estimating unknown parameters in a linear regression model. It minimizes the sum of squared vertical distances between the observed responses in the dataset and the responses predicted by the linear approximation [8]. Since most regression models assume that errors are normally distributed, the OLS is the maximum likelihood estimator. The following is a simple regression model similar to the CAPM model:

$$
\mathbf{y}=\mathbf{X} \boldsymbol{\beta}+\epsilon, \quad \text { where } \epsilon \sim N\left(0, \sigma_{\epsilon}^{2}\right) .
$$

When the number of equations are much larger than the number of unknown variables, the

system cannot be solved precisely. The Least Squares estimator $\hat{\boldsymbol{\beta}}$ is obtained as a value that minimizes the sum of squared residuals of the model:

$$
\hat{\boldsymbol{\beta}}=\operatorname{argmin}_{\beta}\|\mathbf{y}-\mathbf{X} \boldsymbol{\beta}\|,
$$

where $\|$.$\| is the standard L^{2}$ norm in the n-dimensional Euclidean space $R_{n}$. Since the derivation of the method is presented in many books [37], [13], here the final solution is applied:

$$
\hat{\boldsymbol{\beta}}=\left(\left(\mathbf{X}^{\mathbf{T}} \mathbf{X}\right)^{-\mathbf{1}}\right) \mathbf{X}^{\mathbf{T}} \mathbf{y} .
$$

\section{Kalman Filter Algorithm}

The Kalman filter was first described and partially developed in technical papers by Swerling, Kalman and Bucy [31], [5]. The algorithm uses a series of measurements observed over time, containing random noise and other inaccuracies, and produces estimates of unknown variables that tend to be more precise than those that would be based on a single measurement alone [31]. It operates recursively on streams of noisy input data to produce a statistically optimal estimate of the underlying system state. The algorithm includes a two-step process:

- The prediction step: estimates of the current state variables along with their uncertainties are produced. 
- The update step: Once the outcome of the next measurement, which includes some amount of error or random noise is observed, these estimates are updated using a weighted average with more weight being given to higher certainty estimates.

The Kalman filter can easily be performed in financial time series because its observation and state equations are related to multiple financial time series models. In risk analysis, the Kalman filter is applied in many papers to examine the time-varying property of systematic risk [16], [14], [15], [21], [9], [4]. The CAPM model is used as the observation equation and the time-varying beta model(RW, RC, MR and etc.)is used as the state model. Literatures demonstrate that the Kalman filter outperforms the traditional OLS method.

\subsection{Contributions}

In this thesis, multifactor systematic risk is studied in both signal processing and financial point of views. The improvement in estimation accuracy by using monthly data is found through the OLS regression empirical test. As a result, the monthly data frequency is applied to determine the time-varying betas' characteristics in the CAPM and Fama-French model, which represent the single-factor and multifactor market models respectively. The RW, RC, MR, and PC multifactor beta models are used as state models to analyze the time-varying beta characteristic in the two market models. The piecewise mean reverting beta model is proposed to express the behavior of the market risk impacted by economic events and to support the event studies.

The following are the main contributions in this thesis:

1. Constant betas analysis using OLS technique for the CAPM and Fama French model is performed in multiple rolling window sizes and data frequencies. The empirical tests attempt to determine which is the best interval window and data frequency for each model in the US stock market.

2. Time-varying multifactor beta analysis looks at three popular beta stochastic models, such as the RW, RC and MR models. The multivariate Kalman filter algorithm is applied and alternatively use the CAPM and Fama-French model as an observation 
model, along with the multifactor beta stochastic state models to determine the time varying characteristic of betas. The empirical tests evaluate which is the best fit model to track the "market risk", "size risk" and "value risk" based on standard criteria $\left(R^{2}\right.$, MSE, AIC, BIC) and log-likelihood ratio test.

3. The event study is conducted using the detected abnormal changes in the multifactor beta. Different from previous event studies, the PC model is used as a state model in combination with the Fama-French observation model to detect the sudden changes in "market risk", "size risk" and "value risk" resulting from the modified Kalman filter [70]. The modified multivariate Kalman filter detects the abnormal changes in beta based on the jump process in the PC model and the Bayes' criteria. The relationship between the sudden changes in the multifactor beta and the macroeconomic or microeconomic events is then determined.

4. All the comparison tests between the CAPM and the Fama-French model are performed on both individual stocks and portfolios. By doing this, we can verify the many debates regarding the effectiveness of portfolios over individual stocks.

5. The event-study is not only conducted on individual stocks but also on industrial portfolios using the time-varying multifactor systematic risk. The economic events are analyzed based on the sudden changes in multifactor beta.

6. A Piecewise Mean Reverting (PMR) beta model is proposed. In this model, market risk is assumed to have a sudden change when there is a significant event and then revert to its mean with a certain reverting rate until the next event. This reverting rate is estimated using the maximum log-likelihood during the event period. The PMR model attempts to express the different types of events that would affect beta's behaviour. The simulations and empirical tests confirm our assumption.

\subsection{Organization of Thesis}

In chapter II, the constant beta analysis is performed mainly on the OLS method. Two regression models (CAPM and Fama-French model) are used in empirical tests with multiple 
rolling windows (60 days, 1 year, 2 years, 5 years) with different data frequencies (daily and monthly). The comparison of two models to prove the improvement in accuracy of the multifactor beta estimations for selected stocks and industrial portfolios based on the RMSE and R-square criteria will be performed.

In chapter III, the time-varying multi-factor beta is analyzed in different models. The Kalman filter algorithm is the main method to track betas. The two different observation models (CAPM and Fama-French model) along with each time-varying beta model (RW, $\mathrm{RC}$ and MR) are used to observe the changes in betas. The empirical tests are conducted for selected stocks and industrial portfolios. The comparisons of the different time-varying multifactor beta models are based on the RMSE, R-square, AIC, BIC criteria and loglikelihood ratio test for both selected stocks and industrial portfolios.

In chapter IV, application of the multifactor beta on event-study is introduced based on the PC multifactor beta and Fama-French three-factor models. By using the modified multivariate Kalman filter, the abnormal changes in the "market risk", "size risk" and "value risk" are detected. Through case studies, micro-economic and macro-economic events are studied according to the significant changes.

In chapter $\mathrm{V}$, the new PMR is proposed to express the effects of different types of economic events on the behaviour of beta. Both simulations and empirical tests are performed to evaluate the new model.

In chapter VI, the conclusion and future works are presented. 


\section{Chapter 2}

\section{Constant Multi-factor Beta Analysis}

\section{$2.1 \quad$ Introduction}

In literatures, the estimation of beta is most likely based on the CAPM regression model. By assuming that beta is constant during a certain period of time and applying the Ordinary Least Squares (OLS) method, beta is estimated when the asset return, market return and risk free rate are given. Previous research also focuses on demonstrating the differences in estimated betas between periods and the ability of historical betas to predict future betas [45], [61], [62].

The method is simple and easy to apply in the real world. However, an approach to find the best index, time frame, and data frequency for estimating beta, and therefore expected return based on CAPM is yet to be found. There are evidences found from the empirical tests but they are situation-based [32], [19], [39]. Others also examine the impact of dividends and the risk free rate on beta estimation [66]. The Wavelet transform with Haar Wavelet base is used to detect the best time interval for beta estimation [20]. Gencay indicates that the relationship between the return of a portfolio and its beta becomes stronger as the scale increases. That is, predictions of the CAPM are more relevant at medium-to long-run horizons as compared to short time horizons [20].

Mathematically, the more data is used in the estimation period, the smaller the standard error of the estimated beta is. However, using a large number of data points which is equivalent to a long estimation time period could make the constant beta assumption fail. The reason for this is the continuous change in the structural characteristics of the firms. 
For example, during the last decade, many companies have recapitalized, acquired divisions, spun-off divisions, or substantially changed product mix [66]. These changes could be the resources that caused the changes in beta over time. The resulting estimates for beta are biased.

These conflicting empirical results indicate that there is no particular way to solve the problem. In similar matter, this empirical test attempts to find the most suitable regression window length to estimate the beta though the SP500 market. As opposed to the previous method which the in-sample method is used, the leave-one-out method is performed to test the precision of the estimated parameter to the out-sample. The data for testing consists of the latest ten years (2001-2011) in the CRSP SP500 database.

\subsection{Multifactor Systematic Risk Analysis Review}

The multifactor systematic risk in our research includes "market risk", "size risk" and "value risk". While the "market risk" is already well-known in practice, the "size risk" and "value risk" are still on the way to prove their role in systematic risk measurement.

The Fama-French model is formed from the CAPM but it includes size and book-tomarket as explanatory factors in explaining the cross-section of stock returns. It introduces the multi-factor beta analysis. The Small Minus Big (SMB) is designed to measure the additional return investors have historically received from investing in stocks of companies with relatively small market capitalization [36]. This additional return is often referred to as the "size premium". The High Minus Low (HML) is used to measure the "value premium" provided for investing in companies with high book-to-market values. The book-to-market $(\mathrm{B} / \mathrm{M})$ value is a ratio which is used to find the value of a company by comparing the book value of a firm to its market value. Book value is calculated by looking at the firm's historical cost or accounting value, and market value is determined by the stock market through its market capitalization.

The $\beta_{S M B}$ (denoted by s) is a measure of "size risk" which explains why small companies are more sensitive to many risk factors as a result of their undiversified nature and their condensed ability to absorb the negative effects of financial events. The $\beta_{H M L}$ (denoted by 
h) is a measure of "value risk" which suggests a higher risk exposure for typical value stocks (high B/M) versus "growth" stocks (low B/M) [36].

The OLS method is used in the Fama-French model to estimate the multi-factor beta. Fama and French evaluate the performance of their model after determining that beta has little or no ability to explain cross-sectional variation in stock return, as compared to the size and the book-to-market ratio factors [6], [3]. They provide a multi-factor explanation and state that their model successfully explains the anomalies not captured by CAPM.

After this point, multiple research attempt to compare the CAPM and the Fama French in different manners. Kothari et al. suggest that the results of Fama and French in [6] are influenced by survivorship bias and data mining [63]. Daniel and Titman reject the Fama-French multi-factor model in favour of the characteristic-based model that is almost ad hoc [64]. Moreover, Barber observes that the most obvious means of evaluating the data-snooping hypothesis is to test the robustness of the results documented by Fama and French using different time periods, different countries, or a holdout sample. He states that the Fama-French model needs more time and further empirical verification before it can be accepted as a credible theory-based model to replace the CAPM [65]. Mirela finds evidence from France, Germany, and the United Kingdom on the robustness of the Fama-French three-factor model. The evidence of a small firm effect in France and Germany and a big firm effect in the United Kingdom is found, but the seasonal effect is rejected [25].

\subsection{Multi-factor Risk OLS Estimation}

In this section, the OLS method, introduced in the last chapter, is used to estimate the risk factors in both the CAPM and Fama-French model. In the following, the matrix form of each model is presented to fit the OLS regression solution.

\subsubsection{OLS Estimation for Single Factor CAPM}

The CAPM regression model is as follow:

$$
r_{t}-r_{f}=\alpha+\beta \cdot\left(r_{I, t}-r_{f}\right)+\epsilon_{t}, \quad \epsilon_{t} \sim N\left(0, \sigma_{\epsilon}^{2}\right)
$$


where $r_{t}$ is the asset return at time $t, r_{I, t}$ is the market return at time $t, r_{f}$ is the risk free rate, $\alpha$ represents any returns that are not explained by the model, and $\epsilon$ is a normal distribution error term with zero mean and $\sigma_{\epsilon}^{2}$ variance. The model's equation can be written in the matrix form as follow:

$$
\mathbf{Y}=\boldsymbol{\beta}^{T} \cdot \mathbf{X}+\boldsymbol{\epsilon}
$$

where:

$$
\boldsymbol{\beta}=\left(\begin{array}{c}
\alpha \\
\beta
\end{array}\right), \mathbf{Y}=\left(\begin{array}{c}
\left(r_{1}-r_{f}\right) \\
\left(r_{2}-r_{f}\right) \\
\vdots \\
\left(r_{T}-r_{f}\right)
\end{array}\right), \mathbf{X}=\left(\begin{array}{cc}
1 & \left(r_{I, 1}-r_{f}\right) \\
1 & \left(r_{I, 2}-r_{f}\right) \\
\vdots & \vdots \\
1 & \left(r_{I, T}-r_{f}\right)
\end{array}\right), \boldsymbol{\epsilon}=\left(\begin{array}{c}
\epsilon_{1} \\
\epsilon_{2} \\
\vdots \\
\epsilon_{T}
\end{array}\right)
$$

The OLS regression of beta in matrix form is:

$$
\widehat{\boldsymbol{\beta}}=\left(\mathbf{X}^{T} \cdot \mathbf{X}\right)^{-1} \cdot \mathbf{X}^{T} \cdot \mathbf{Y}
$$

where $\mathbf{X}^{T}$ denotes the transpose of matrix $\mathbf{X}$ and (.) $)^{-1}$ denotes the inversion of matrix.

\subsubsection{OLS Estimation for Fama-French Three Factors Model}

The Fama-French model explains the expected return of a portfolio with elimination of the risk-free rate $\left\{r_{t}-r_{f}\right\}$ by the sensitivity of its return to the three factors:

- the excess return of a broad market portfolio $\left\{r_{I, t}-r_{f}\right\}$,

- the difference between the return of a portfolio containing small stocks and the return of a portfolio containing large stocks (SMB).

- the difference between the return of a portfolio of high book-to-market stocks and the return of a portfolio of low book-to-market stocks (HML).

The Fama-French regression model is as follow:

$$
r_{t}-r_{f}=\alpha+\beta .\left(r_{I, t}-r_{f}\right)+s . S M B_{t}+h . H M L_{t}+\epsilon_{t},
$$

where $\epsilon_{t} \sim N\left(0, \sigma_{\epsilon}^{2}\right) ; \beta, \mathrm{s}, \mathrm{h}$ present the "market risk", "size risk", "value risk" respectively. The model's equation can be written in the matrix form as follow:

$$
\mathbf{Y}=\boldsymbol{\beta}_{F F}^{T} \cdot \mathbf{X}_{F F}+\boldsymbol{\epsilon}
$$


where

$$
\boldsymbol{\beta}_{F F}=\left(\begin{array}{c}
\alpha \\
\beta \\
s \\
h
\end{array}\right), \mathbf{Y}=\left(\begin{array}{c}
\left(r_{1}-r_{f}\right) \\
\left(r_{2}-r_{f}\right) \\
\vdots \\
\left(r_{T}-r_{f}\right)
\end{array}\right), \mathbf{X}_{F F}=\left(\begin{array}{cccc}
1 & \left(r_{I, 1}-r_{f}\right) & S M B_{1} & H M L_{1} \\
1 & \left(r_{I, 2}-r_{f}\right) & S M B_{2} & H M L_{2} \\
\vdots & \vdots & \vdots & \vdots \\
1 & \left(r_{I, T}-r_{f}\right) & S M B_{T} & H M L_{T}
\end{array}\right) .
$$

The OLS regression of the beta in matrix form is:

$$
\widehat{\overline{\boldsymbol{\beta}}}_{F F}=\left(\mathbf{X}_{F F}^{T} \cdot \mathbf{X}_{F F}\right)^{-1} \cdot \mathbf{X}_{F F}^{T} \cdot \mathbf{Y}
$$

\subsection{Empirical Tests}

\subsubsection{Leave-one-out Method}

As the name suggests, leave-one-out cross-validation (LOOCV) involves using a single observation from the original sample as the validation data and the remaining observations as the training data. This is repeated so that each observation in the sample is used once as the validation data. In this method, the error is calculated for the last sample in each rolling time period. For instance, the one year rolling window of daily data (252 trading days) is chosen, the first 251 data points are to estimate the beta and the last sample is to calculate the error. Then, the data rolls to the next window and performs the same procedure. The mean error of these out-samples is then calculated. This test aims to archive the best rolling window which generate minimal error during the estimation.

\subsubsection{Data Sources}

In this empirical test, the different frequency data, individual stock returns, portfolio returns, market returns, risk free rates, and the Fama-French factors (HML, HMB) are required. Our main data sources come from the Center for Research in Security Prices (CRSP) database ${ }^{1}$ and the Fama-French website ${ }^{2}$.

- Individual stock return: the S\&P500 dataset is used as a data source. The dataset includes five hundred tickers and the latest list of these tickers is downloaded from the

\footnotetext{
${ }^{1}$ http://wrds-web.wharton.upenn.edu/wrds/

${ }^{2}$ http://mba.tuck.dartmouth.edu/pages/faculty/ken.french/index.html
} 
Standard \& Poor website. This ticker's list is used to download the data from the CRSP database. The two different frequencies such as daily and monthly are applied. The ten years daily data from 01-Jan-2001 to 31-Dec-2011 and the whole historical monthly data of the 500 tickers are extracted to perform the tests.

- Market return: S\&P500 index return is from the CRSP database. The excess return in the market, which is the value-weight return on all NYSE, AMEX, and NASDAQ stocks from the Fama-French website, is also used as another option for the market return in this test.

- The risk free rate: is the one-month Treasury bill rate from the Fama-French website.

- The portfolio return: is the forty-eight industrial monthly and daily portfolios downloaded from the Fama-French website.

- Fama-French factors (HML,SML): from the Fama-French website.

\subsubsection{Empirical Test Procedure}

The basic concept of choosing a rolling window length is the risks are assumed to be invariant during that time range. The question here is how to choose the best window. The iterating test is performed for all tickers in the S\&P500 dataset to observe the RMSE and $R^{2}$. The procedure for the test is described below.

\subsubsection{Estimation Performance Criteria}

In these tests, the performance of the OLS estimation of systematic risks in the Fama-Fench model and the CAPM is evaluated based on the following criteria:

Root Mean Squared Error (RMSE)

$$
\operatorname{RMSE}=\sqrt{\frac{\sum_{t=1}^{T}\left(r_{t}-\hat{r}_{t}\right)^{2}}{T}} .
$$

Coefficient of determination $\mathbf{R}$-square $\left(R^{2}\right)$ provides a measure of how well future outcomes are likely to be predicted by the model:

$$
R^{2}=1-\frac{S_{e r r}}{S_{t o t}}
$$




\section{OLS regression empirical tests procedure}

Require: $\mathbf{r}, \mathbf{r}_{I}, \mathbf{r}_{f}, \mathrm{HML}, \mathrm{SMB}$

Initial Values: select data frequency (monthly or daily) and a rolling window size.

$\mathrm{k}=$ rolling_window

while $\mathrm{i} \leq$ Number of stocks/portfolios do

while $\{\mathrm{k} \leq$ Number of Observations $\}$

OLS regression for beta using the CAPM model.

OLS regression for multifactor beta using the Fama-French model.

end while

Calculate mean of RMSE for each model.

Calculate mean of $R^{2}$ for each model.

end while

return Parameters (beta, RMSE, $R^{2}$ )

$$
S_{t o t}=\sum_{t}\left(r_{t}-\bar{r}\right)^{2}, \text { and } S_{\text {err }}=\sum_{t}\left(r_{t}-\hat{r}_{t}\right)^{2}
$$

where $r_{t}$ is the asset return, $\hat{r}_{t}$ is the calculated asset return based on the estimated singleor multi-factor beta, and $\bar{r}$ is the mean of the asset return.

\subsubsection{Results}

Table 2.1 shows the estimation statistic of both models for the daily data of 500 tickers from the S\&P500 dataset. The RSME and $R^{2}$ are slightly improved in the Fama-French three factors model as compared to the CAPM model. While the five years rolling window gave the highest $R^{2}$ for the CAPM, the three months rolling window is more suitable for the Fama-French model. The $R^{2}$ increased by $13 \%$ and the RMSE reduced by $8.8 \%$ when using the Fama-French model in its best case compared to the CAPM's best case.

Table 2.1: Leave-one-out test results for S\&P500: daily data

\begin{tabular}{|c|c|c|c|c|c|c|}
\hline \hline & \multicolumn{3}{|c|}{ CAPM } & \multicolumn{3}{c|}{ F-F Model } \\
\hline Rolling window & RMSE & $R^{2}$ & $\begin{array}{c}\text { out-sample's } \\
\text { residual }\end{array}$ & RMSE & $R^{2}$ & $\begin{array}{c}\text { out-sample's } \\
\text { residual }\end{array}$ \\
\hline 3 months & 0.0179 & 0.3199 & 0.0179 & 0.0169 & 0.3883 & 0.0187 \\
1 year & 0.0183 & 0.3344 & 0.0166 & 0.0177 & 0.3702 & 0.0171 \\
2 years & 0.0187 & 0.3387 & 0.0157 & 0.0181 & 0.3711 & 0.0163 \\
5 years & 0.0184 & 0.3435 & 0.0147 & 0.0179 & 0.3724 & 0.0155 \\
\hline
\end{tabular}

For the monthly data, the results are shown in Table 2.2. In this case, the minimum 
error for the out-sample is at a five year rolling window in both models. However, for the in-samples, both models have the best $R^{2}$ and RMSE at the one year rolling window. The Fama-French is still a better estimation performance in this case. By using the Fama-French model, the $R^{2}$ increases by $40.5 \%$ and the RMSE reduces by $16.9 \%$ as compared to the CAPM. The $R^{2}$ increases by $20 \%$ compared to the daily data.

Table 2.2: Leave-one-out test results for S\&P500: monthly data

\begin{tabular}{|c|c|c|c|c|c|c|}
\hline \hline & \multicolumn{3}{|c|}{ CAPM } & \multicolumn{3}{c|}{ F-F Model } \\
\hline Rolling window & RMSE & $R^{2}$ & $\begin{array}{c}\text { out-sample's } \\
\text { residual }\end{array}$ & RMSE & $R^{2}$ & $\begin{array}{c}\text { out-sample's } \\
\text { residual }\end{array}$ \\
\hline 1 year & 0.0653 & 0.2945 & 0.0847 & 0.0542 & 0.4955 & 0.1026 \\
2 years & 0.0709 & 0.2664 & 0.0766 & 0.0643 & 0.3869 & 0.0857 \\
3 years & 0.0730 & 0.2591 & 0.0733 & 0.0675 & 0.3591 & 0.0810 \\
5 years & 0.0741 & 0.2495 & 0.0693 & 0.0696 & 0.3339 & 0.0765 \\
\hline
\end{tabular}

For the daily portfolio test, the estimation error and linear-fit measurement are shown in Table 2.3. In this case, the minimum error for the out-sample is at the five year rolling window in both models. However, for the in-sample, both models have the best $R^{2}$ and RMSE at one year rolling window. Using the Fama-French model, the $R^{2}$ increases by $5.8 \%$. One of the intersting observation here is the RMSE and $R^{2}$ show little to no change when the rolling window varies. However, if compared to the results of the single stocks, there is a huge improvement. The $R^{2}$ increases by $34.38 \%$ and the RMSE reduces by $51.9 \%$. This result is consistent with the conclusion from Fama and French for their model.

Table 2.3: Leave-one-out test results for 48 portfolios: daily data

\begin{tabular}{|c|c|c|c|c|c|c|}
\hline \hline & \multicolumn{3}{|c|}{ CAPM } & \multicolumn{3}{c|}{ F-F Model } \\
\hline Rolling window & RMSE & $R^{2}$ & $\begin{array}{c}\text { out-sample's } \\
\text { residual }\end{array}$ & RMSE & $R^{2}$ & $\begin{array}{c}\text { out-sample's } \\
\text { residual }\end{array}$ \\
\hline 3 months & 0.0078 & 0.5289 & 0.0075 & 0.0072 & 0.5836 & 0.0085 \\
1 year & 0.0081 & 0.5376 & 0.0074 & 0.0076 & 0.5822 & 0.0083 \\
2 years & 0.0083 & 0.5416 & 0.0073 & 0.0078 & 0.5841 & 0.0082 \\
3 years & 0.0083 & 0.5547 & 0.0071 & 0.0079 & 0.5954 & 0.0080 \\
5 years & 0.0085 & 0.5602 & 0.0069 & 0.0081 & 0.5994 & 0.0078 \\
\hline
\end{tabular}

Table 2.4 shows the increase in $R^{2}$ measurement not only for the monthly data of the Fama-French model but also for the CAPM as compared to the daily portfolios data in Table 
2.3. The RMSE of both models for this case does not indicate a significant change when the rolling window size varies. The $R^{2}$ of the Fama-French Model is $19.35 \%$ higher than those of CAPM and slightly increases compared to the daily data by $14.3 \%$.

Table 2.4: Leave-one-out test results for 48 portfolios: monthly Data

\begin{tabular}{|c|c|c|c|c|c|c|}
\hline \hline & \multicolumn{3}{|c|}{ CAPM } & \multicolumn{3}{c|}{ F-F Model } \\
\hline Rolling window & RMSE & $R^{2}$ & $\begin{array}{c}\text { out-sample's } \\
\text { residual }\end{array}$ & RMSE & $R^{2}$ & $\begin{array}{c}\text { out-sample's } \\
\text { residual }\end{array}$ \\
\hline 1 year & 0.0352 & 0.5644 & 0.0959 & 0.0280 & 0.6999 & 0.1034 \\
2 years & 0.0393 & 0.5600 & 0.0921 & 0.0342 & 0.6526 & 0.0972 \\
3 years & 0.0413 & 0.5616 & 0.0900 & 0.0368 & 0.6412 & 0.0937 \\
5 years & 0.0437 & 0.5611 & 0.0874 & 0.0397 & 0.6300 & 0.0906 \\
\hline
\end{tabular}

Figure 2.1 to Figure 2.3 display examples of the five year rolling window beta using the CAPM and the Fama-French model for AAPL and GE stocks. These figures indicate an improvement on the R_square and RMSE criteria of the Fama-French model over the CAPM. They also show the differences of the "market risk" in the two models. The "market risk" in the Fama-French model is truncated as compared to the CAPM. The two other risk factors are much smaller than the "market risk".
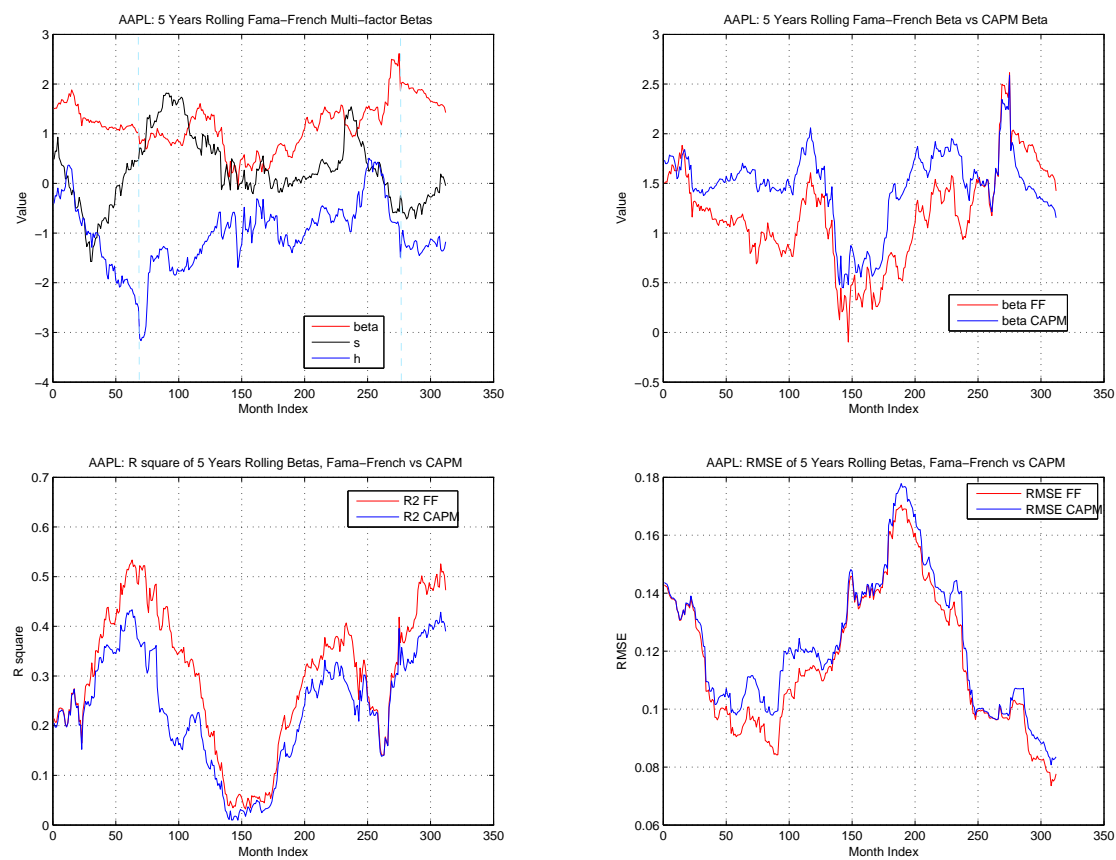

Figure 2.1: 5 years rolling betas of AAPL 

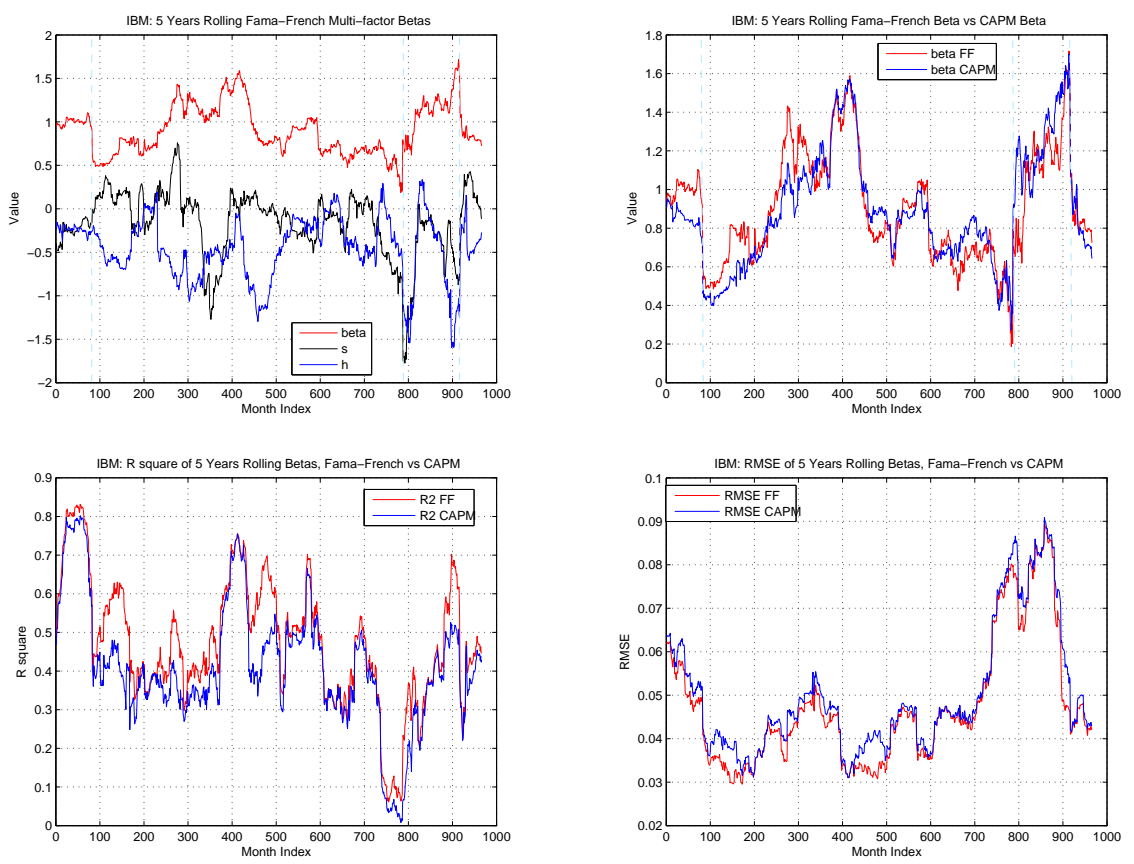

Figure 2.2: 5 years rolling betas of IBM
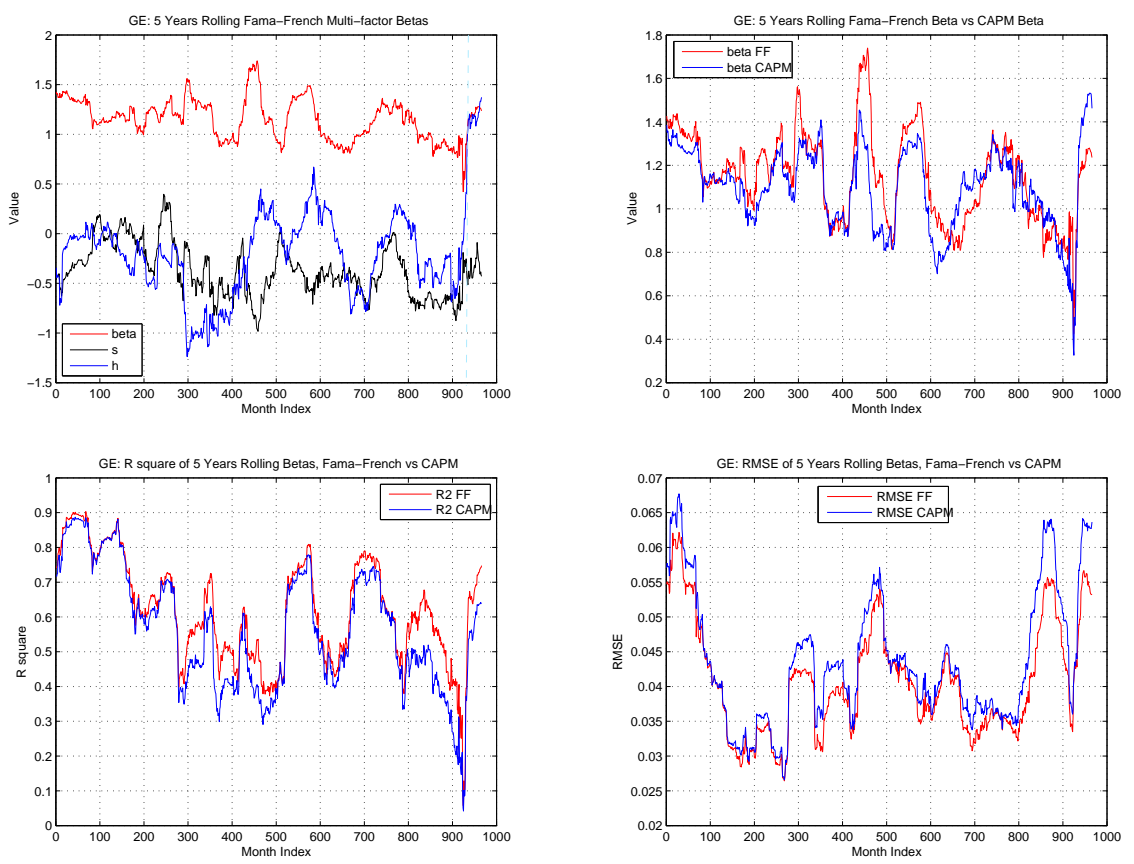

Figure 2.3: 5 years rolling betas of GE 


\subsection{Summary}

In this chapter, the traditional OLS method used to estimate betas in the CAPM and Fama-French is reviewed. From the empirical tests, there is a difference in the multifactor risk estimation performance between the different data frequencies and time intervals (rolling window sizes). There is also a significant improvement in the performance evaluation criteria $\left(R^{2}, \mathrm{RMSE}\right)$ when the portfolio returns are used instead of individual stock returns. Besides, these results demonstrate that for stocks in the S\&P 500 dataset, the five year rolling window is the best fit for daily data in the CAPM while three months rolling window is more suitable for the Fama-French model. In contrast, the one year rolling window size is the best fit for both the CAPM and Fama-French model for monthly data. With the portfolio's test, both models achieve better performance in the five year rolling window size for daily data and the one year rolling window size for monthly data. In all these cases, the $R^{2}$ improves when using monthly data rather than daily data and the Fama-French model rather than the CAPM. The empirical test results confirm the improvement in the estimation performance using the Fama-French model over the CAPM as in previous research [6], [3]. The variance in estimation performance of the different estimation intervals and frequencies data in the empirical test is the basis to which research is performed on the time-varying beta in the chapters to follow. 


\section{Chapter 3}

\section{Multi-factor Time-varying Beta Analysis}

\subsection{Introduction}

In the previous chapter, the estimation of beta with the assumption that beta is constant during a certain period of time is investigated. However, the estimation results evaluated based on the R-squared and RMSE criteria for the different rolling windows and data frequencies do not indicate that there are certain time intervals guaranteed to succeed the constant beta assumption. These results are also supported by many literatures that show the evidence in the instability of beta in [32], [42], [35], [15] and [43].

The constant beta assumption is used in most literatures to study multi-factor market models as in the Fama-French three-factor model [6], [3] and the Carhart four-factor model [26]. There are few papers that consider the time-varying systematic risk in multi-factor models [68]. The Random Walk (RW), Random Coefficient (RC) and Mean Reverting (MR) models are proven to have significant roles in analyzing beta in the CAPM [40], [17], but only Hansson [68] uses RW and MR models to analyze the multifactor beta in the Fama-French three-factor model using an out-of-sample method.

Our research attempts to verify that these RW, RC and MR models are valid in tracking the multifactor beta in the Fama-French model. Similar to [68], we apply the time-varying signal processing models to analyze the multifactor beta using the multivariate Kalman filter. The RC model which is not studied in [68] is included in our tests. Different to Hansson's method, the standard Information Criteria (AIC, BIC), RMSE and log likelihood 
hypothesis test are used to evaluate the model's performance. In our testing procedure, not only portfolios but also individual stocks are used to determine the validity of the multifactor beta models. This testing method provides an explanation on the important role of the portfolios' risk estimation as compared to the individual stocks' risk estimation in the timevarying beta manner.

\subsection{Time-varying Multi-factor Beta Analysis using Kalman Filter}

In this section, the testing module based on the multivariate Kalman filter is built to flexibly adapt to the changes in the observation model and time-varying beta model. Our goal is to use the combination of each of the two observation models (CAPM and Fama-French model) and each of the three state models (RW, RC and MR models) in order to estimate the multi-factor systematic risks in different time-varying models.

Since the MR model can cover both the RW and RC models, we can start the testing module with the MR model and then set specific cases for the others. Since the Fama-French model contains three betas $\left(\beta, \beta_{S M B}\right.$ (denoted by s) and $\beta_{H M L}($ denoted by $\mathrm{h})$ ), we assume that these betas are all time-varying and follow the same process in each case. For example, in the combination of the Fama-French model and the MR beta model, the three betas are following the MR model.

The state models can be formalized as follow:

$$
\begin{array}{cc}
\beta_{t}=\bar{\beta}+\phi\left(\beta_{t-1}-\bar{\beta}\right)+\zeta_{t}, \quad \zeta_{t} \sim N\left(0, \sigma_{\zeta}^{2}\right), \quad E\left[\epsilon_{t} \zeta_{t}\right]=0, \\
s_{t}=\bar{s}+\phi_{s}\left(s_{t-1}-\bar{s}\right)+\zeta_{s, t}, \quad \zeta_{s, t} \sim N\left(0, \sigma_{\zeta_{s}}^{2}\right), \quad E\left[\epsilon_{t} \zeta_{s, t}\right]=0, \\
h_{t}=\bar{h}+\phi_{h}\left(h_{t-1}-\bar{h}\right)+\zeta_{h, t}, \quad \zeta_{h, t} \sim N\left(0, \sigma_{\zeta_{h}}^{2}\right), \quad E\left[\epsilon_{t} \zeta_{h, t}\right]=0,
\end{array}
$$

where $\zeta_{t}, \zeta_{s, t}$, and $\zeta_{h, t}$ are the error terms in the state models and assumed to be identical in normal distribution, independent, and uncorrelated; $\epsilon_{t}$ is the error term in the observation model which is assumed to be normally distributed and uncorrelated to the error terms in state models; $\phi, \phi_{s}, \phi_{h}$ are the reverting factors and $\bar{\beta}, \bar{s}, \bar{h}$ are the constant means of the three betas. 
Depending on the assumption of each parameter in (3.1), (3.2), and (3.3), we will have different versions of beta models. These models are described in detail in the previous section. Here, we just look at the mathematical equation of these time-varying beta models.

- If $\phi=0, \phi_{s}=0$, and $\phi_{h}=0$ : the RC model (assuming that beta fluctuates randomly around a mean value).

$$
\begin{aligned}
& \beta_{t}=\bar{\beta}+\zeta_{t}, \\
& s_{t}=\bar{s}+\zeta_{s, t}, \\
& h_{t}=\bar{h}+\zeta_{h, t} .
\end{aligned}
$$

- If $\phi=1, \phi_{s}=1, \phi_{h}=1$ and $\bar{\beta}=0, \bar{s}=0, \bar{h}=0$ : RW model

$$
\begin{aligned}
& \beta_{t}=\beta_{t-1}+\zeta_{t}, \\
& s_{t}=s_{t-1}+\zeta_{s, t}, \\
& h_{t}=h_{t-1}+\zeta_{h, t} .
\end{aligned}
$$

- Otherwise: the MR model. Next period beta will be a weighted average of this period's coefficient and its long term mean value $\bar{\beta}$.

Rewrite (3.1), (3.2), (3.3):

$$
\begin{aligned}
& \beta_{t}=(1-\phi) \bar{\beta}+\phi \beta_{t-1}+\zeta_{t}, \\
& s_{t}=\left(1-\phi_{s}\right) \bar{s}+\phi_{s} s_{t-1}+\zeta_{s, t}, \\
& h_{t}=\left(1-\phi_{h}\right) \bar{h}+\phi_{h} h_{t-1}+\zeta_{h, t} .
\end{aligned}
$$

\section{CAPM Model and Kalman Filter}

Suppose we have the return series of an asset $r_{t}$ and the return series of an index $r_{I, t}$, with $t=1,2, \ldots, T$. $T$ indicates the number of observations.

Since the MR model includes the RW and the RC models, we first apply the Kalman filter for the MR model. Then by setting up the suitable values of $\phi, \bar{\beta}$ as mentioned in the above section, we will easily apply the algorithm to the other models.

For the Kaman filter algorithm, we set up the following equations:

$$
\begin{array}{cl}
\text { Observation equation: } & r_{t}-r_{f, t}=\alpha_{t}+\beta_{t}\left(r_{I, t}-r_{f, t}\right)+\epsilon_{t} . \\
\text { State equation: } & \beta_{t}=(1-\phi) \bar{\beta}+\phi \beta_{t-1}+\zeta_{t} .
\end{array}
$$


The observation equation in 3.4 can be rewritten in the matrix form as follow:

$$
\mathbf{Z}_{t}=\mathbf{H}_{t} \mathbf{X}_{t}+\epsilon_{t}
$$

where $\mathbf{Z}_{t}=\left(r_{t}-r_{f, t}\right), \mathbf{X}_{t}=\left[\begin{array}{c}\alpha_{t} \\ \beta_{t}\end{array}\right], \mathbf{H}_{t}=\left[\begin{array}{c}1 \\ \left(r_{I, t}-r_{f, t}\right)\end{array}\right]^{\prime}, \epsilon_{t} \sim N(0, \mathbf{R})$, and $\mathbf{R}=\sigma_{\epsilon}^{2}$.

The alpha and beta are assumed to be time-varying, thus, the state equation (3.5) can be rewritten as follow:

$$
\mathbf{X}_{t}=(\mathbf{I}-\mathbf{F}) \overline{\mathbf{X}}+\mathbf{F} * \mathbf{X}_{t-1}+\boldsymbol{\zeta}_{t}
$$

where $\boldsymbol{\zeta}_{t} \sim N(0, \mathbf{Q}), \mathbf{F}=\left[\begin{array}{cc}\phi_{\alpha} & 0 \\ 0 & \phi_{\beta}\end{array}\right], \mathbf{Q}=\left[\begin{array}{cc}\sigma_{\zeta_{\alpha}}^{2} & 0 \\ 0 & \sigma_{\zeta_{\beta}}^{2}\end{array}\right], \mathbf{I}=\left[\begin{array}{ll}1 & 0 \\ 0 & 1\end{array}\right]$, and $\overline{\mathbf{X}}=\left[\begin{array}{c}\bar{\alpha} \\ \bar{\beta}\end{array}\right]$.

The Kalman filter is very well-known and mentioned in many papers [5], [31], [9], and [21]. Thus, we will apply the algorithm directly to the CAPM and the time-varying beta models as presented in equation (3.6) and (3.7).

\section{Fama-French Model and Kalman Filter}

Recall the time series regression of the Fama-French model of a portfolio or an asset as follow:

$$
r_{t}-r_{f, t}=\alpha_{t}+\beta_{t} \cdot\left(r_{I, t}-r_{f, t}\right)+s_{t} . S M B_{t}+h_{t} . H M L_{t}+\epsilon_{t},
$$

where $t=1,2 \ldots T$, with $T$ being the number of observations.

The equation (3.8) is the observation equation in the Kalman filter method. Here, the $\beta, \beta_{S M B}$ (denoted by s) and $\beta_{H M L}$ (denoted by $\mathrm{h}$ ) are assumed to be time-varying. The observation and state equations will be written in matrix form as follow:

$$
\text { Observation equation: } \mathbf{Z}_{t}=\mathbf{H}_{t} * \mathbf{X}_{t}+\epsilon_{t} \text {, }
$$

where $\mathbf{Z}_{t}=\left[r_{t}-r_{f, t}\right], \epsilon_{t} \sim N(0, \mathbf{R}), \mathbf{R}=\sigma_{\epsilon}^{2}, \mathbf{X}_{t}=\left[\begin{array}{c}\alpha_{t} \\ \beta_{t} \\ s_{t} \\ h_{t}\end{array}\right]$, and $\mathbf{H}_{t}=\left[\begin{array}{c}1 \\ \left(r_{I, t}-r_{f, t}\right) \\ S M B_{t} \\ H M L_{t}\end{array}\right]^{\prime}$.

State equation: $\mathbf{X}_{t}=(\mathbf{I}-\mathbf{F}) * \overline{\mathbf{X}}+\mathbf{F} * \mathbf{X}_{t-1}+\boldsymbol{\zeta}_{t}$, 
where $\boldsymbol{\zeta}_{t} \sim N(0, \mathbf{Q}), \overline{\mathbf{X}}=\left[\begin{array}{llll}\bar{\alpha} & \bar{\beta} & \bar{s} & \bar{h}\end{array}\right]$ and

$\mathbf{I}=\left[\begin{array}{llll}1 & 0 & 0 & 0 \\ 0 & 1 & 0 & 0 \\ 0 & 0 & 1 & 0 \\ 0 & 0 & 0 & 1\end{array}\right], \mathbf{F}=\left[\begin{array}{cccc}\phi_{\alpha} & 0 & 0 & 0 \\ 0 & \phi_{\beta} & 0 & 0 \\ 0 & 0 & \phi_{s} & 0 \\ 0 & 0 & 0 & \phi_{h}\end{array}\right], \mathbf{Q}=\left[\begin{array}{cccc}\sigma_{\zeta_{\alpha}}^{2} & 0 & 0 & 0 \\ 0 & \sigma_{\zeta_{\beta}}^{2} & 0 & 0 \\ 0 & 0 & \sigma_{\zeta_{s}}^{2} & 0 \\ 0 & 0 & 0 & \sigma_{\zeta_{h}}^{2}\end{array}\right]$

The beta estimation in the Fama-French model using the Kalman filter algorithm consists of the following steps:

- Step 1: (Initialization step) - Choose the state model (RW, MR, RC) by setting up the value of $\mathbf{X}_{0}, \mathbf{F}$, and $\overline{\mathbf{X}}$

- Assign the initial value to $\mathbf{X}_{0}, \mathbf{R}, \mathbf{Q}$, and $\mathbf{P}_{0}$.

- Step 2: (Prediction step) Compute $\mathbf{X}_{1 \mid 0}$ and $\mathbf{P}_{1 \mid 0}$ by using the following equations:

$$
\begin{array}{r}
\mathbf{X}_{t \mid t-1}=(\mathbf{I}-\mathbf{F}) * \overline{\mathbf{X}}+\mathbf{F} * \mathbf{X}_{t-1 \mid t-1} \\
\mathbf{P}_{t \mid t-1}=\mathbf{F} * \mathbf{P}_{t-1 \mid t-1} * \mathbf{F}^{\prime}+\mathbf{Q}
\end{array}
$$

where $\hat{\mathbf{X}}_{\mathbf{t} \mid \mathbf{t}-\mathbf{1}}$ denotes an estimator of unknown state variable $\mathbf{X}_{t}$ based on the available information up to time ( $t-1)$, and $\mathbf{P}_{t \mid t-1}$ is its estimation error covariance.

- Step 3: (Updating step) Compute $\hat{\mathbf{X}}_{1 \mid 1}$ and $\mathbf{P}_{1 \mid 1}$ by using the following equations:

$$
\begin{array}{r}
\text { Measurement Residual: } \tilde{\mathbf{Y}}_{t}=\mathbf{Z}_{t}-\mathbf{H}_{t} * \hat{\mathbf{X}}_{t \mid t-1} . \\
\text { Innovation Covariance: } \mathbf{S}_{\mathbf{t}}=\mathbf{H}_{t} * \mathbf{P}_{t \mid t-1} * \mathbf{H}_{k}^{\prime}+\mathbf{R} . \\
\text { Kalman Gain: } \mathbf{K}_{t}=\mathbf{P}_{t \mid t-1} * \mathbf{H}_{t}^{\prime} * \mathbf{S}_{t}^{-1} . \\
\text { Update: } \hat{\mathbf{X}}_{t \mid t}=\hat{\mathbf{X}}_{t \mid t-1}+\mathbf{K}_{\mathbf{t}} * \tilde{\mathbf{Y}}_{t} . \\
\mathbf{P}_{t \mid t}=\left(\mathbf{I}-\mathbf{K}_{t} * \mathbf{H}_{t}\right) * \mathbf{P}_{t \mid t-1} .
\end{array}
$$

- Step 4: Repeat step 2 and compute $\hat{\mathbf{X}}_{2 \mid 1}$ and $\mathbf{P}_{2 \mid 1}$.

- Step 5: Repeat step 3 and compute $\hat{\mathbf{X}}_{2 \mid 2}$ and $\mathbf{P}_{2 \mid 2}$.

Repeat the procedure up to the last available observation. 


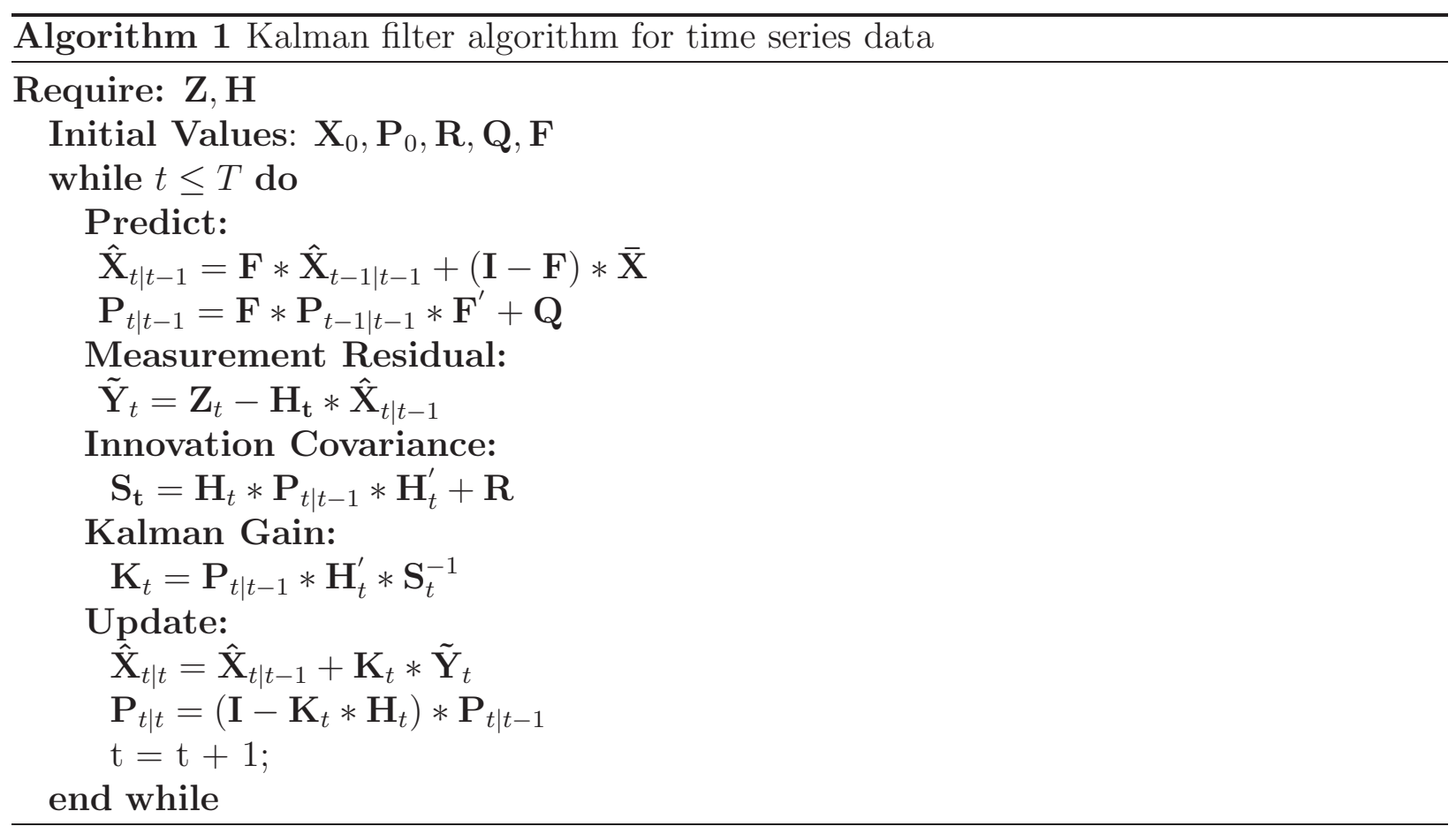

\section{Maximum Likelihood Estimation}

In order to optimize the parameters of each model, the log likelihood function is used since the noises are assumed to be normally distributed. The details of the proof can be found at [31], [10]. Here, we directly use the results.

The maximum likelihood estimation of the model parameters' set $\boldsymbol{\theta}=\{\boldsymbol{F}, \boldsymbol{Q}, \boldsymbol{R}\}$ can be done by performing the maximization of the $\log$ likelihood function $\log \boldsymbol{L}$ for $T$ observations with respect to $\boldsymbol{\theta}$ found in the below equation:

$$
\log \mathbf{L}\left(\boldsymbol{\theta} \mid \mathbf{Z}_{t}\right)=-\frac{T}{2} * \log (2 \pi)-\frac{1}{2} * \sum_{t=1}^{T} \log \mathbf{S}_{t}-\frac{1}{2} * \sum_{t=1}^{T} \widetilde{\mathbf{Y}}_{t}^{\prime} * \mathbf{S}_{t}^{-1} * \widetilde{\mathbf{Y}}_{t} .
$$

The maximum likelihood estimates of $\boldsymbol{\theta}$ are found by using a type of maximization routine on equation (3.18) to find the set of parameters $\hat{\boldsymbol{\theta}}=\{\boldsymbol{F}, \boldsymbol{Q}, \boldsymbol{R}\}$ that maximize the likelihood. In this thesis, we use the fminsearch function from Matlab which uses the multidimensional unconstrained nonlinear minimization (Nelder-Mead) algorithm. The algorithm 2 shows the details of the model's parameters estimation procedure. 


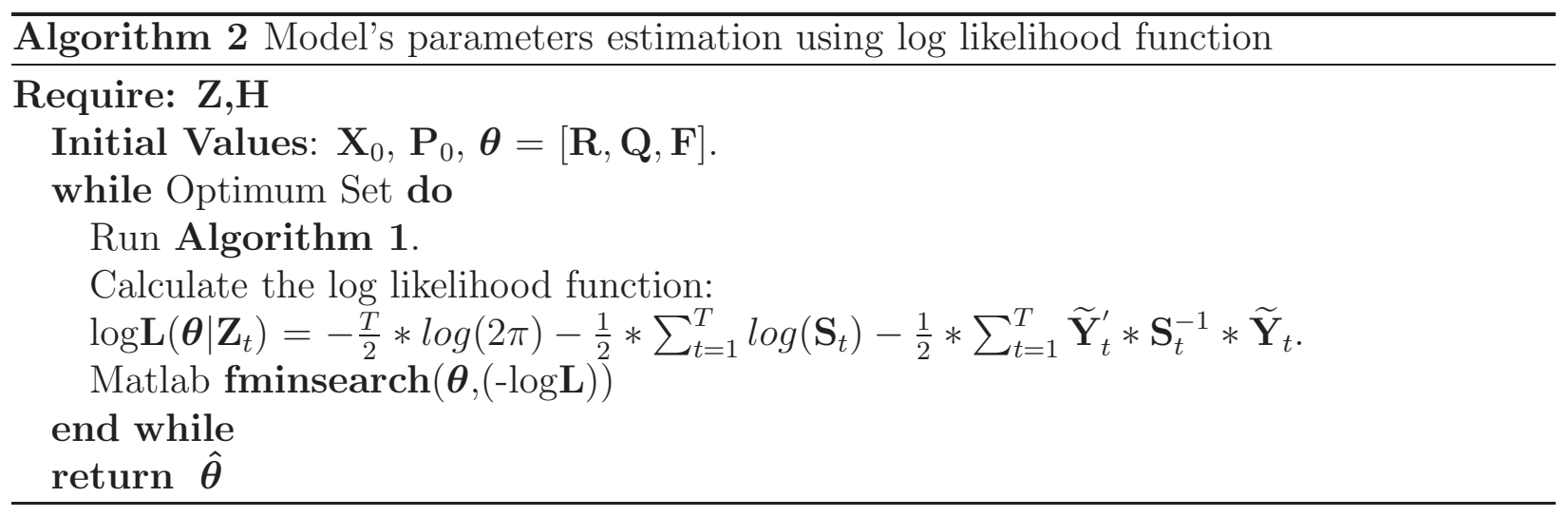

\subsection{Empirical Tests}

\subsubsection{Empirical Tests Module}

In the empirical tests module completed using the Kalman filter algorithm, there are two observation models (CAPM and Fama-French ) along with three state space models (RW, $\mathrm{RC}$ and MR). Thus, six different combinations of each observation model and state model are set up for the Kalman filter:

- CAPM and Random Walk (denoted by CAPM-RW)

- CAPM and Random Coefficient (denoted by CAPM-RC)

- CAPM and Mean Reverting (denoted by CAPM-MR)

- Fama-French and Random Walk (denoted by FF-RW)

- Fama-French and Random Coefficient (denoted by FF-RC)

- Fama-French and Mean Reverting (denoted by FF-MR)

The details of the models and parameters selection are presented in the Algorithm 3.

\subsubsection{Estimation Performance Criteria}

Other than the two criteria ( $R^{2}$ and RMSE) that are used in chapter II, the two additional Information Criterion (Akaike and Bayes) are used to evaluate the performance of the timevarying beta estimation using Kalman filer. 


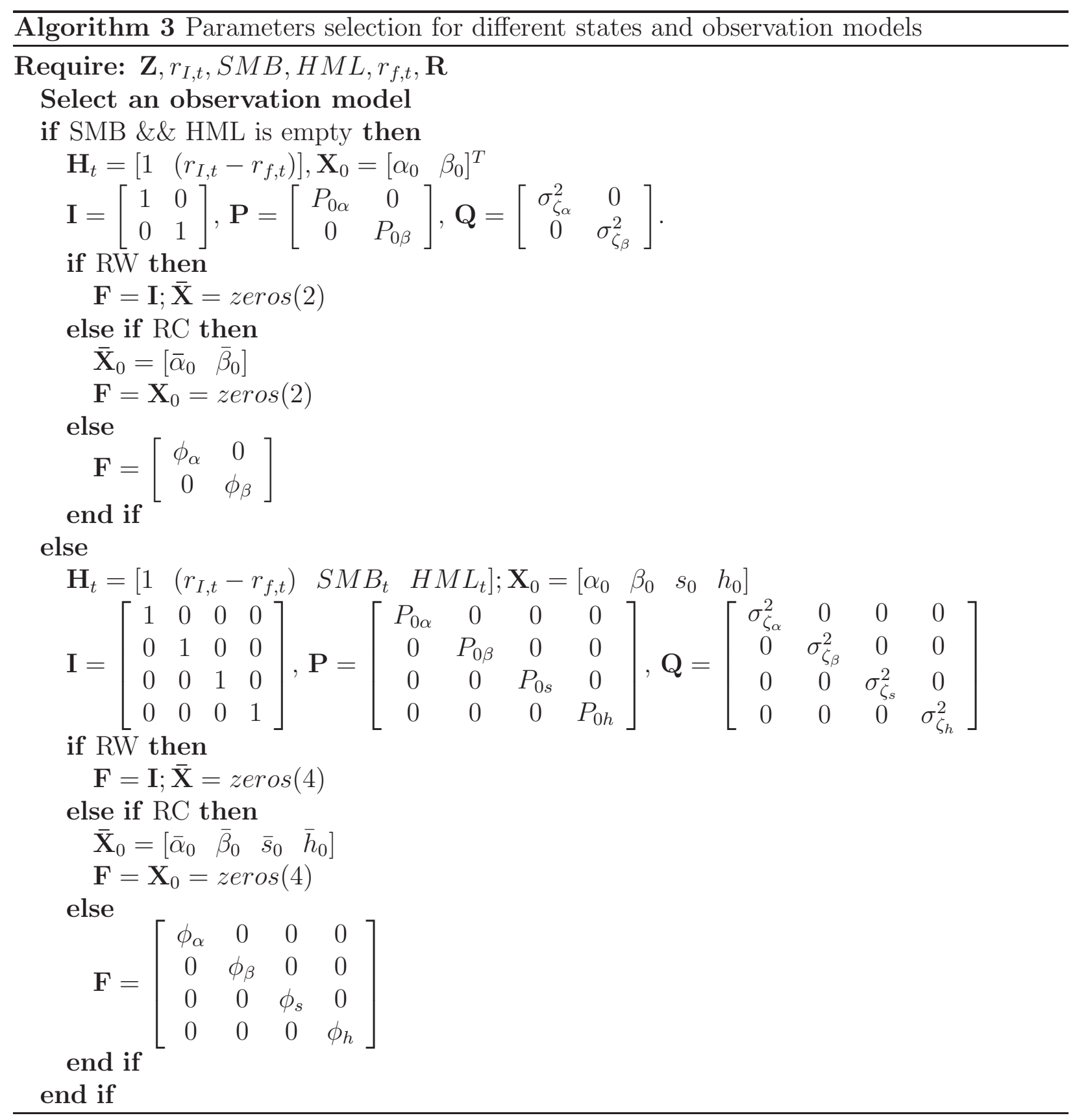


The AIC was developed by Akaike [11] and it measures the relative goodness of fit of a statistical model.

Akaike Information Criterion (AIC):

$$
\mathrm{AIC}=-\frac{2}{T} \log \widehat{\mathbf{L}}+2 \frac{k}{T}
$$

Bayes Information Criterion (BIC):

$$
\mathrm{BIC}=-\frac{2}{T} \log \widehat{\mathbf{L}}+k \frac{\log T}{T}
$$

where $k$ is the number of estimated parameters, $T$ is the number of observations, and $\log \widehat{\mathbf{L}}$ is calculated based on the equation (3.18).

The BIC was developed by Schwarz [54] and very closely related to the AIC. It is an increasing function of error variance and an increasing function of the number of free parameters to be estimated. Hence, lower BIC implies either fewer explanatory variables, better fit, or both. The AIC and BIC try to strike a balance between goodness of fit and parsimonious specification of the model. In general, the model that minimizes the AIC and BIC is the preferred one.

As suggested by [8], the Information Criterion should be used to compare non-nested models like the random coefficient model versus the random walk model. For nested models, such as the MR model, other tests like the likelihood ratio test or the Wald test can be used. In this thesis, the likelihood ratio test is used to compare random coefficient versus mean reverting and random walk versus mean reverting models.

\section{Log Likelihood-ratio Test}

Since the maximum likelihood is used to estimate the models' parameters, it makes sense to apply the log-likelihood-ratio test to evaluate the better fit model.

Null model hypothesis $\left(H_{0}\right)$ : RW or RC model.

Alternative model hypothesis $\left(H_{1}\right)$ : MR model.

The null hypothesis represents a special case of the alternative hypothesis. The test is based on the likelihood $\operatorname{ratio}(\mathbf{D})$ :

$$
\mathbf{D}=-2 * \log \mathbf{L}\left(\boldsymbol{\theta} \mid \mathbf{Z}_{H_{0}, t}\right)+2 * \log \mathbf{L}\left(\boldsymbol{\theta} \mid \mathbf{Z}_{H_{1}, t}\right),
$$


where $\log \mathbf{L}\left(\boldsymbol{\theta} \mid \mathbf{Z}_{H_{0}, t}\right)$ is the $\log$ likelihood for the null model and $\log \mathbf{L}\left(\boldsymbol{\theta} \mid \mathbf{Z}_{H_{1}, t}\right)$ is the $\log$ likelihood for the alternative model. The probability distribution of the test statistic is approximately a chi-squared distribution with degrees of freedom $(\mathbf{d})$ equal to: $\mathbf{d}=\mathbf{d}_{\mathbf{1}}-\mathbf{d}_{\mathbf{0}}$, where $\mathbf{d}_{\mathbf{0}}$ and $\mathbf{d}_{\mathbf{1}}$ represent the number of free parameters of the null model and the alternative model respectively [12].

\subsubsection{Data Sources}

- Stocks return: CRSP database.

- Market return: the excess return on the market is the value-weight return on all NYSE, AMEX, and NASDAQ stocks (from CRSP)

- Industrial portfolios return: the Fama-French website.

- Fama-French factors (SMB, HML) and the risk free rate: from the FamaFrench website.

For individual stocks testing, the following stocks in Table 3.1 are chosen. AAPL, MSFT, IBM and XOM are stocks with very high market capitalization and are considered big size companies.

Table 3.1: Historical Stocks' Data for the Empirical Tests

\begin{tabular}{llll}
\hline \hline Ticker & Company's Name & Start Date & End Date \\
\hline AAPL & Apple Computer Inc. & $01 / 1981$ & $11 / 2011$ \\
XOM & Exxon Mobil Corporation & $07 / 1926$ & $11 / 2011$ \\
MSFT & Microsoft Corp. & $04 / 1986$ & $11 / 2011$ \\
IBM & International Business Machines Corp & $07 / 1926$ & $11 / 2011$ \\
GE & General Electric & $07 / 1926$ & $11 / 2011$ \\
CSCO & Cisco Systems, Inc & $02 / 1990$ & $11 / 2011$ \\
RIMM & Research In Motion Limited & $03 / 1999$ & $11 / 2011$ \\
\hline
\end{tabular}

For portfolios testing, the five industrial portfolios are downloaded from the Fama-French website. It is the historical data from April 1926 to December 2011. The categories of these industries are presented in Table 3.3. 
Table 3.2: Historical Empirical Tests Stocks' Market Cap in April 2012

\begin{tabular}{lll}
\hline \hline Ticker & Primary Industry & Market Capitalization \\
\hline AAPL & Electronics & $568.55 \mathrm{~B}$ \\
XOM & Oil and gas & $388.59 \mathrm{~B}$ \\
MSFT & Information technology & $265.15 \mathrm{~B}$ \\
IBM & Information technology & $242.17 \mathrm{~B}$ \\
GE & Conglomerate & $207.81 \mathrm{~B}$ \\
CSCO & Networking hardware & $105.67 \mathrm{~B}$ \\
RIMM & Electronics & $7.32 \mathrm{~B}$ \\
\hline
\end{tabular}

Table 3.3: Historical Industrial Portfolios' Data for the Empirical Tests

\begin{tabular}{ll}
\hline \hline Portfolio & Industrial Type \\
\hline Industry I & $\begin{array}{l}\text { Consumer Durables, Non-Durables, Wholesale, Retail, } \\
\text { and Some Services (Laundries, Repair Shops). }\end{array}$ \\
Industry II & Manufacturing, Energy, and Utilities. \\
Industry III & Business Equipment, Telephone and Television Transmission. \\
Industry IV & Health care, Medical Equipment, and Drugs. \\
Industry V & Other such as Mines, Construction, Transit, \\
& Hotels, Bus Services, Entertainment, Finance. \\
\hline
\end{tabular}

\subsubsection{Results}

\section{Table Description}

The tables show the estimation results including the optimized parameters for each model and the calculated criteria values. The results in the tables are from both the CAPM and Fama-French models with three different state models for the selected stocks and industrial portfolios.

\section{Time-varying beta in CAPM model:}

Table 3.4 indicates the optimized model parameters based on the log-likelihood estimation and the calculated criteria for the selected stocks in Table 3.1. The first observation determined from the results is a great improvement in $R^{2}$, which was used as the main evaluation criteria in the constant beta analysis in chapter II. The biggest improvement can be found in AAPL with an increase of almost four times $R^{2}$ (from 0.2351 in OLS to 0.9697 in MRM using the Kalman filter). Other stocks results in a higher $R^{2}$ and lower RMSE. In the comparison of the time-varying beta models, the RCM performs better than the RWM based 
on it being higher in $R^{2}$ and lower in RMSE, AIC and BIC for all the selected stocks in the experiment. The log likelihood ratio test is performed to compare the performance between the nested MRM and the RWM or RCM with a degree of freedom equal to four. At $5 \%$ confidence level, the hypothesis test rejects the $\mathrm{RC}$ model hypothesis for all selected stocks and rejects four out of seven cases in the RWM. This indicates that the results from the time-varying systematic analysis of a single stock using the MR model based on the CAPM are in favor of the RC model.

Table 3.5 indicates the optimized model parameters based on the log likelihood estimation and the calculated criteria for the industrial portfolios in Table 3.3. The $R^{2}$ which is around 0.85 in the five year OLS estimation improves when time-varying beta models are used. In all of the selected portfolios, the $R^{2}$ criteria for the RC model is higher than the RW model. The log likelihood ratio test is also performed on two pairs of models (RW vs MR and RC vs MR) at 5\% confidence level. The test accepts the RC hypothesis for all portfolios and rejects the RW hypothesis for only Portfolio III over the MR model. The results indicate that the $\mathrm{RC}$ model is the best fit for the systematic risk estimation based on the CAPM model for the portfolios. 
Table 3.4: Time-varying beta analysis in CAPM: empirical tests results of RW,RC and MR models for the individual stocks including the estimated models' parameters, the maximum $\log$ likelihood $(\log (L))$ and the performance criteria $\left(R M S E, R^{2}\right.$, $B I C, A I C)$.

\begin{tabular}{|c|c|c|c|c|c|c|c|c|c|c|c|c|c|c|c|c|c|}
\hline Ticker & $\begin{array}{l}\text { Betas' } \\
\text { Model }\end{array}$ & $\alpha_{0}$ & $\beta_{0}$ & $P_{0, \alpha}$ & $P_{0, \beta}$ & $\sigma_{\zeta \alpha}$ & $\sigma_{\zeta \beta}$ & $\begin{array}{l}\text { Parameter } \\
\qquad \bar{\alpha}\end{array}$ & $\bar{\beta}$ & $\phi_{\alpha}$ & $\phi_{\beta}$ & $\sigma_{\epsilon}$ & $\log (\mathrm{L})$ & RMSE & $R^{2}$ & BIC & AIC \\
\hline \multirow[t]{4}{*}{ AAPL } & RW & 0.6454 & -1.5921 & 0.1788 & 0.4378 & 0.0015 & 0.2299 & 0 & $\overline{0}$ & $\overline{1}$ & 1 & 0.1235 & 229.9876 & 0.1167 & 0.3249 & $\begin{array}{l}-1.1989 \\
\end{array}$ & -1.1251 \\
\hline & $\mathrm{RC}$ & 0 & 0 & 0.2425 & 0.0303 & 0.0865 & 0.4025 & 0.0100 & 1.7207 & 1 & 1 & 0.0897 & 243.0267 & 0.0639 & 0.7975 & -1.2690 & -1.1952 \\
\hline & $\mathrm{MR}$ & 0.0180 & 0.0028 & 0.0518 & 0.2137 & 0.1215 & 0.3423 & 0.0112 & 1.4553 & 0.0057 & 0.8170 & 0.0170 & 239.3291 & 0.0023 & 0.9697 & -1.2577 & -1.1419 \\
\hline & OLS & & & & & & & & & & & & & 0.0963 & 0.2351 & & \\
\hline \multirow[t]{4}{*}{ IBM } & RW & 0.4685 & 0.0646 & 0.2791 & 0.1757 & 0.0005 & 0.0394 & 0 & 0 & 1 & $\overline{1}$ & 0.0528 & 1532.9 & 0.0515 & 0.4721 & -2.9745 & -2.9409 \\
\hline & $\mathrm{RC}$ & 0 & 0 & 0.2062 & 0.2764 & 0.0441 & 0.2472 & 0.0059 & 0.8272 & 0 & 0 & 0.0292 & 1531.3 & 0.0157 & 0.9506 & -2.9713 & -2.9376 \\
\hline & MR & -0.0035 & -0.0035 & 0.2467 & 0.1769 & 0.0006 & 1.2091 & 0.7391 & 0.1547 & 1.0000 & 0.4027 & 0.0481 & 1395.2 & 0.0347 & 0.7602 & -2.6982 & -2.6453 \\
\hline & OLS & & & & & & & & & & & & & 0.0403 & 0.4131 & & \\
\hline \multirow[t]{4}{*}{ MSFT } & RW & 0.2346 & 1.1321 & 0.2868 & 0.0415 & 0.0017 & 0.0223 & 0 & 0 & 1 & 1 & 0.0872 & 306.0359 & 0.0851 & 0.3630 & -1.9355 & -1.8509 \\
\hline & $\mathrm{RC}$ & 0 & 0 & -0.3976 & 1.3465 & 0.0687 & 0.5101 & 0.0142 & 1.2799 & 0 & 0 & 0.0515 & 309.6298 & 0.0300 & 0.9211 & -1.9588 & -1.8742 \\
\hline & $\mathrm{MR}$ & 0.0045 & 0.0001 & 0.0822 & 0.2243 & 0.0000 & 0.4203 & 0.0810 & 1.1849 & 1.0023 & 0.6145 & 0.0847 & 309.6996 & 0.0805 & 0.4308 & -1.9333 & -1.8004 \\
\hline & OLS & & & & & & & & & & & & & 0.0627 & 0.2932 & & \\
\hline \multirow[t]{4}{*}{$\overline{\mathrm{CSCO}}$} & RW & 0.6017 & 0.7932 & 0.2560 & 0.0386 & 0.0028 & 0.0905 & 0 & 0 & 1 & $\overline{1}$ & 0.0903 & 244.9307 & 0.0873 & 0.4629 & -1.8094 & -1.7143 \\
\hline & $\mathrm{RC}$ & 0 & 0 & 0.3099 & 0.4239 & 0.0885 & 0.0000 & 0.0167 & 1.5895 & 0 & 0 & 0.0343 & 246.1206 & 0.0124 & 0.9892 & -1.8184 & -1.7233 \\
\hline & $\mathrm{MR}$ & 0.0124 & 0.0095 & 0.1884 & 0.1622 & 0.0788 & 0.1546 & 0.0177 & 0.4889 & 0.0875 & 0.9923 & 0.0481 & 244.4115 & 0.0244 & 0.9579 & -1.7750 & -1.6256 \\
\hline & OLS & & & & & & & & & & & & & 0.0708 & 0.4001 & & \\
\hline \multirow[t]{4}{*}{ GE } & RW & 0.6383 & 0.5277 & 0.2688 & 0.1108 & 0.0000 & 0.0344 & 0 & 0 & 1 & $\overline{1}$ & 0.0462 & 1672.9 & 0.0450 & 0.6805 & -3.2474 & -3.2138 \\
\hline & $\mathrm{RC}$ & 0 & 0 & 0.1253 & 0.5129 & 0.0257 & 0.3493 & 0.0008 & 1.1477 & 0 & 0 & 0.0351 & 1689.9 & 0.0268 & 0.8870 & -3.2805 & -3.2468 \\
\hline & MR & 0.0045 & 0.0014 & 0.1010 & 0.1182 & 0.0000 & 0.4880 & 0.9797 & 1.1522 & 1.0000 & 0.1639 & 0.0416 & 1683.5 & 0.0376 & 0.7776 & -3.2602 & -3.2073 \\
\hline & OLS & & & & & & & & & & & & & 0.0436 & 0.5661 & & \\
\hline \multirow[t]{4}{*}{$\mathrm{XOM}$} & RW & 0.2698 & 0.6088 & 0.2385 & 0.0732 & 0.0000 & 0.6818 & 0 & $\overline{0}$ & 1 & $\overline{1}$ & 0.0335 & 1609.2 & 0.0263 & 0.8079 & -3.1232 & -3.0896 \\
\hline & $\mathrm{RC}$ & 0 & 0 & 0.2121 & 0.1901 & 0.0354 & 0.4238 & 0.0037 & 0.7305 & 0 & 0 & 0.0155 & 1768.9 & 0.0057 & 0.9911 & -3.4346 & -3.4009 \\
\hline & MR & 0.0033 & 0.0008 & 0.1177 & 0.0711 & 0.0000 & 0.8707 & 0.4561 & 0.3307 & 1.0000 & 0.3284 & 0.0346 & 1690.9 & 0.0265 & 0.8051 & -3.2747 & -3.2218 \\
\hline & OLS & & & & & & & & & & & & & 0.0403 & 0.4185 & & \\
\hline \multirow[t]{4}{*}{ RIMM } & RW & 0.6791 & -0.4372 & 0.1302 & 0.3063 & 0.0137 & 0.3415 & 0 & 0 & 1 & 1 & 0.1770 & 28.0809 & 0.1662 & 0.4568 & -0.2738 & -0.1357 \\
\hline & $\mathrm{RC}$ & 0 & 0 & 0.2448 & 0.0140 & 0.1716 & 1.6838 & 0.0354 & 2.4011 & 0 & 0 & -0.0420 & 35.2008 & 0.0093 & 0.9983 & -0.3662 & -0.2282 \\
\hline & $\mathrm{MR}$ & -0.1185 & 0.0694 & 0.8372 & 0.6569 & 0.0163 & 2.7062 & -5.7087 & 2.4712 & 0.9997 & 0.3609 & 0.1340 & 39.3014 & 0.1015 & 0.7975 & -0.3676 & -0.1506 \\
\hline & OLS & & & & & & & & & & & & & 0.1517 & 0.3374 & & \\
\hline
\end{tabular}


Table 3.5: Time-varying beta analysis in CAPM: empirical tests results of RW,RC and MR models for the industrial portfolios including the estimated models' parameters, the maximum log likelihood $(\log (L))$ and the performance criteria (RMSE, $\left.R^{2}, B I C, A I C\right)$.

\begin{tabular}{|c|c|c|c|c|c|c|c|c|c|c|c|c|c|c|c|c|c|}
\hline$\overline{\text { Portfolio }}$ & $\overline{\text { Betas'Model }}$ & \multicolumn{10}{|c|}{$\overline{\text { Parameters }}$} & $\sigma_{\epsilon}$ & $\log (\mathrm{L})$ & RMSE & $R^{2}$ & AIC & BIC \\
\hline Industry I & $\overline{\mathrm{RW}}$ & 0.0592 & 1.2177 & 0.2832 & 0.0987 & 0.0000 & 0.0361 & 0 & $\overline{0}$ & $\overline{1}$ & $\overline{1}$ & 0.0173 & 2647.9 & 0.0130 & 0.9084 & -5.1479 & -5.1142 \\
\hline & $\mathrm{RC}$ & 0 & 0 & -0.0981 & 0.2301 & 0.0071 & 0.2030 & 0.0013 & 0.9205 & 0 & 0 & 0.0144 & 2643.5 & 0.0116 & 0.9537 & -5.1393 & -5.1056 \\
\hline & $\begin{array}{l}\text { MR } \\
\text { OLS }\end{array}$ & -0.0030 & -0.0476 & -0.0371 & -0.2872 & 0.0000 & 0.7480 & 4.4410 & 0.7021 & 1.0000 & 1.2518 & 0.0134 & 2182.5 & $\begin{array}{l}0.0074 \\
0.0137\end{array}$ & $\begin{array}{c}\mathbf{0 . 9 8 1 1} \\
0.8437\end{array}$ & -4.2330 & -4.1801 \\
\hline Industry II & RW & 0.5052 & -0.2215 & 0.0111 & 0.5974 & 0.0001 & 0.0197 & $\overline{0}$ & $\overline{0}$ & $\overline{1}$ & $\overline{1}$ & 0.0138 & 2881.0 & 0.0133 & 0.9438 & -5.6023 & -5.5686 \\
\hline & $\mathrm{RC}$ & 0 & 0 & -0.0477 & 0.3145 & 0.0028 & 0.1766 & 0.0006 & 0.9625 & 0 & 0 & 0.0124 & 2861.5 & 0.0107 & 0.9632 & -5.5644 & -5.5307 \\
\hline & $\mathrm{MR}$ & 0.0094 & 0.0077 & 0.2429 & 0.2122 & 0.0000 & 0.3181 & 0.5407 & -0.1805 & 1.0000 & 0.9690 & 0.0115 & 2690.1 & 0.0079 & 0.9802 & -5.2225 & -5.1696 \\
\hline & OLS & & & & & & & & & & & & & 0.0108 & 0.9014 & & \\
\hline Industry III & $\overline{\mathrm{RW}}$ & 0.5963 & 0.2495 & 0.1649 & 0.1927 & 0.0000 & 0.0094 & 0 & 0 & 0 & $\overline{0}$ & 0.1427 & 1032.2 & 0.0238 & 0.8254 & -1.9984 & -1.9648 \\
\hline & $\mathrm{RC}$ & 0 & 0 & 0.1075 & 0.2304 & 0.0006 & 0.3001 & 0.0003 & 0.9973 & 0 & 0 & 0.0190 & 2419.6 & 0.0164 & 0.9166 & -4.7030 & -4.6693 \\
\hline & $\begin{array}{l}\text { MR } \\
\text { OLS }\end{array}$ & 0.0064 & 0.0021 & 0.3079 & 0.0169 & 0.0000 & 0.9412 & 0.5950 & -0.2333 & 1.0000 & 0.8259 & 0.0154 & 2114.1 & $\begin{array}{l}0.0082 \\
0.0161\end{array}$ & $\begin{array}{c}\mathbf{0 . 9 7 9 1} \\
0.8381\end{array}$ & -4.0996 & -4.0467 \\
\hline Industry IV & $\overline{R W}$ & 0.5011 & 3.0418 & 0.1109 & 0.2653 & 0.0000 & 0.0489 & 0 & $\overline{0}$ & $\overline{1}$ & $\overline{1}$ & 0.0319 & 2029.6 & 0.0304 & 0.7188 & -3.9426 & -3.9090 \\
\hline & $\mathrm{RC}$ & 0 & 0 & 0.0428 & 0.1452 & 0.0114 & 0.3565 & 0.0023 & 0.8258 & 0 & 0 & 0.0263 & 2053.0 & 0.0216 & 0.8574 & -3.9883 & -3.9547 \\
\hline & $\mathrm{MR}$ & 0.0053 & 0.0012 & 0.2808 & 0.1063 & 0.0000 & 0.6385 & 0.7120 & -0.3115 & 1.0000 & 0.8910 & 0.0267 & 1896.9 & 0.0194 & 0.8856 & -3.6763 & -3.6234 \\
\hline & OLS & & & & & & & & & & & & & 0.0248 & 0.6266 & & \\
\hline Industry V & RW & 0.2828 & 1.3868 & 0.1521 & 0.2455 & 0.0001 & 0.0623 & 0 & 0 & $\overline{1}$ & $\overline{1}$ & 0.0198 & 2483.8 & 0.0181 & 0.9234 & -4.8281 & -4.7944 \\
\hline & $\mathrm{RC}$ & 0 & 0 & 0.1121 & 0.4796 & 0.0145 & 0.2650 & -0.0010 & 1.0891 & 0 & 0 & 0.0094 & 2525.1 & 0.0044 & 0.9955 & -4.9086 & -4.8750 \\
\hline & $\mathrm{MR}$ & 0.0036 & 0.0047 & -0.0300 & 0.1371 & 0.0000 & 0.6279 & 0.7332 & 0.6267 & 1.0000 & 0.3881 & 0.0151 & 2317.8 & 0.0102 & 0.9759 & -4.4967 & -4.4438 \\
\hline & OLS & & & & & & & & & & & & & 0.0163 & 0.8637 & & \\
\hline
\end{tabular}




\section{Time-varying Beta in Fama-French model:}

Table 3.6 demonstrates the optimized model parameters based on the log-likelihood estimation and the calculated criteria for selected stocks in Table 3.1. There is great improvement in $R^{2}$ within the time-varying beta models as compared to its constant beta OLS estimation. The RMSE is also reduced for all cases with different state models. The RCM is in favor of the RWM since it has a lower $\mathrm{AIC}, \mathrm{BIC}$, and RMSE. The $R^{2}$ of RCM is also higher than RWM in all testing stocks. In the log-likelihood ratio test at $5 \%$ confidence level, the hypothesis test rejects the MRM and accepts RCM and RWM for all the testing stocks. Thus, based on the emperical test, the $\mathrm{RC}$ model is the best fit for multi-factor risk in the Fama-French model.

Table 3.7 indicates the optimized model parameters based on the log-likelihood estimation and the calculated criteria for selected stocks in Table 3.3. While the $R^{2}$ is very close between RWM and RCM, the RWM has better AIC and BIC as compared to RCM. The log-likelihood ratio test rejects the MRM and accepts RWM and RCM for all selected portfolios. These two results confirm the important role of the RWM model in analyzing the multifactor systematic risk for portfolios since its evaluation criteria is better than the other two models.

\section{Graph Description:}

In each ticker or industrial portfolio, there are two six-figures to display the results. Figure 3.1, for example, displays the results for the industry I portfolio. The three sub-graphs on the left side are to display the three betas $\left(\beta, \beta_{S M B}\right.$ and $\left.\beta_{H M L}\right)$ in the Fama-French model with different state models (RW, RC, MR). The other three sub-graphs on the right side are to compare the market risk $(\beta)$ in the CAPM model versus the $\beta$ in the Fama-French model. Figure 3.2, for example, is the second graph to display the results for the industry I portfolio. Each graph on the left side is a comparison of each beta ( $\beta$ or $\mathrm{s}$ or $\mathrm{h}$ ) in the Fama-French model with three different state models. Each graph on the right side is used to compare the $\beta, \beta_{S M B}$ and $\beta_{H M L}$ of the CAPM and Fama-French model with the RW state models and the OLS rolling beta. 
Table 3.6: Time-varying betas analysis in Fama-French model: empirical tests results of RW,RC and MR models for the individual stocks including the estimated models' parameters, the maximum loglikelihood $(\log (L))$ and the performance criteria ( $\left.R M S E, R^{2}, B I C, A I C\right)$.

\begin{tabular}{|c|c|c|c|c|c|c|c|c|c|c|c|c|c|c|c|}
\hline \multirow[t]{2}{*}{ Parameters } & \multicolumn{3}{|c|}{ AAPL } & \multicolumn{3}{|c|}{$\overline{\mathrm{IBM}}$} & \multicolumn{3}{|c|}{$\overline{\mathrm{CSCO}}$} & \multicolumn{3}{|c|}{$\overline{\mathrm{GE}}$} & \multicolumn{3}{|c|}{$\mathrm{XOM}$} \\
\hline & RW & $\mathrm{RC}$ & MR & KW & $\mathrm{RC}$ & MR & RW & $\mathrm{RC}$ & MR & RW & RC & MR & RW & $\mathrm{RC}$ & $\mathrm{MR}$ \\
\hline $\begin{array}{l}\alpha_{0} \\
\beta_{0}\end{array}$ & 0.2834 & 0 & 0.0014 & -0.6154 & 0 & -0.0040 & 0.1293 & 0 & -0.0144 & 0.3138 & 0 & 0.0076 & 0.4306 & 0 & -0.0084 \\
\hline $\begin{array}{l}\beta_{0} \\
s_{0}\end{array}$ & $\begin{array}{c}-0.3012 \\
0.1521\end{array}$ & 0 & $\begin{array}{l}0.0021 \\
0.0038\end{array}$ & $\begin{array}{c}0.4292 \\
-0.005\end{array}$ & $\begin{array}{l}0 \\
0\end{array}$ & $\begin{array}{l}-0.0012 \\
\end{array}$ & -0.4063 & 0 & 0.0027 & -0.2019 & 0 & -0.0130 & 2.0691 & 0 & 0.0003 \\
\hline$h_{0}$ & 0.2931 & 0 & -0.0193 & 0.6041 & 0 & 0.0012 & 0.2046 & 0 & 0.0062 & 0.1119 & 0 & 0.0015 & -0.0496 & $\begin{array}{l}0 \\
0\end{array}$ & $\begin{array}{c}0.0010 \\
-0.0002\end{array}$ \\
\hline$\overline{P_{\alpha 0}}$ & 0.0276 & -0.0974 & 0.0764 & 0.1448 & 0.4905 & 0.0560 & 0.1569 & 0.0191 & 0.1425 & 0.3013 & 0.3384 & 0.1165 & 0.2247 & 0.0872 & 0.1832 \\
\hline$P_{\beta 0}$ & 0.3454 & 0.3261 & 0.1616 & 0.3286 & 0.2334 & 0.0749 & 0.3300 & 0.0781 & 0.1907 & 0.1802 & 0.2983 & 0.3260 & 0.1917 & 0.1003 & 0.0842 \\
\hline$P_{s 0}$ & 0.1763 & 0.3244 & 0.1891 & -0.1099 & 0.3403 & 0.1462 & 0.0956 & -0.0561 & 0.1808 & -0.0496 & -1.2542 & 0.0147 & 0.0625 & 0.3844 & 0.1719 \\
\hline$P_{h 0}$ & 0.1549 & 0.2833 & 0.1390 & 0.4451 & 0.0634 & 0.2669 & 0.1249 & 0.5452 & 0.1398 & 0.7073 & 1.2797 & 0.1369 & 0.0579 & 0.3472 & 0.3177 \\
\hline$\sigma_{\zeta \alpha}$ & 0.0011 & 0.0375 & 0.0000 & 0.0017 & 0.0243 & -0.0000 & 0.0030 & 0.0414 & 0.0003 & 0.0000 & 0.0007 & 0.0412 & 0.0000 & 0.0010 & 0.0001 \\
\hline$\sigma_{\zeta \beta}^{\zeta \alpha}$ & 0.0001 & 0.6047 & 0.2782 & 0.0000 & 0.3427 & 0.0736 & 0.0803 & 0.3170 & 1.2815 & 0.0033 & 0.3077 & 0.9659 & 0.1118 & 0.3907 & 0.0089 \\
\hline$\sigma_{\zeta_{s}}$ & 0.0052 & 1.4508 & 0.0165 & 0.1264 & 0.7362 & 0.3968 & 0.0084 & 1.1347 & 1.1902 & 1.4641 & 1.1796 & 0.7863 & 0.6375 & 0.3897 & 1.96383 \\
\hline$\sigma_{\zeta_{h}}^{s_{s}}$ & 0.5807 & 0.3595 & 3.3738 & 0.0653 & 0.7597 & 4.3818 & 1.5456 & 0.4330 & 0.1142 & 0.1358 & 0.9468 & 0.1241 & 0.0187 & 0.3479 & 0.0032 \\
\hline$\overline{\bar{\alpha}}$ & 0 & 0.0127 & 1.1782 & $\overline{0}$ & 0.0066 & 1.3556 & $\overline{0}$ & 0.0188 & 1.0636 & $\overline{0}$ & 0.0045 & 1.4936 & $\overline{0}$ & 0.0031 & 0.6298 \\
\hline $\bar{\beta}$ & 0 & 1.1685 & 1.3304 & 0 & 0.8942 & 0.5988 & 0 & 1.4073 & 1.8544 & 0 & 1.0072 & 0.5236 & 0 & 0.8319 & 0.2509 \\
\hline $\bar{s}$ & 0 & 0.8003 & 1.1928 & 0 & 0.0282 & 1.6051 & 0 & 0.1362 & 0.5124 & 0 & 0.0269 & 0.6603 & 0 & -0.4863 & 0.7944 \\
\hline $\bar{h}$ & 0 & -0.7528 & 1.5601 & 0 & -0.4559 & 0.3766 & 0 & -0.9923 & 1.4468 & 0 & -0.8686 & 2.2362 & 0 & 0.3489 & 1.9784 \\
\hline$\overline{\phi_{\alpha}}$ & 1 & 0 & 0.9999 & 1 & $\overline{0}$ & 1.0000 & 1 & 0 & 1.0003 & 1 & $\overline{0}$ & 1.0064 & 1 & $\overline{0}$ & 1.0000 \\
\hline$\phi_{\beta}$ & 1 & 0 & 0.9525 & 1 & 0 & 0.9828 & 1 & 0 & 0.0052 & 1 & 0 & -0.5738 & 1 & 0 & -0.9965 \\
\hline$\phi_{s}$ & 1 & 0 & -0.9893 & 1 & 0 & -0.7304 & 1 & 0 & -0.6881 & 1 & 0 & -1.0319 & 1 & 0 & 0.8577 \\
\hline$\phi_{h}$ & 1 & 0 & 0.3172 & 1 & 0 & 3.9304 & 1 & 0 & 1.0007 & 1 & 0 & 0.9986 & 1 & 0 & 1.0000 \\
\hline$\sigma_{\epsilon}$ & 0.1167 & 0.1085 & 0.1416 & 0.0804 & 0.0366 & 0.1000 & 0.0802 & 0.0701 & 0.0552 & 0.0430 & 0.0366 & 0.0038 & 0.0494 & 0.0335 & 0.2090 \\
\hline$\overline{L o g}(\mathrm{~L})$ & 236.6315 & 251.4094 & 197.5989 & 317.8894 & 1553.0 & 296.8920 & 226.5282 & 260.9132 & 229.5455 & 1509.1 & 1583.0 & 1129.3 & 1647.1 & 1836.9 & 165.2525 \\
\hline RSME & 0.1083 & 0.0949 & 0.0964 & 0.0754 & 0.0255 & 0.0287 & 0.0632 & 0.0553 & 0.0469 & 0.0272 & 0.0268 & 0.00199 & 0.0297 & 0.0285 & 0.0215 \\
\hline$R^{2}$ & 0.4183 & 0.5536 & 0.5394 & 0.5000 & 0.8706 & 0.8354 & 0.7181 & 0.7844 & 0.8447 & 0.8837 & 0.8868 & 0.9888 & 0.7545 & 0.7744 & 0.8713 \\
\hline AIC & -1.2023 & -1.2818 & -0.9495 & -1.9734 & -3.0019 & -0.6197 & -1.6238 & -1.8853 & -1.5859 & -2.9163 & -3.0604 & -2.1605 & -3.1854 & -3.5553 & -0.3631 \\
\hline $\mathrm{BIC}$ & -1.0654 & -1.1448 & -0.7282 & -1.8163 & -2.9394 & -0.7206 & -1.4472 & -1.7087 & -1.3007 & -2.8538 & -2.9979 & -2.0595 & -3.1229 & -3.4928 & -0.4640 \\
\hline
\end{tabular}


Table 3.7: Time-varying betas analysis in Fama-French model: empirical tests results of RW,RC and MR models for the industrial portfolios including the estimated models' parameters, the maximum loglikelihood $(\log (L))$ and the performance criteria (RMSE, $\left.R^{2}, B I C, A I C\right)$.

\begin{tabular}{|c|c|c|c|c|c|c|c|c|c|c|c|c|c|c|c|}
\hline \multirow[t]{2}{*}{ Parameters } & \multicolumn{3}{|c|}{ Industry I } & \multicolumn{3}{|c|}{ Industry II } & \multicolumn{3}{|c|}{ Industry III } & \multicolumn{3}{|c|}{ Industry IV } & \multicolumn{3}{|c|}{ Industry V } \\
\hline & RW & $\mathrm{RC}$ & MIR & RW & & MIR & RW & & MR & RW & & MR & RW & & MR \\
\hline$\alpha_{0}$ & 0.0722 & 0 & 0.0079 & 0.3675 & 0 & $\begin{array}{l}-0.0043 \\
\end{array}$ & 0.0027 & $\overline{0}$ & -0.0370 & 0.0017 & $\overline{0}$ & 0.0018 & -0.1029 & $\overline{0}$ & -0.0030 \\
\hline$\beta_{0}$ & -0.8884 & 0 & 0.0093 & -0.6398 & 0 & 0.0046 & -0.5111 & 0 & 0.0038 & 2.8470 & 0 & 0.0000 & -0.2879 & 0 & 0.0028 \\
\hline$s_{0}$ & 0.1073 & 0 & -0.0077 & 0.3229 & 0 & 0.0058 & 0.1242 & 0 & 0.0100 & -0.1532 & 0 & 0.0028 & -0.0415 & 0 & 0.0058 \\
\hline & 0.0157 & 0 & -0.0007 & 0.2390 & 0 & 0.0087 & 0.1899 & 0 & 0.0220 & 0.2079 & 0 & -0.0086 & -0.0311 & 0 & -0.0091 \\
\hline$\overline{P_{\alpha 0}}$ & 0.3281 & -0.3770 & 0.1623 & 0.2140 & 0.1960 & 0.1428 & 0.1844 & 0.5835 & 0.2057 & 0.2618 & 0.3574 & 0.1191 & 0.3675 & 0.5525 & 0.0557 \\
\hline$P_{\beta 0}$ & 0.2105 & 0.1433 & 0.2128 & 0.1015 & 0.3301 & 0.1667 & 0.2145 & -0.0142 & 0.4094 & 0.1974 & 0.2296 & 0.0843 & 0.0838 & -0.3965 & 0.2908 \\
\hline$P_{s 0}$ & 0.0884 & 0.1242 & 0.2953 & 0.1548 & 0.4001 & 0.1824 & 0.1113 & -0.2153 & 0.2399 & 0.0257 & 0.0416 & 0.1413 & 0.0265 & -0.3702 & 0.1334 \\
\hline$P_{h 0}$ & 0.6516 & 0.9002 & 0.2521 & 0.5303 & 0.3144 & -0.0129 & 0.5054 & -0.1621 & 0.4848 & 0.1119 & 0.1795 & 0.2172 & 1.0011 & -0.2286 & 0.1881 \\
\hline$\sigma_{\zeta \alpha}$ & 0.0000 & 0.0014 & 1.4940 & 0.0000 & 0.0001 & 0.0095 & 0.0000 & 0.0002 & 0.0000 & 0.0000 & 0.0003 & 0.0001 & $\overline{0.0000}$ & 0.0001 & -0.0000 \\
\hline$\sigma_{\zeta \beta}$ & 0.0165 & 0.1609 & 0.1154 & 0.0095 & 0.5662 & 0.2457 & 0.0400 & 0.1863 & 0.0063 & 0.0546 & 0.2402 & 8.8718 & 0.0442 & 0.2594 & 0.0007 \\
\hline$\sigma_{\zeta_{s}}$ & 0.0289 & 0.3296 & 0.0245 & 0.0110 & 1.5361 & 0.6248 & 0.0359 & 0.6721 & 6.7398 & 0.0100 & 0.5084 & 9.0988 & 0.0296 & 0.9452 & 5.0102 \\
\hline$\sigma_{\zeta_{h}}^{s_{n}}$ & 0.0539 & 0.2588 & 0.0539 & 0.0587 & 1.1099 & 6.9513 & 1.2469 & 1.9722 & 0.1240 & 0.0479 & 0.5131 & 9.7878 & 0.0481 & 0.6864 & 0.2271 \\
\hline$\frac{\bar{\alpha}}{\bar{\alpha}}$ & $\overline{0}$ & 0.0012 & 0.6655 & $\overline{0}$ & -0.0044 & 1.2252 & 0 & -0.0015 & 0.7176 & 0 & 0.0033 & 0.9915 & 0 & -0.0030 & 2.1859 \\
\hline $\bar{\beta}$ & 0 & 0.9631 & 0.9249 & 0 & 1.8173 & 1.1887 & 0 & 1.1506 & -1.0360 & 0 & 0.9515 & 0.6841 & 0 & 0.9659 & 0.0027 \\
\hline $\bar{s}$ & 0 & -0.0666 & 0.6807 & 0 & 0.6391 & 0.2628 & 0 & -0.6995 & -1.5782 & 0 & -0.5808 & 0.8694 & 0 & 1.1080 & 1.0150 \\
\hline $\bar{h}$ & 0 & -0.0068 & 0.1945 & 0 & 0.7726 & 0.7624 & 0 & 1.5952 & -0.1925 & 0 & -0.3485 & 0.7496 & 0 & 1.0454 & -0.1983 \\
\hline$\overline{\phi_{\alpha}}$ & $\overline{1}$ & 0 & 0.2584 & $\overline{1}$ & 1 & 1.0011 & 1 & 1 & 1.0000 & $\overline{1}$ & 1 & 1.0000 & 1 & $\overline{1}$ & 1.0000 \\
\hline$\phi_{\beta}$ & 1 & 0 & 0.5488 & 1 & 1 & -1.1077 & 1 & 1 & 1.0002 & 1 & 1 & 0.6610 & 1 & 1 & 1.0002 \\
\hline$\phi_{s}$ & 1 & 0 & 0.9991 & 1 & 1 & 0.9391 & 1 & 1 & -0.1964 & 1 & 1 & -0.8360 & 1 & 1 & 0.6553 \\
\hline$\phi_{h}$ & 1 & 0 & 0.9889 & 1 & 1 & 0.6570 & 1 & 1 & 0.2472 & 1 & 1 & 0.1616 & 1 & 1 & -0.9419 \\
\hline$\sigma_{\epsilon}$ & 0.0152 & 0.0132 & 0.0742 & 0.0113 & 0.0180 & 0.1946 & 0.0142 & 0.0194 & 0.0232 & 0.0286 & 0.0252 & 0.4474 & 0.0142 & 0.0118 & 0.2452 \\
\hline$\overline{\log (\mathrm{L})}$ & 2723.7 & 2666.5 & 2015.5 & 3018.2 & 1738.6 & 248.1352 & 2233.8 & 1735.0 & 1286.1 & 2102.4 & 2059.2 & 645.5393 & 2754.6 & 2158.7 & 320.6732 \\
\hline RSME & 0.0137 & 0.0100 & 0.0032 & 0.0101 & 0.0070 & 0.0233 & 0.0076 & 0.0098 & 0.0046 & 0.0264 & 0.0197 & 0.0186 & 0.0121 & 0.0056 & 0.0218 \\
\hline$R^{2}$ & 0.9356 & 0.9656 & 0.9410 & 0.9673 & 0.9841 & 0.8271 & 0.9820 & 0.9704 & 0.9934 & 0.7875 & 0.8818 & 0.8944 & 0.9659 & 0.9926 & 0.8892 \\
\hline AIC & -5.2839 & -5.1725 & -3.9698 & -5.8580 & -3.3638 & -0.4428 & -4.3290 & -3.3566 & -2.4660 & -4.0730 & -3.9886 & -1.2993 & -5.3443 & -4.1827 & -0.5842 \\
\hline BIC & -5.2214 & -5.1099 & -4.0708 & -5.7955 & -3.3013 & -0.3418 & -4.2665 & -3.2941 & -2.3650 & -4.0104 & -3.9261 & -1.4003 & -5.2818 & -4.1201 & -0.4832 \\
\hline
\end{tabular}



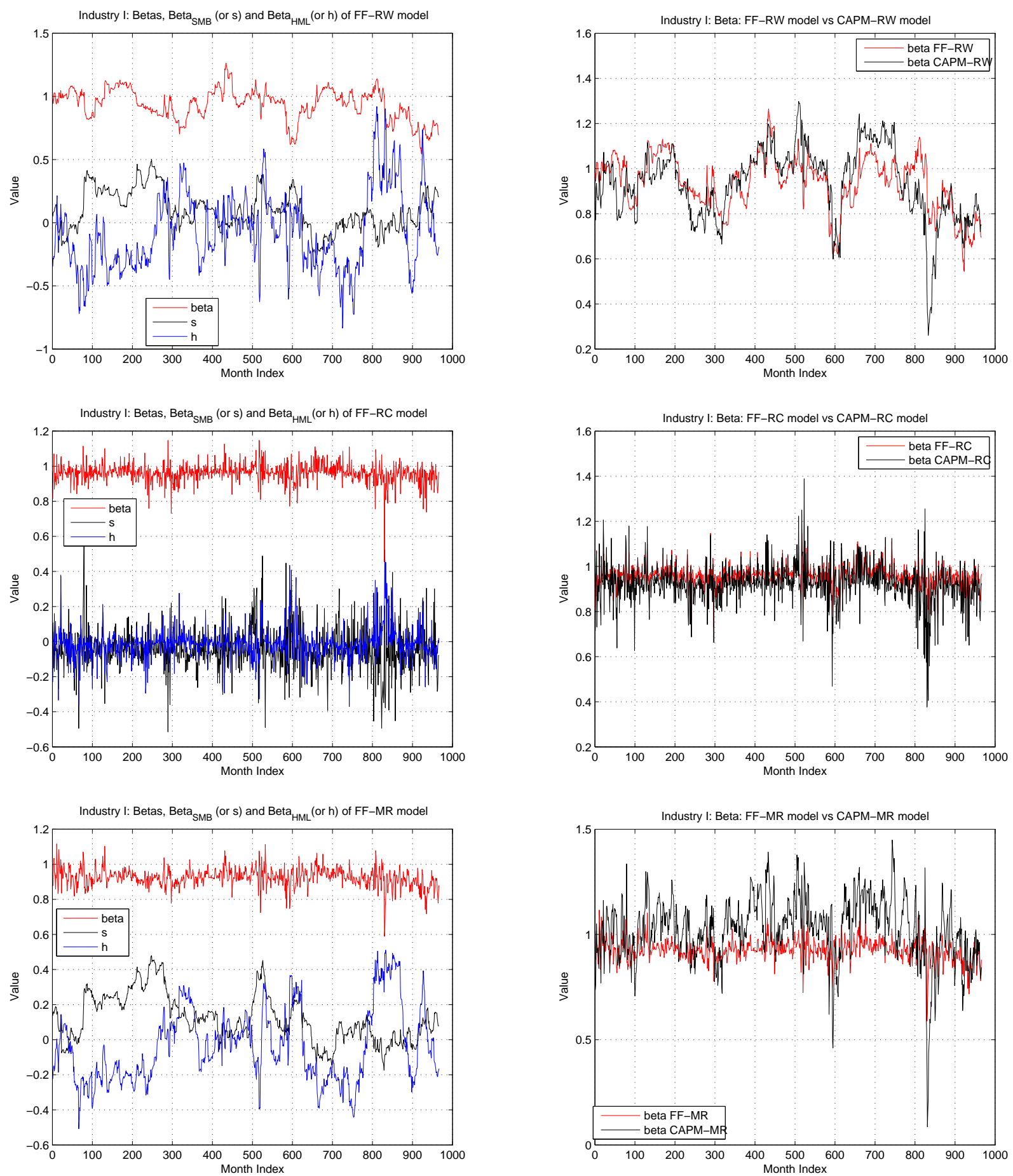

Figure 3.1: Time-varying multi-factor beta of industry I (a): $\beta, s$ and $h$ in FF-RW, FF-RC and FF-MR analysis; the RW, RC and MR of "market risk" in FFM vs in CAPM 

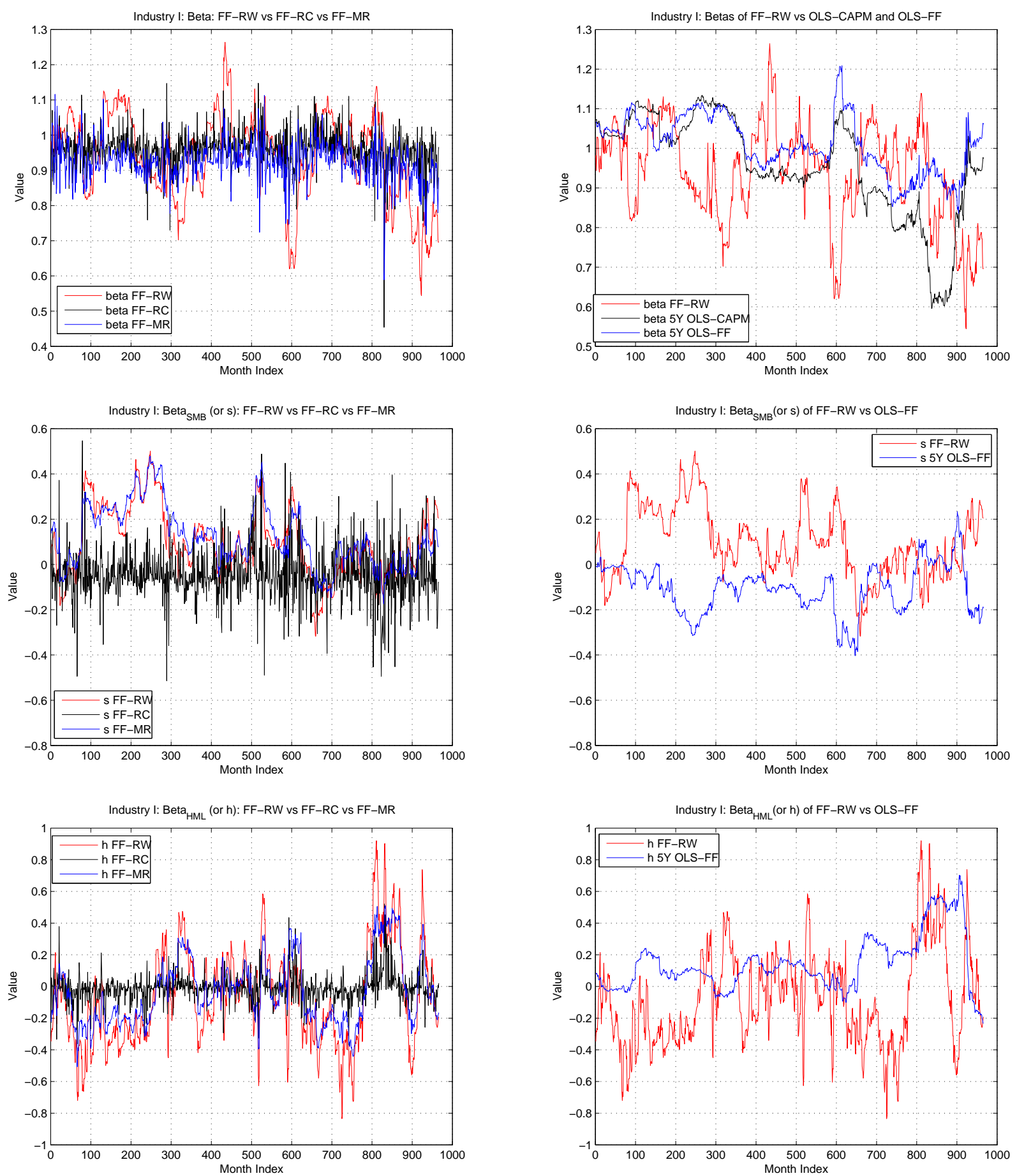

Figure 3.2: Time-varying multi-factor beta of industry I (b): FF-RW vs FF-RC vs FF-MR analysis of $\beta, s$, and $h$; the time-varying $\beta$ vs the 5 year rolling $\beta$ 

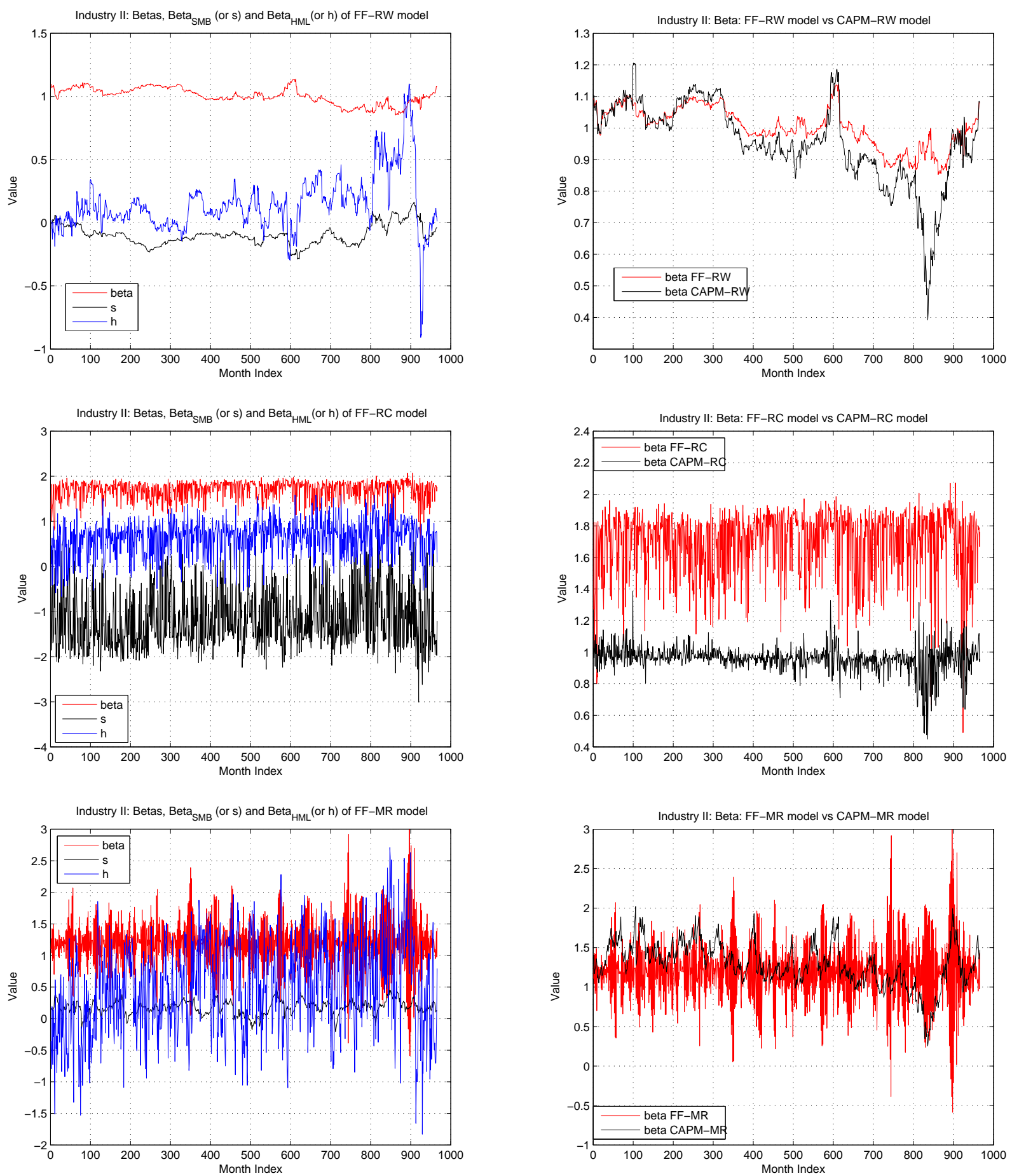

Figure 3.3: Time-varying multi-factor beta of industry II (a): $\beta, s$ and $h$ in FF-RW, FF-RC and FF-MR analysis; the RW, RC and MR of "market risk" in FFM vs in CAPM 

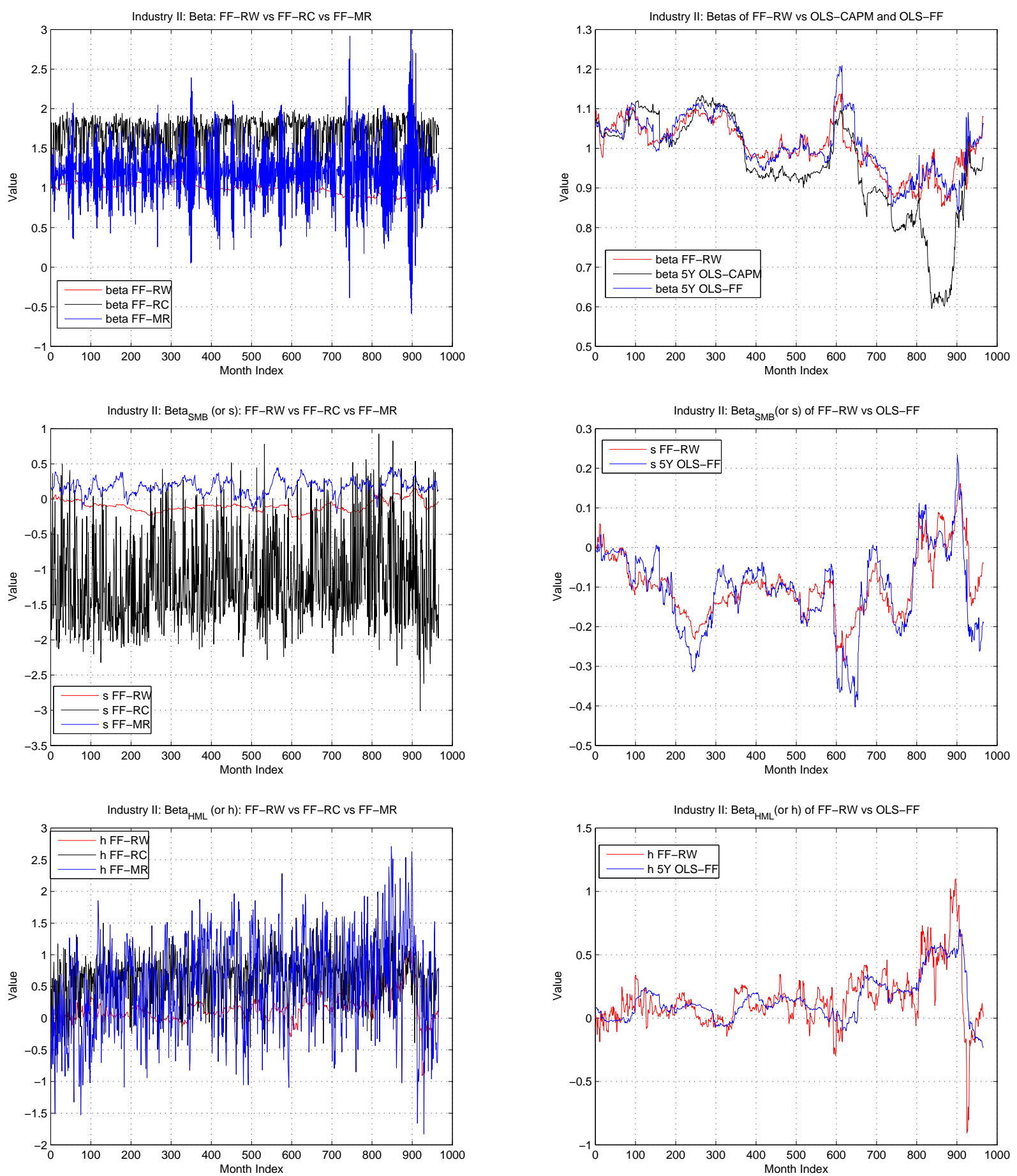

Figure 3.4: Time-varying multi-factor beta of industry II (b): FF-RW vs FF-RC vs FF-MR analysis of $\beta, s$, and $h$; the time-varying $\beta$ vs the 5 year rolling $\beta$ 

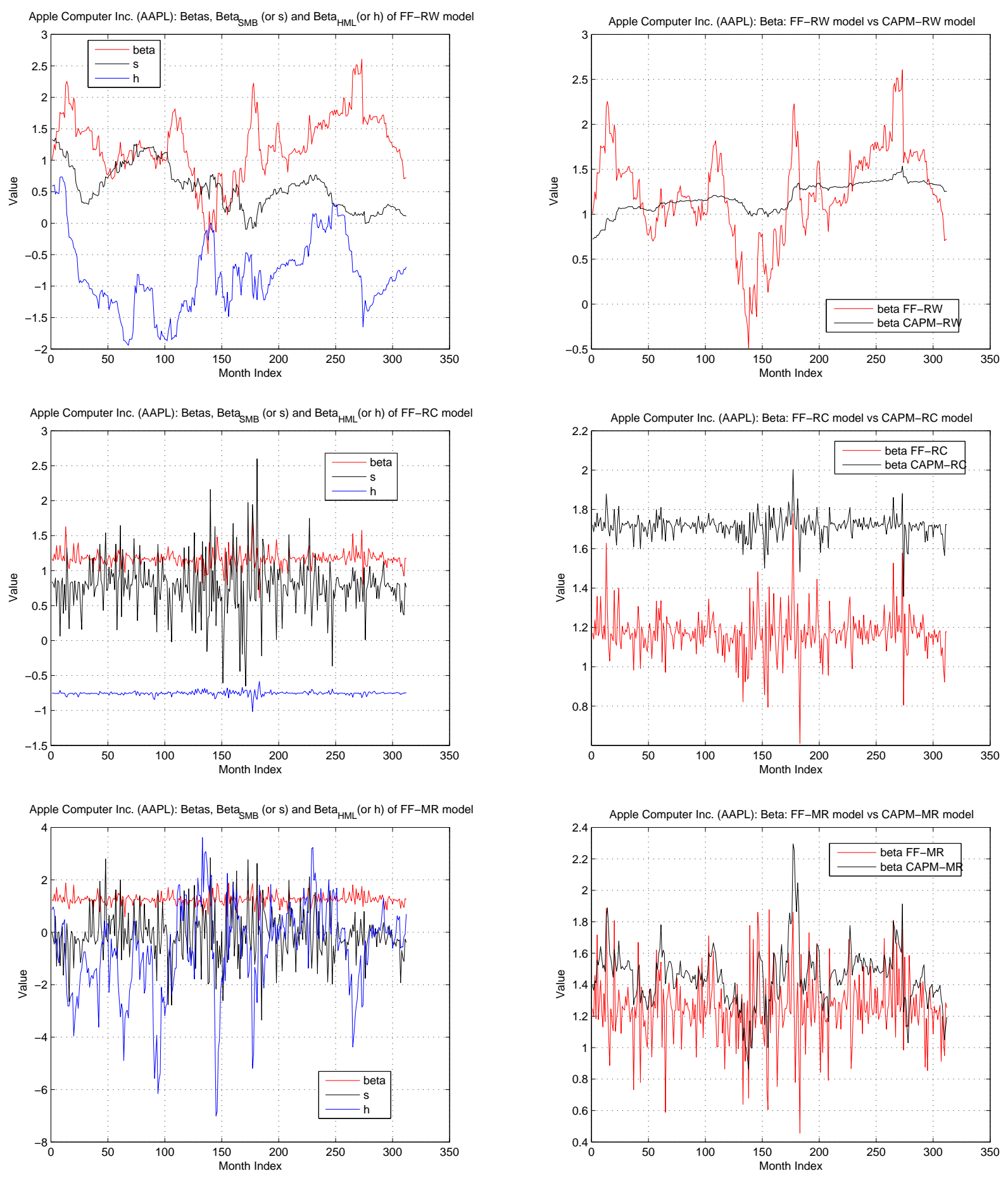

Figure 3.5: Time-varying multi-factor beta of AAPL (a): $\beta, s$ and $h$ in FF-RW, FF-RC and FF-MR analysis; the RW, RC and MR of "market risk" in FFM vs in CAPM 

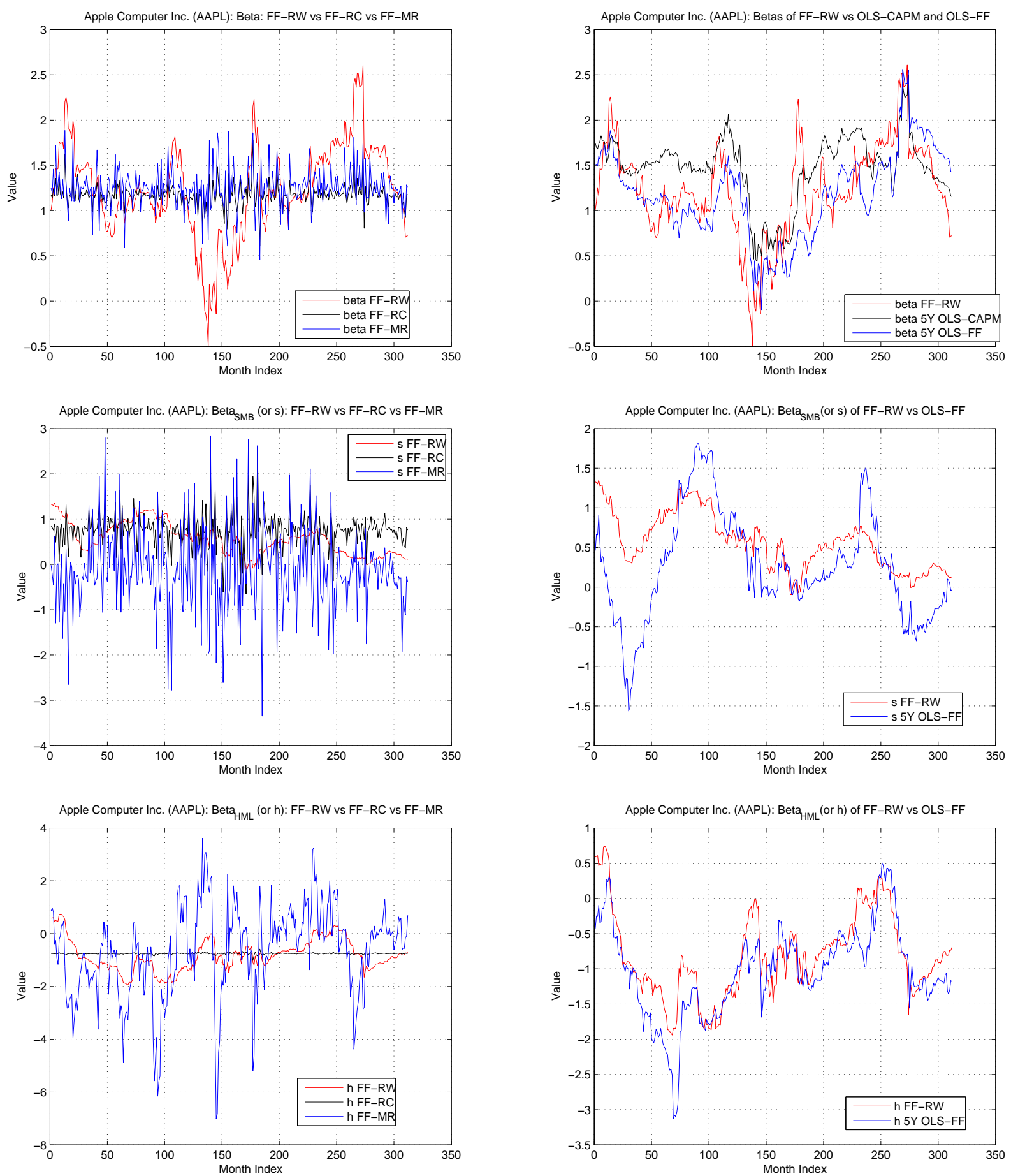

Figure 3.6: Time-varying multi-factor beta of AAPL (b): FF-RW vs FF-RC vs FF-MR analysis of $\beta, s$, and $h$; the time-varying $\beta$ vs the 5 year rolling $\beta$ 

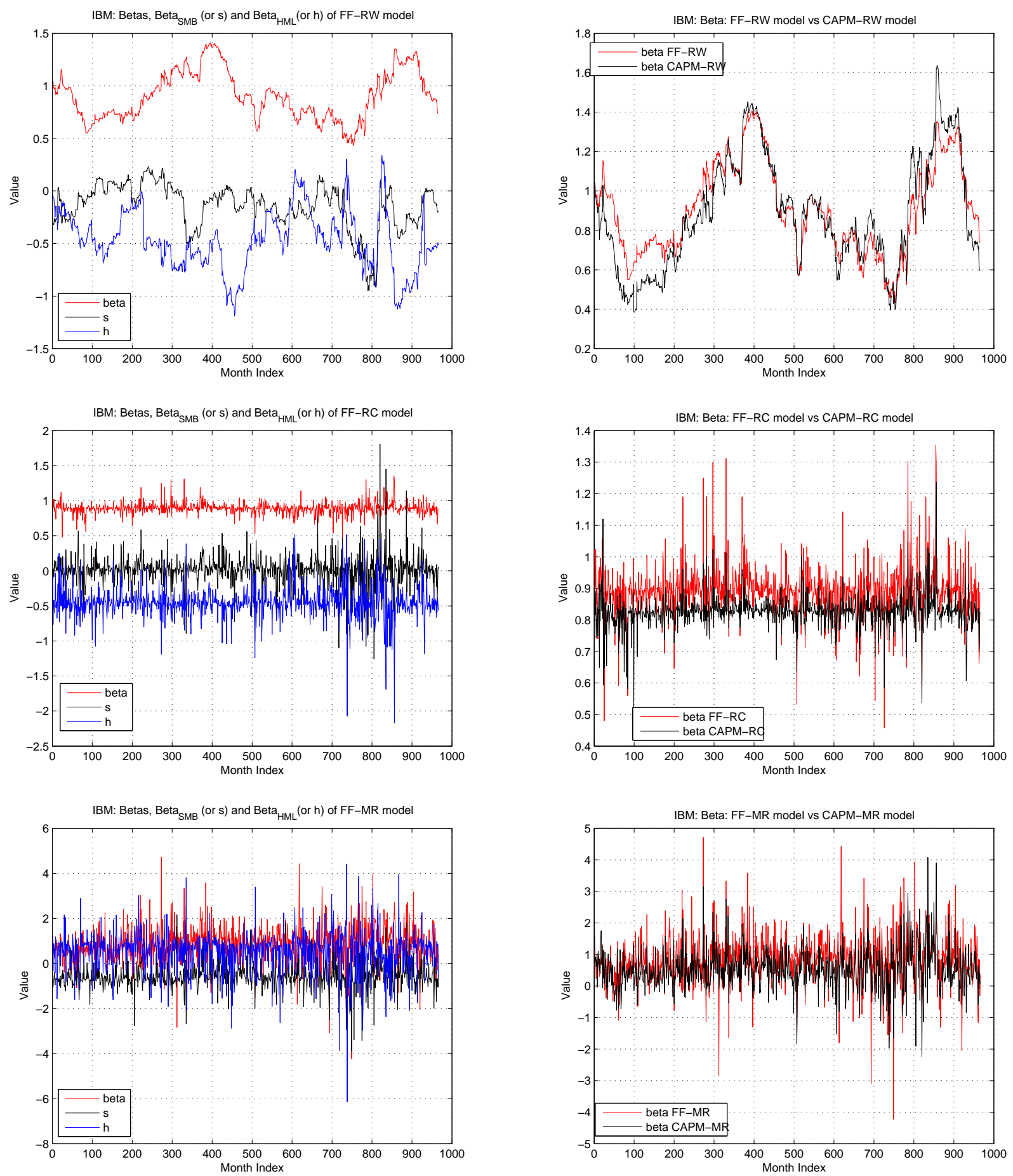

Figure 3.7: Time-varying multi-factor beta of IBM (a): $\beta, s$ and $h$ in FF-RW, FF-RC and FF-MR analysis; the RW, RC and MR of "market risk" in FFM vs in CAPM 

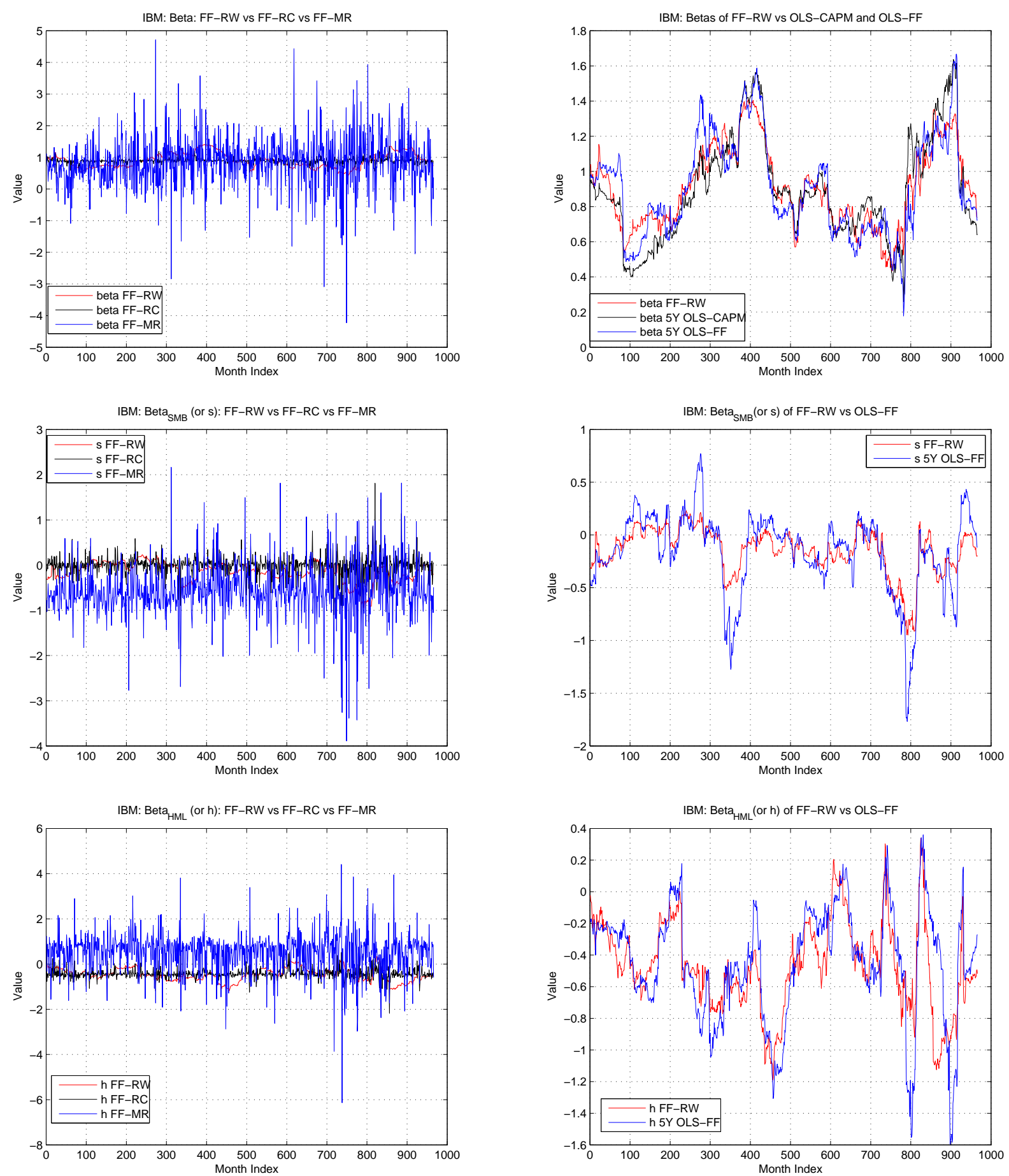

Figure 3.8: Time-varying multi-factor beta of IBM (b): FF-RW vs FF-RC vs FF-MR analysis of $\beta, s$, and $h$; the time-varying $\beta$ vs the 5 year rolling $\beta$ 

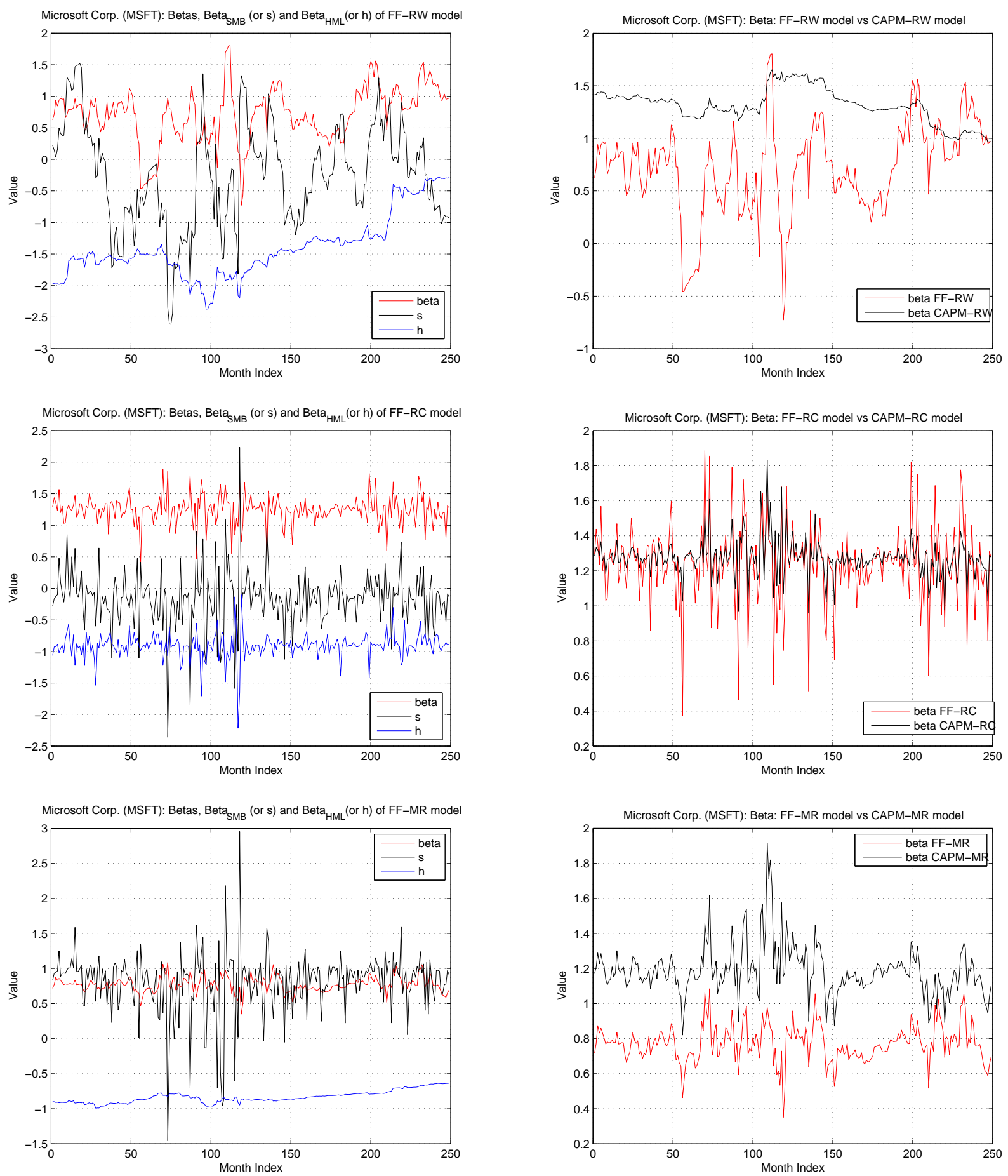

Figure 3.9: Time-varying multi-factor beta of MSFT (a): $\beta, s$ and $h$ in FF-RW, FF-RC and FF-MR analysis; the RW, RC and MR of "market risk" in FFM vs in CAPM 

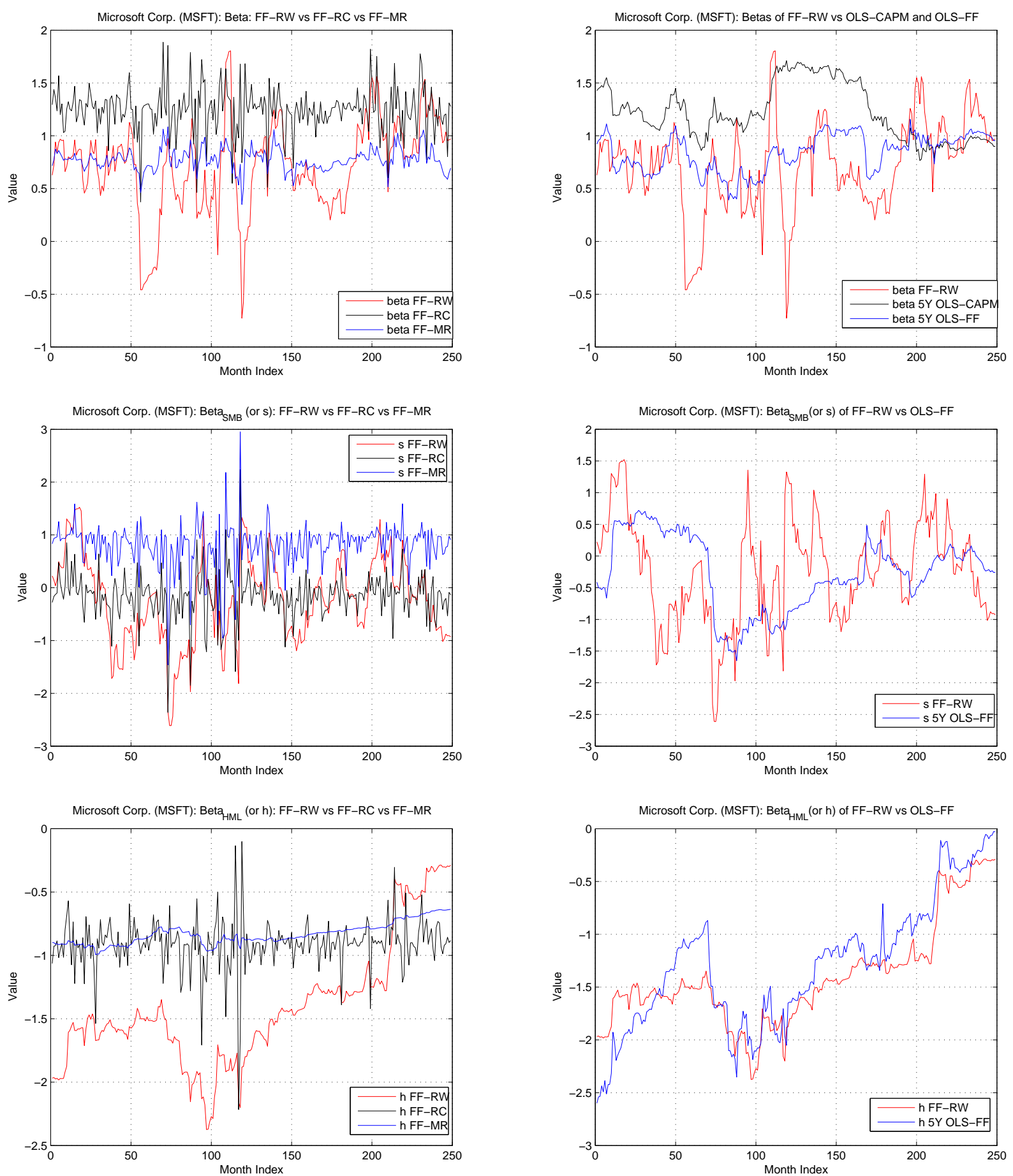

Figure 3.10: Time-varying multi-factor beta of MSFT (b): FF-RW vs FF-RC vs FF-MR analysis of $\beta, s$, and $h$; the time-varying $\beta$ vs the 5 year rolling $\beta$ 


\subsection{Summary}

In this chapter, we present the empirical test module to evaluate the performance of the single and multi-factor time-varying systematic risk models. We extend the three well-known time-varying models for "market risk" in the CAPM to the time-varying multi-factor risk as described in the Fama-French model. Our test module using the Kalman filter provides a comparison between the CAPM and the Fama-French model in the time-varying systematic risk manner. Based on the standard criteria (RMSE, $R^{2}$, AIC, BIC), the empirical tests for individual stocks and industrial portfolios indicate that all three time-varying beta models show great improvement on beta estimation performance. For the industrial portfolios, the RCM shows the best fit for the CAPM while the RWM is the best fit for the Fama-French model. For the individual stocks, the MRM is in favour for the CAPM and the RCM is in favour for the Fama-French model. Besides, the Fama-French model with multi-factor risk analyzed on the portfolios provide a more accurate estimation as compared to the individual stocks. It is consistent to many financial experts' suggestion in which systematic risk should be estimated based on the portfolios rather than single stocks. 


\section{Chapter 4}

\section{Apply Piecewise Constant Multi-factor Beta Model on Event Study}

\subsection{Introduction}

Event-study is an empirical study done on a security that has gone through significant events or impacted news related to the firm, and has subsequently changed dramatically in value as a result of that event or news. An event can have either a positive or negative effect on the value of the security. The traditional event-study methods try to detect abnormal returns at a certain significance level [58]. Event studies are used in a large variety of studies, including mergers and acquisitions, earnings announcements, debt or equity issues, corporate reorganizations, investment decisions and corporate social responsibility [59], [60].

Previous research focuses only on mean returns during the event, while ignoring other valuable factors such as systematic risk and accounting factors [28], [56]. In addition, the choice of event intervals in previous scholars is not evident. A specific way to find the "right" interval can not be determined. Researchers implicitly acknowledge this by providing results over several different intervals.

Based on the observation from our time-varying multifactor beta analysis in chapter III, there are abnormal changes in the multifactor systematic risk. We believe that these changes are impacted by significant economic events. However, no event study has researched based on the time-varying multifactor systematic risk. 
The time-varying characteristic of beta researched in the previous sections shows improvement in reducing the estimation errors. Thus, our goal is to detect the sudden changes in the whole time series beta resulting from the Kalman filter method and determine the impact of financial events on these changes. The initial work is done by T. Rajbhandary [70] on tracking the changes in beta using the Kalman filter with the CAPM observation model and Piecewise Constant state model, which only focuses on the market risk represented by a single factor in the CAPM. Based on the Fama-French model, we believe that other factors such as market cap and book-to-market value also cause changes in the systematic risk. Thus, event-study based on the multi-factor systematic risk including "market risk", "size risk", and "value risk" is performed to demonstrate the significant effects of the economic events on the multifactor systematic risk.

In this research, the Piecewise Constant (PC) multifactor beta model is used to detect the significant events in the history of companies or industries based on the Fama-French model. The macro-economic and micro-economic events are determined based on the sudden changes in the betas' time series. Our empirical tests indicate that significant events are successfully captured by the PC multifactor beta model in connection with the Fama-French three-factor model.

\subsection{Apply PCM and Fama-French Model to Detect Events using Kalman Filter}

\subsubsection{Piecewise Constant Model (PCM)}

PCM is formulated for the "market risk" [69] in the following equation:

$$
\beta_{t}=\beta_{t-1}+z_{t} u_{t}+\zeta_{t}
$$

where $\beta_{t}$ at time $t$ is assumed to be the previous beta at time $(t-1)$ plus the error term $\zeta_{t}$ and the jump process $z_{t} u_{t}$. The disturbances $u_{t}$ and $\zeta_{t}$ are assumed to be uncorrelated, independently and identically normally distributed with zero means and $\sigma_{u}^{2}, \sigma_{\zeta}^{2}$ variances respectively:

$$
u(t) \sim N\left(0, \sigma_{u}^{2}\right) \text { and } \zeta_{t} \sim N\left(0, \sigma_{\zeta}^{2}\right)
$$


The $z_{t}$ is the Bernoulli random process as follow:

$$
z_{t}=\left\{\begin{array}{cc}
1 & \text { w.p. } \eta \\
0 & \text { w.p. } 1-\eta
\end{array} .\right.
$$

\subsubsection{Detect a Jump Using the Modified Kalman Filter Review}

In order to detect an abnormal change in the multi-factor beta, we apply the modified Kalman filter presented in [70] with additional modifications to fit the multi-factor beta.

In our event-study, we assume that during the event interval $\Delta t$, there is either an event or no events $(P[N(\Delta t)>1]=0)$. Thus, there are two probabilities based on Poisson process with density $\lambda$ :

$$
\begin{gathered}
P[N(\Delta t)=0]=e^{-\lambda \Delta t}, \\
P[N(\Delta t)=1]=(\lambda \Delta t) e^{-\lambda \Delta t} .
\end{gathered}
$$

The equation (4.3) represents the probability of no event (no jump) occurring in interval $\Delta t$ and the equation (4.4) represents the probability of one event (one jump) occurring in interval $\Delta t$. Let $p^{0}(. \mid$.$) and p^{1}(. \mid$.$) represent the conditional likelihood distributions when z_{t}$ $=0$ and $z_{t}=1$ respectively:

$$
\begin{aligned}
& p^{0}\left(r_{t} \mid r_{t-1}\right) \sim N\left(r_{t} ; \beta_{t \mid t-1}, \mathbf{P}_{t \mid t-1}^{0}+\mathbf{R}\right), \\
& p^{1}\left(r_{t} \mid r_{t-1}\right) \sim N\left(r_{t} ; \beta_{t \mid t-1}, \mathbf{P}_{t \mid t-1}^{1}+\mathbf{R}\right),
\end{aligned}
$$

where $N\left(r_{t} ; \beta_{t \mid t-1}, \mathbf{P}().\right)$ is a Gaussian density with argument $r_{t}$, mean $\beta_{t \mid t-1}$, and covariance $\mathbf{P}($.$) .$

In the Kalman filter method, the prediction step includes the error covariance calculation $\left(\mathbf{P}_{t \mid t-1}\right)$. Since there are two probabilities that the beta will jump or not in this state model, the two corresponding covariances are calculated. Thus, in order to apply the Kalman filter, the algorithm needs to identify which state $z_{t}$ is more likely to be one or zero to select one of the covariances. Based on the Bayes' criteria, the jump is detected if there is a larger value of the weighted likelihood: $\left((1-\eta) * p^{0}\left(r_{t} \mid r_{t-1}\right) \leq \eta * p^{1}\left(r_{t} \mid r_{t-1}\right)\right)$ and otherwise. The details of the modified Kalman filter algorithm can be found in [70]. 


\subsubsection{Event-study Based on the Kalman Filter}

In order to apply the Kalman filter, a set of observations and state equations need to be set up. In this event-study research, the Fama-French three-factor model is used as an observation equation and the multivariate Piecewise Constant model is used as a state equation. Recall the Fama-French model:

$$
r_{t}-r_{f, t}=\alpha+\beta_{t} \cdot\left(r_{I, t}-r_{f, t}\right)+s_{t} . S M B_{t}+h_{t} . H M L_{t}+\epsilon_{t} .
$$

The Fama-French model can be rewritten in the matrix form as follow:

$$
\mathbf{Z}_{t}=\mathbf{H}_{t} * \mathbf{X}_{t}+\epsilon_{t}
$$

where $\mathbf{Z}_{t}=\left(r_{t}-r_{f, t}\right), \mathbf{X}_{t}=\left[\begin{array}{c}\alpha \\ \beta_{t} \\ s_{t} \\ h_{t}\end{array}\right], \mathbf{H}_{t}=\left[\begin{array}{c}1 \\ \left(r_{I, t}-r_{f, t}\right) \\ S M B_{t} \\ H M L_{t}\end{array}\right]^{T}$ and $\epsilon_{t} \sim N\left(0, \sigma_{\epsilon}^{2}\right)$.

Since the observation model has three factors, the three state equations need to be established. Assuming that alpha is constant and all three betas ( $\beta$, s and $\mathrm{h}$ ) follow the Piecewise Constant model:

$$
\begin{aligned}
& \beta_{t}=\beta_{t-1}+z_{\beta, t} u_{\beta, t}+\zeta_{\beta, t}, \\
& s_{t}=s_{t-1}+z_{s, t} u_{s, t}+\zeta_{s, t}, \\
& h_{t}=h_{t-1}+z_{h, t} u_{h, t}+\zeta_{h, t} .
\end{aligned}
$$

We can rewrite the three state equations above in the matrix form as follow:

$$
\mathbf{X}_{t}=\mathbf{F} * \mathbf{X}_{t-1}+\boldsymbol{z}_{t} * \boldsymbol{u}_{t}+\boldsymbol{\zeta}_{t}
$$

where $\boldsymbol{u}_{t} \sim N(0, \mathbf{U})$ and $\boldsymbol{\zeta}_{t} \sim N(0, \mathbf{Q})$.

$$
\mathbf{F}=\left[\begin{array}{lll}
1 & 0 & 0 \\
0 & 1 & 0 \\
0 & 0 & 1
\end{array}\right], \mathbf{U}=\left[\begin{array}{ccc}
\sigma_{u_{\beta}}^{2} & 0 & 0 \\
0 & \sigma_{u_{s}}^{2} & 0 \\
0 & 0 & \sigma_{u_{h}}^{2}
\end{array}\right], \mathbf{Q}=\left[\begin{array}{ccc}
\sigma_{\zeta_{\beta}}^{2} & 0 & 0 \\
0 & \sigma_{\zeta_{s}}^{2} & 0 \\
0 & 0 & \sigma_{\zeta_{h}}^{2}
\end{array}\right]
$$

Now we can apply the modified Kalman filter to detect the significant changes in "market risk", "size risk" and "value risk". The modified multivariate Kalman filter is different from 
the traditional one since it uses the Bayes' criteria selection to determine the jump in each observation. When an abnormal change occurs, the algorithm will detect it and record it as an index (denote by $\mathbf{J}$ ). These indexes finally are mapped with the dates denoted by $\mathbf{D}$ to find the events which caused these changes. The mid-steps are added on the original Kalman filter to detect the jump right before the innovation covariance is calculated. The details of the algorithm is described in Algorithm 4.

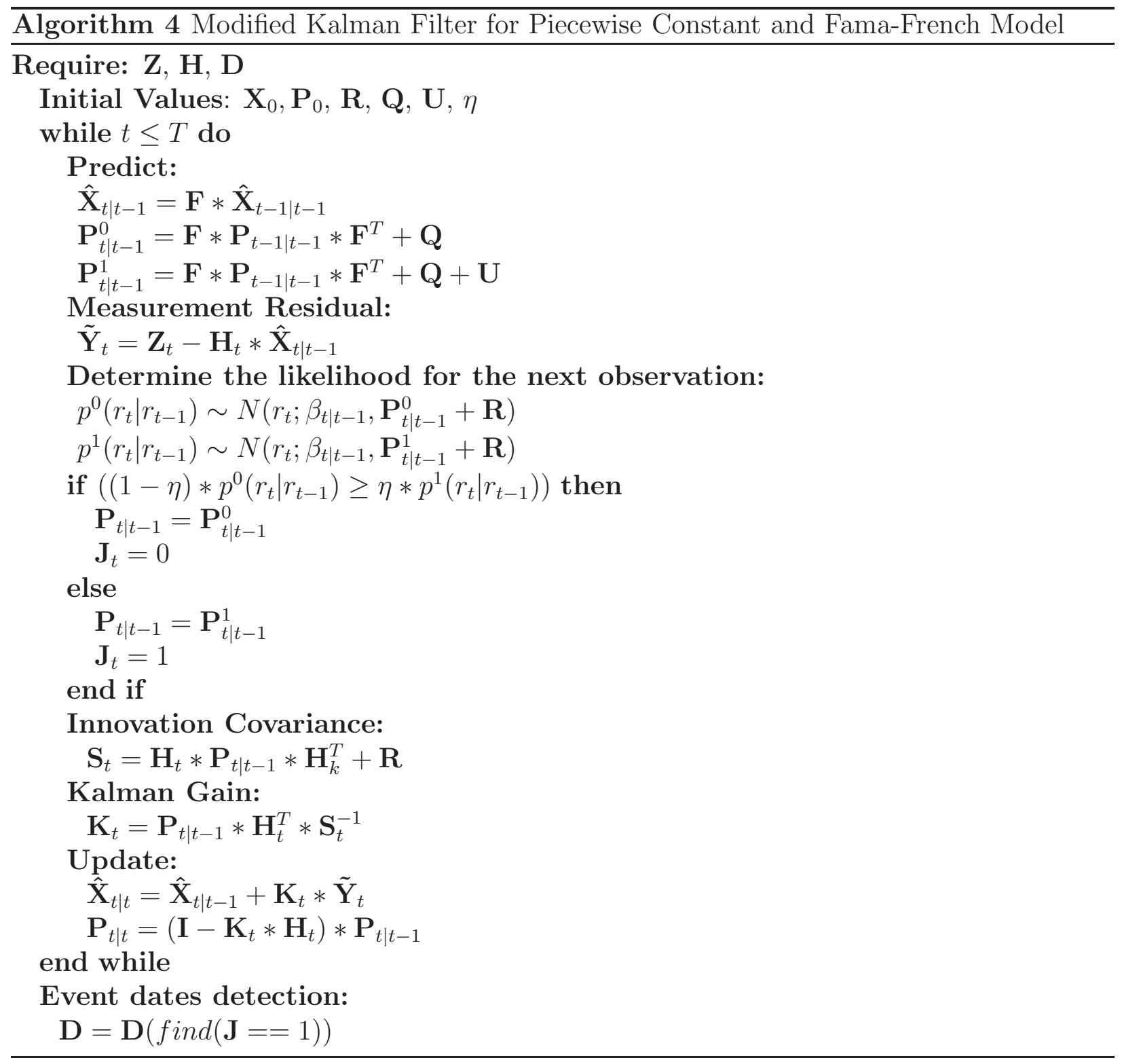




\subsection{Empirical Tests}

In the empirical tests, instead of using a single factor model (CAPM) for individual stocks in [70], the Fama-French three-factor model is used as the observation model and the empirical test is performed on both industrial portfolios and individual stocks. The CAPM model is also tested on the portfolios with the Piecewise Constant model (PCM). The empirical test evaluates the performance of the PCM as compared to other models which are presented in chapter III in each combination to the CAPM or the Fama-French model. Based on the estimated multi-factor systematic risk, the abnormal changes in the three betas is detected using the PCM when the betas are observed from the Fama-French model. The economic events on the detected date changes are studied to verify the sufficiency of the methods and explain the economic matters of the change in the multi-factor beta.

\subsubsection{Procedure}

- Select an observation model (CAPM or Fama-French model) and a security (individual stocks or portfolios)

- Perform the beta tracking algorithm as described in Algorithm 4.

- Calculate the criteria: RMSE, AIC and perform the log-likelihood ratio test.

- Record the date indexes of the abnormal changes in beta, s, h; then, map to the corresponding dates.

- Research the macro and micro-economic events on these dates.

\subsubsection{Data Sources}

\section{Individual stocks}

The same set of stocks from the previous empirical test (described in chapter III) is repeated for usage in the event-study.

\section{Industrial Portfolios}

The data is downloaded from the Fama-French's website including forty-eight industrial 
portfolios. All of these industrial portfolios have the same historical date range from July 1926 to December 2011. Six of these portfolios are selected for this experiment. The details can be seen in Table 4.1 .

Table 4.1: Industrial portfolios for the empirical tests of the PC beta model

\begin{tabular}{ll}
\hline \hline Industrial Portfolio & Standard Industrial Classification (SIC) code \\
\hline Automobiles and Trucks & $2296,2396,3010-3011,3537,3647,3694,3700$, \\
& $3710,3711,3713-3716,3790-3792,3799$ \\
Oil & $1310-1339,1370-1382,1389,2900-2912$, \\
& $1300,2990-2999$ \\
Computers & $3570-3689,3695,7373-7373$ \\
Banking & $6090-6100,6010-6036,6040-6062,6080-6082$, \\
& $6000,6110-6113,6120-6179,6190-6199$ \\
Real Estate & $6540-6541,6510,6512-6515,6517-6532$, \\
& $6500,6550-6553,6590-6599,6610-6611$ \\
\hline
\end{tabular}

\subsubsection{Results}

By applying the Piecewise Constant model (PCM) on the two market models (CAPM and Fama-French model), the multi-factor risks are estimated and the performance of the estimation is evaluated based on the criteria displayed in Table 4.2 and Table 4.3.

Table 4.2 presents the criteria in the CAPM versus in the Fama-French model for the empirical test for individual stocks. The RMSEs of both models are very close and have slight improvement when using the Fama-French model in combination with the PCM (FF$\mathrm{PC}$ ) as compared to the CAPM in combination with the PCM (CAPM-PC). The AICs are balanced between the two models since four of the stocks have better AICs in FF-PC and the other three are in contrast.

Table 4.3 presents the criteria for the CAPM versus the Fama-French model for the industrial portfolios' empirical test. While the AICs are lower in CAPM-PC, the RMSEs show improvement in FF-PC for all portfolios.

These results confirm the validity of the multi-factor PC beta model since it still can keep the advantage of the time-varying model as verified in the previous chapter (improve RMSE and $R^{2}$ ) and is also able to detect the significant events which affect the multi-factor risk changes. The impacts of the significant events on the changes in the multifactor beta 
are studied in the following event-study cases.

Table 4.2: CAPM-PC vs FF-PC criteria for individual stocks

\begin{tabular}{|c|c|c|c|c|c|c|}
\hline \hline & \multicolumn{3}{|c|}{ CAPM } & \multicolumn{3}{c|}{ F-F Model } \\
\hline Ticker & RMSE & AIC & $\begin{array}{c}\text { Max-log } \\
\text { likelihood }\end{array}$ & RMSE & AIC & $\begin{array}{c}\text { Max-log } \\
\text { likelihood }\end{array}$ \\
\hline AAPL & 0.1423 & -1.1149 & 213.3745 & 0.1416 & -0.9425 & 183.3078 \\
IBM & 0.0712 & -2.8501 & 1468.1 & 0.0710 & -2.8803 & 1485.6 \\
GE & 0.0801 & -3.1175 & 1605.3 & 0.0797 & -3.1721 & 1635.3 \\
XOM & 0.0607 & -3.2717 & 1684.4 & 0.0602 & -3.3583 & 1730.8 \\
CSCO & 0.1213 & -1.608 & 216.4015 & 0.1209 & -0.7237 & 103.17 \\
MSFT & 0.1056 & -1.7551 & 277.1528 & 0.1050 & -0.8210 & 134.8519 \\
RIMM & 0.2216 & -0.0133 & 7.0211 & 0.2224 & -0.0401 & 11.0804 \\
\hline
\end{tabular}

Table 4.3: CAPM-PC vs FF-PC criteria for portfolios

\begin{tabular}{|c|c|c|c|c|c|c|}
\hline \hline & \multicolumn{3}{|c|}{ CAPM } & \multicolumn{3}{c|}{ F-F Model } \\
\hline Portfolio & RMSE & AIC & $\begin{array}{c}\text { Max-log } \\
\text { likelihood }\end{array}$ & RMSE & AIC & $\begin{array}{c}\text { Max-log } \\
\text { likelihood }\end{array}$ \\
\hline Oil & 0.0620 & -3.5953 & 1852.4 & 0.0528 & -3.0047 & 1549.4 \\
Autos & 0.0818 & -3.4973 & 1802.1 & 0.0643 & -2.8688 & 1479.7 \\
Banking & 0.0729 & -3.3864 & 1745.2 & 0.0569 & -3.0419 & 1568.5 \\
Real Estate & 0.0995 & -2.6232 & 1353.7 & 0.0768 & -2.4082 & 1243.4 \\
Computers & 0.0744 & -3.4218 & 1736.4 & 0.0643 & -2.8688 & 1479.7 \\
\hline
\end{tabular}

\subsubsection{Event-study Cases}

Apple Inc. (AAPL)

Figure 4.1 displays the significant changes in the three-factor systematic risk of Apple Inc. The detected month indexes are 7, 20, 141, 192, and 220 which corresponds to September 1982, October 1983, November 1993, February 1998, and June 2000. The following economic events are studied in order to explain the sudden changes in the "market risk", "size risk", and "value risk".

\section{October 1983}

All three-factor risks decrease based on our analysis. During this time, Apple published its fourth quarter results indicating that earnings were at 5.1 million of sales of $\$ 273.2$ 


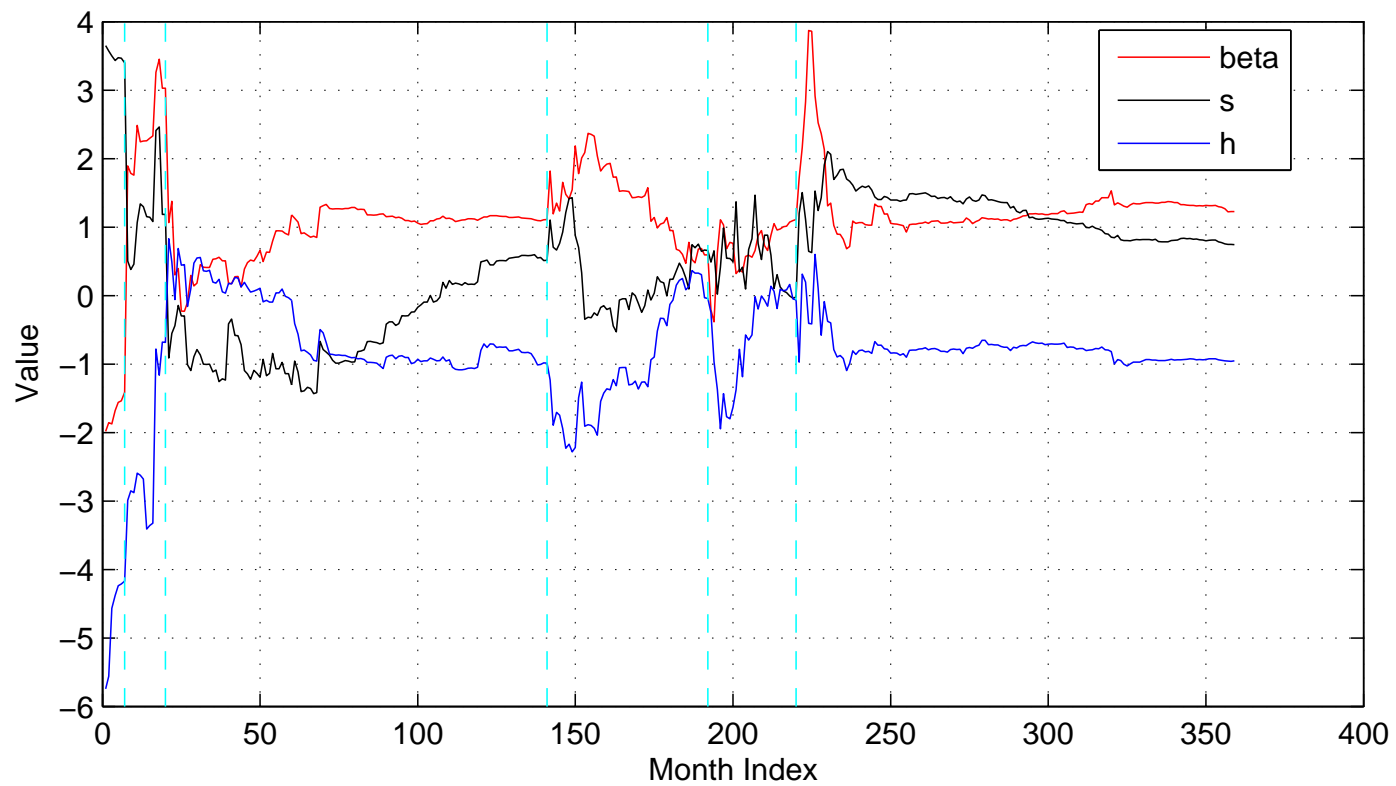

Figure 4.1: FF-PC: abnormal changes in multifactor systematic risk of AAPL

million. The reason for the poor results in the fourth quarter was due to the aggressive price competition from IBM. As a result, Apple was forced to cut Lisa's price by $18 \%$. Despite the poor fourth quarter's profit, AAPL still showed multiple positive signals allowing investors to be optimistic in the next period which caused the decline in the market risk. There was also talk of Apple's newest computer product "Macintosh" that would be introduced early of 1984 costing less and would aim at a different market. Sales still increased $69 \%$ in the fourth quarter and was promising for the next period when the new "Macintosh" released causing the value risk and size risk to fall ${ }^{1}$.

\section{November 1993}

The "market risk" and "size risk" increase suddenly during this month while there is a small rally in "value risk". They are affected by a big announcement made on 15-Oct-1993 by Apple Inc. declaring that the CEO, John Sculley, had resigned. Sculley's resignation occurred one day after Apple reported a 97 percent drop in earnings for its most recent quarter, to just $\$ 2.7$ million. The company blamed the decline on the industry-wide cut-throat pricing war. Sculley stepped aside as chief executive officer in the midst of a personal-computer

\footnotetext{
1"Apple sharply lower in quarter", Paul Taylor, The Financial Times Limited , 25-Oct-1983
} 
price war and internal tension over the company's direction, while remaining chairman just in June. The poor business performance and the unstableness in management caused the increase in Apple stocks' risk since investors lost confidence in the company ${ }^{2}$.

\section{February 1998}

All three-factor risks are down based on our analysis. Apple announced in February 27, 1998 that they would stop producing Newtown software and products to centralize their focus on the Macintosh operating system. This was due to the increased competition in the palmtop computing market which used Microsoft Windows CE. After this news was released, shares increased by $12.5 \%$. In addition to this, Apple also acquired Compaq Computer Corp, Timothy D. Cook to manage its manufacturing and operations distribution. Rumours were also stating that Apple was in the process of developing a "media player" and would be acquired by a bigger firm. Apple had taken some very positive steps to focus the business to create trust in investors. This was indicated by the great decline in their risks ${ }^{3}$.

\section{June 2000}

According to Figure 4.1 (month index: 220), the "market risk" and "size risk" increase while the "value risk" decreases. The "market risk" and "size risk" are affected by the stock split event on June 21, 2000. The stock split was acting as a catalyst to wake investors ahead of Macworld in July or to the fact that the stock is oversold and undervalued. Shareholders were following up on their Apple investment due to the stock split and may have responded to the positive QuickTime news. In addition, investors were anticipating a strong earnings announcement on July 18th from the company in spite of the slightly slower iMac sales. However, the street.com article pointed out that the Janus Strategic Value fund has 3\% of their nearly $\$ 3$ billion in assets invested in Apple's stock. That places Apple in the top ten picks of this hot new mutual fund which had recently opened at the end of February but was up 5.9\% in spite of the recent tech sell-off . This caused the decrease in the value risk of AAPL ${ }^{4}$. 


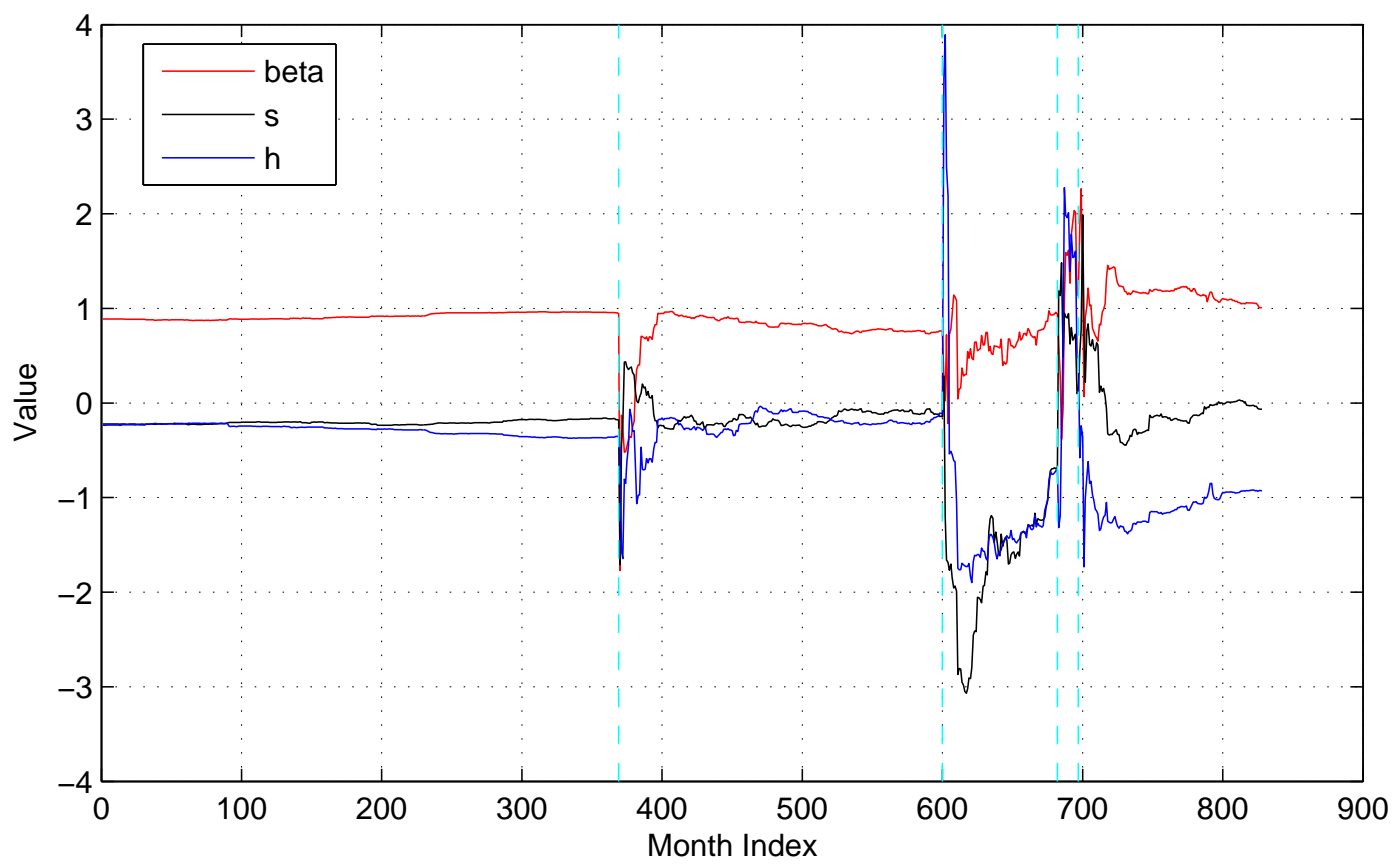

Figure 4.2: FF-PC: abnormal changes in multifactor systematic risk of IBM

\section{IBM}

Figure 4.2 displays the significant changes in the three-factor systematic risk of IBM Corp. The detected monthly indexes are 369,600,683, and 697 which corresponds to October 1973, January 1993, December 1999, and February 2001.

\section{October 1973}

According to our analysis, all risks suddenly drop down. Looking at IBM's history, October 1973 was the date that Dr. Leo Esaki, an IBM's fellow, won the Nobel Prize in Physics proving the tunneling phenomena in semiconductors ${ }^{5}$. Esaki was engaged in semiconductor research at the IBM Thomas J. Watson Research Centre since 1960. He developed the tunnel diode to be used in high frequency oscillation and amplification for circuit switching to increase the speed of computers. This event provided people and shareholders confidence and belief in IBM's capability in technology innovation, as this year marked the first time

\footnotetext{
${ }^{2}$ Chicago Tribune News, 15 October 1993

${ }^{3}$ The New York Times, Page 3, Column1, 28-Feb-1998

${ }^{4}$ http://www.macobserver.com/news/00/june/000621/applstocksplit2.shtml

${ }^{5}$ http://www.nobelprize.org/nobel_prizes/physics/laureates/1973/press.html
} 
ever that IBM's gross income passed $\$ 10$ billion dollar level in which they earned $\$ 10.99$ billion and their net earnings increased to $\$ 1.57$ billion ${ }^{6}$.

\section{January 1993}

The analysis in Figure 4.2 indicates a decrease in market risk and an increase in the other two risks. At the end of December 1992, IBM announced its plan to reduce its worldwide workforce by about 25,000 employees in 1993 while further reducing its global manufacturing capacity. By announcing the reduction in the amount of employees worldwide and manufacturing capacity, this caused the size and value risks to go up ${ }^{7}$.

\section{December 1999}

While the "market risk" and "value risk" are down significantly, "size risk" is up according to our analysis. The annual report indicated an exceptional business performance during 1999 with revenue increase of $7 \%$ and net earnings up by $22 \%$ over the prior year. IBM also announced in December 1999 a $\$ 100$ million research initiative to build "Blue Gene", a supercomputer that is 500 times faster than the top desktop computer of that time. The speed and power of "Blue Gene" will aid scientists in modeling the folds of human proteins to gain better knowledge in diseases and methods to control them. Market risk and size risk would go down as this event would be perceived as good news by shareholders and the general public because people would be impressed by IBM's technology advancement and business performance ${ }^{8}$.

\section{February 2001}

Market risk is suddenly up along with the slight increase in two other risks shown in index 697th in Figure 4.2. IBM was faced with an Alien Tort Claims Act filed against them in February 2001 for their controversial business practice of their role in IBM's subsidiary, the Dehomag, during World War II. The Dehomag gave the Nazi party the means for a large census of the population and for searching its data through the punch card technology that facilitated the Holocaust. IBM was accused of providing the punch card, in which they leased and maintained the Nazi's collection of card punch machines, and for covering up the

\footnotetext{
${ }^{6}$ http://www-03.ibm.com/ibm/history/documents/pdf/1970-1984.pdf

${ }^{7}$ http://www-03.ibm.com/ibm/history/documents/pdf/1990-1995.pdf

${ }^{8}$ http://www-03.ibm.com/ibm/history/documents/pdf/1996-1999.pdf
} 
Dehomag's actions. Market-risk would go up in this case as this is a very controversial issue in which the general public's view on the company's morals and ethics are impacted. People are less likely to invest or feel confident in a company that does not have a high standard of business practice and ethics especially for a company that is as large as IBM ${ }^{9}$.

\section{GE}

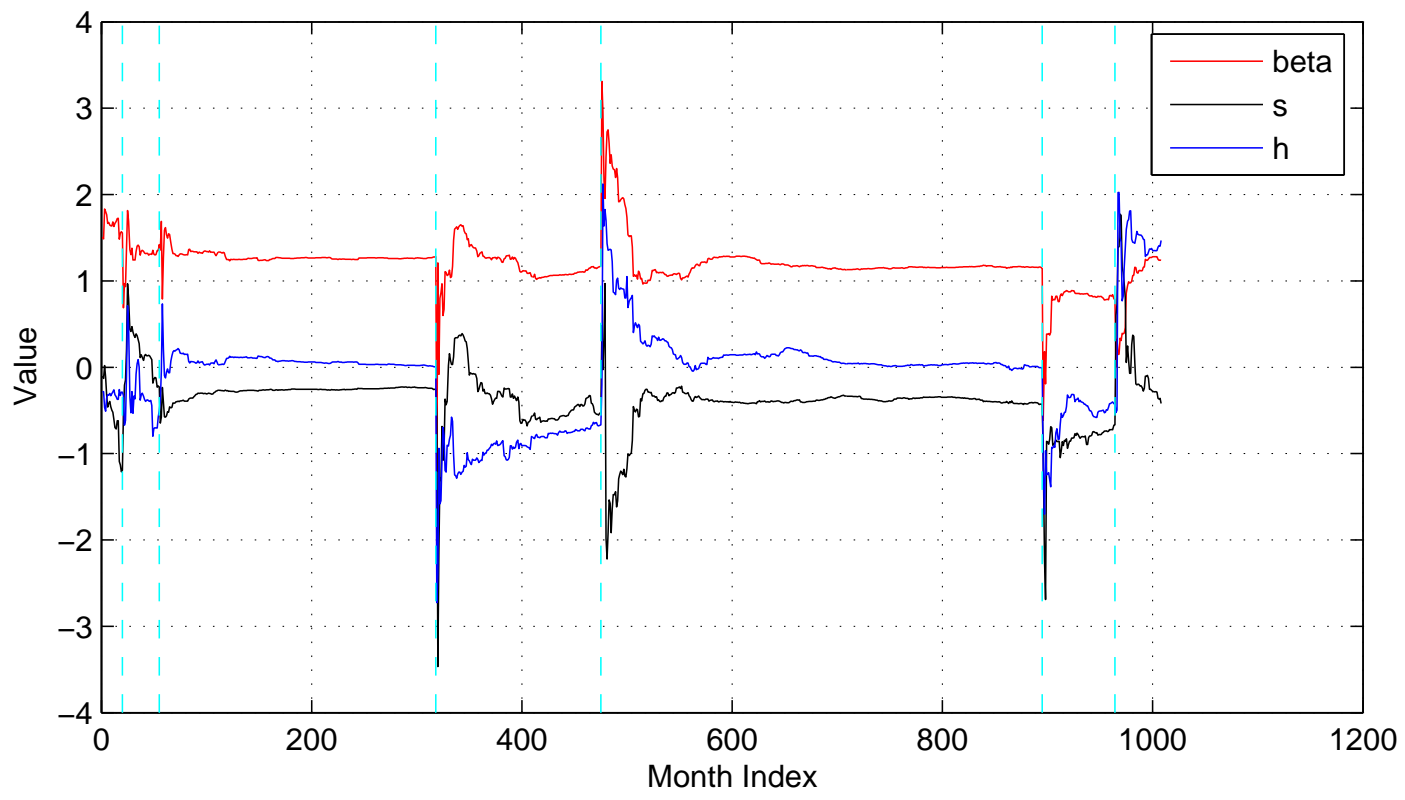

Figure 4.3: FF-PC: abnormal changes in multifactor systematic risk of GE

Figure 4.3 displays significant changes in the three-factor systematic risk of General Electric Co (GE). The detected month indexes are 20, 55, 318, 475, 895, and 964 which corresponds to Sept. 1929, Aug. 1932, July 1954, Aug. 1967, Aug. 2002, and May 2008.

\section{May 2008}

The month index 964th indicates the decrease in the "market risk" in contrast to the increase in the other two risk factors. In May of 2008, General Electric announced that it would sell its appliances division. At that point, the appliances division was slow-growing and putting a drag on the company. Thus, GE announced to close it down so that they could focus on their faster-growth products. Shares of GE went down 24 cents. The closing-

\footnotetext{
${ }^{9}$ http://www-03.ibm.com/press/us/en/pressrelease/1388.wss
} 
down would reduce the size of the firm and increase the "size risk". Shortly before this announcement, GE had shocked analysts by falling short of their first quarter earnings estimates. In addition, they had a $6 \%$ decrease in profit and lowered their forecast for the rest of the year which explains the increase in value risk. One of the causes for the poor results was due to the increase in metal prices and aggressive competition overseas as GE only competes within America and did not expand overseas. However, the event did not affect market risk much since it still showed a positive trend in GE when they were focused on their fast-growing business division ${ }^{10}$.

\section{August 2002}

All risks abruptly are down at month index 895th according to our analysis. GE cooperated with NASA in August 2002 in a study to develop a jet engine to power the space shuttle's rocket booster back to land so that they would not have to be retrieved from the ocean. Their current practice involved the rocket boosters being parachuted in to the sea and retrieved from the sea for reuse after launch. GE's study with NASA consisted of designing and developing a jet engine that would fly the rockets' boosters to a designated landing place shortly after launch ${ }^{11}$. Thia project boosts GE as a leader in Jet Engines and their innovation capability. Investors would feel confident about this big project and the "market risk" and "value risk" of GE stock during this time reduced significantly.

\section{July 1967}

What happened to GE stocks at index 475th when all the risks rise fiercely? The Surgeon General of the U.S. Public Health Service said that General Electric Co. had been unable to locate about 9000 color television sets that may be leaking excessive X-rays. He urged anyone owning a suspected set pull the plug. With this serious problem with TV products and the bad news announcement, it would be hard to convince stock buyers that the company's shares are not risky to invest in ${ }^{12}$.

\section{July 1954}

All risks are down at index 318th which indicates a positive sign for GE stock. According

\footnotetext{
${ }^{10}$ Frank Ahrens , The Washington Post, 17-May-2008 and Shawn Langlois, Dow Jones Business News, 15-May-2008

${ }^{11}$ Associated Press Newswires, 29-Aug-2002

${ }^{12}$ J.V. Reistrup, The Washington Post, 22-July-1967
} 
to the quarterly report, the company's earnings for the first six months of 1954 reached a record of $\$ 93,856000$, an increase of 24 per cent over last year's first-half earnings of $\$ 75,417,000$, Ralph J. Cordiner, president, announced in 21-July-1954. This good news would encourage investors to invest in GE as the company had strong earnings, thereby reducing the systematic risks. ${ }^{13}$.

\section{Oil Portfolio:}

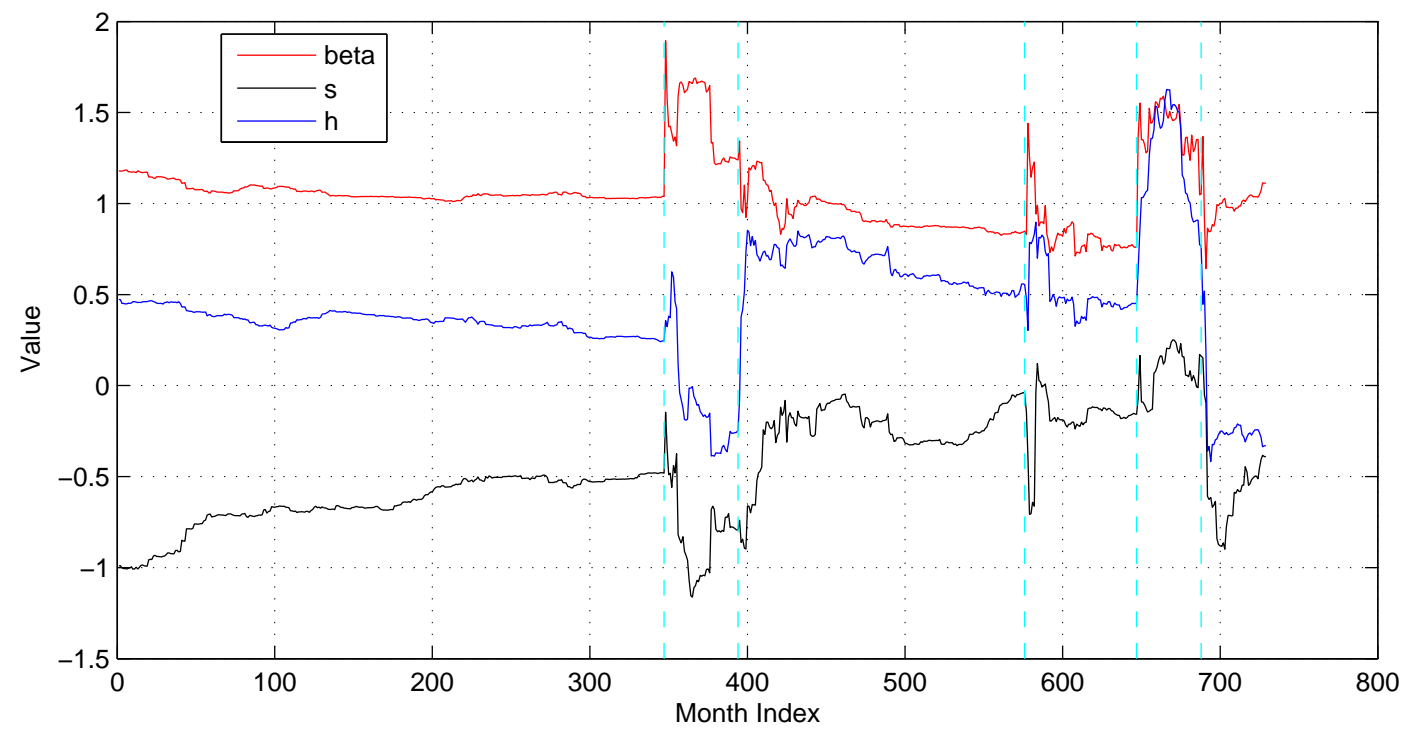

Figure 4.4: FF-PC: abnormal changes in multifactor systematic risk of oil portfolio

Figure 4.4 displays the significant changes in the three-factor systematic risk of the oil portfolio. The detected monthly indexes are 394, 576, 647, and 688 which corresponds to Feb. 1984, Apr. 1999, Mar. 2005, and Aug.2008.

\section{August 2008}

According to Figure 4.4, all three risk factors decrease. Oil prices plummeted because it was predicted that demands for oil and gas will decrease in the future. Chairman Bernanke issued a statement to the Senate that high energy prices and slower economic growth limited US households to purchase fuel and other necessities. The prices of commodities were rapidly deflating because of the recession US was facing. Oil prices were $16 \%$ from the closing high.

\footnotetext{
${ }^{13}$ Baltimore , The Sun, 21-Jul-1954
} 
The risks would decrease in this case as long-term investors saw the price decline in stocks as a buying opportunity and the statement made by the chairman would create some reaction from the government to recover the energy industry. For example, in 2006 when crude prices fell from over $\$ 70$ to $\$ 50$ a barrel, investors flocked to buy oil stocks as they believed it would be a "safe haven" as prices will eventually go back up again which Exxon Mobil witnessed as one of its largest stock gains ever of over $30 \% 14$.

\section{March 2005}

All three risk factors suddenly increase during this time. Shares in oil declined as oil prices past $\$ 53$ a barrel due to a series of refinery problems in Texas. Rising oil prices caused a decrease in the stock market as they raised costs for companies and consumers. During this time period, there was a shortage in the supply of oil and OPEC had announced that they would increase the production ceiling by $1 / 2$ a million barrels a day. Demand being greater than supply drove the oil prices higher in trading while shares of oil fell greatly. A part of the cause for a shortage of supply was due to China. China consumes roughly 6.4 million barrels a day and was predicted to double by 2020. China in 2005 had 20 million cars and trucks which could easily be 120 million by $2020{ }^{15}$.

\section{April 1999}

During this period, while market risk $(\beta)$ increases firmly, the two other risk factors decrease. Oil share prices increased in April 1999 because of the Balkins crisis in Kosova between the Serbs and ethnic Albanians combined with the export cuts by Iran and Saudi Arabia. Crude increased as reports of the Serbian force had crossed the border into Albanian territory. War creates a great demand for jet fuel and heating oil causing oil prices to become more expensive. To summarize, oil prices rose and shares fell as people were uncertain about the war in Kosova and the supply cut from major exporting countries. This affected the market risk in a negative way since investors were worried about the war which would decrease the stocks' price $^{16}$. In addition, this was also a time period of increasing oil surplus due to the economic recession in Asia lowering demand for oil. However, major oil producing

\footnotetext{
${ }^{14}$ http://money.cnn.com/2008/07/16/markets/oil/index.htm

${ }^{15}$ Robert J., "A New Era for Oil", The Washington Post, 30 March 2005

${ }^{16}$ Catherine Evans, "Oil firms cash in on price rises", Reuters News, 1 April 1999
} 
nations were trying to impose productions quotas to curve worldwide oil surplus. This action to reduce the surplus situation caused the reduction in the value risk and size risk as investors reacted to the the reduction of the oil surplus. This was indicated in crude futures rising 64 cents and oil companies such as Exxon rose $\$ 3.25$ in share price confirming that the problem was effectively being dealt with.

\section{February 1984}

There is a significant increase in value risk as compared to the two other factors during February 1984. Fears of an Iranian blockade off the Strait of Hormuz, which is one of the main lifelines of world oil supply, caused international oil prices on spot markets to rise.US spot crude oil prices rose sharply to reflect the fear that individuals faced. Investors were uncertain about the outcome of this potential blockade, thus making them unsure about the real market value of oil stocks relative to companies value. As a result value risk went up. Again, we can see the important role the Arab countries play in controlling the oil industry. The war in the area affected the world oil supply and more specifically the US ${ }^{17}$.

\section{Banking Portfolio}

Figure 4.5 displays the significant changes in three-factor systematic risk of the banking portfolio. The detected month indexes are 277, 447, 566, 680, and 777 which corresponds to Nov. 1966, Jan. 1981, Dec. 1990, May 2000, and July 2008.

\section{June 2008}

All risks increase significantly according to our analysis. US bank stocks declined at their lowest level after analysts predicted that credit losses would increase. Analysts also predicted that quarterly earnings would fall short of already low expectations involving more capital raises, dividend cuts, and more asset sales which caused panic in the stock markets. Bad news had piled up in the U.S. Several issues had caused the decline. The first was the failure of a mid-sized bank, IndyMac Bancorp, owning $\$ 18$ billion in deposits marked the biggest US bank failure in nearly 25 years. However, IndyMac was not the only bank as ninety other banks were also on the watch. Falling home prices contributed to the losses

\footnotetext{
${ }^{17}$ Seth Mydans, "Oil Up Sharply on Fear Of an Iranian Blockade", The New York Times, 28 February 1984
} 


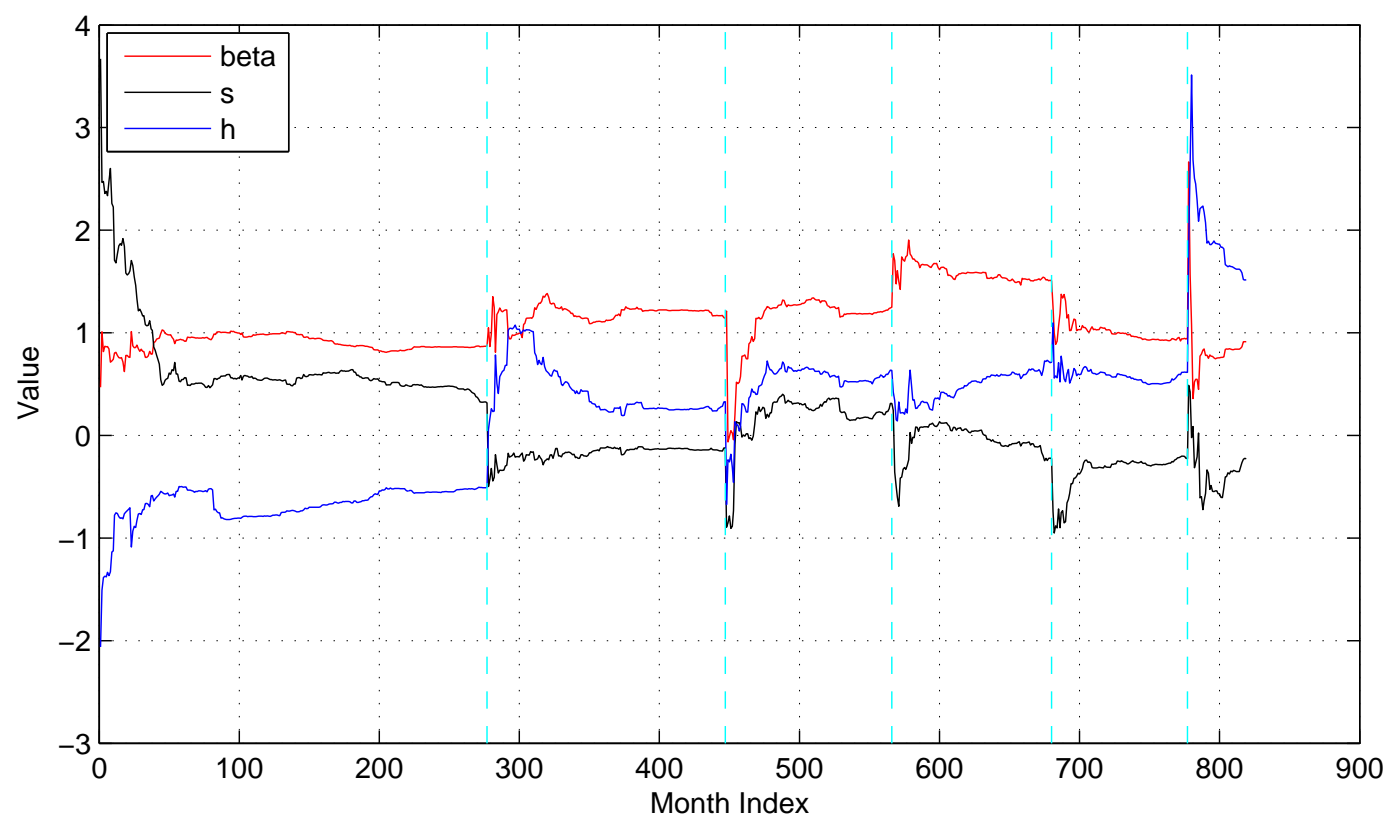

Figure 4.5: FF-PC: abnormal changes in multifactor systematic risk of banking portfolio

for financial institutions holding mortgages. Fannie Mae and Freddie Mac, government sponsored agencies that held 5.2 trillion in mortgage debt and owned half of US home loans had also cried for help. In addition to the bank failure, falling unemployment rates added to delinquency problems among mortgage borrowers ${ }^{18}$.

\section{May 2000}

All risks decrease in April 2000 (index 680th) and then quickly increase a few months after. After the long term effect by the world economic crisis and $\$ 3$ billion collapse of the US hedge fund Long Term Capital Management (LTCM), the Clinton administration described the financial situation as the most serious in the post-war period. Interest rate cuts at the end of 1998 and in the lead-up to 2000 helped inflate the US financial bubble even further, until it reached its peak in April $2000{ }^{19}$. The bubble was caused by the public's obsession with the Internet and speculation in stocks which caused the stock market to be overvalued. Investors poured money into Internet stocks. What this meant for the financial side is that when the economy is in a bubble, the financial systems have excessive monetary liquidity

\footnotetext{
${ }^{18}$ Dan Wilchins, Reuters News , 7 July 2008

${ }^{19}$ http://www.theamericanconservative.com/articles/banking-on-the-bubble/
} 
translating to easy credit and large disposables income. Thus, more money, credit, and debt are created. All risks would go down because this was a time period where everyone would turn to banks to borrow money in order to invest in higher return investments as interest rates were low and returns would be greater than having a savings account at the bank ${ }^{20}$.

\section{December 1990}

According to our analysis, the market risk increases strongly at index 566th while other risks have very small fluctuations. December 1990 marked the announcement made by the Federal Deposit Insurance Corporation, which guaranteed deposits in US banks, that they could run out of money by mid-1991 due to the crisis faced by US banking industry that could lead to widespread failures the following year. The US had their largest banks operating over the edge of insolvency. The FDIC projected that there would be $\$ 63$ billion linked to bank failures. The crisis in the banking system arose from declining industrial production, rising unemployment, high inflation, depressed retail sales, and declining property market. Market risk increased in this case because of the public's fear of bank failures and their deposits not being guaranteed. The FDIC was predicted to run out of money for these guarantees. By the end of 1990, three hundred and eighty two banks had failed in the US and two hundred and seventy one banks failed the following year ${ }^{21}$.

\section{December 1980}

All risks are down according to our analysis. Wall Street trading volumes sky-rocketed to 69.6 million shares in December 1980 as banks reached what investors called "peak fever". There was an expectation of a cresting in interest rates. The prime rate was at 21 percent a record high. Bank stocks in particular increased as analysts, James Wooden and James Carter from Merrill Lynch, stated that near-term earnings would be favorable for banks in a period of falling interest rates. All risks would go down because of the optimistic feedback from the analysts providing a belief that investments in the banking industry would yield a positive return ${ }^{22}$.

\footnotetext{
${ }^{20}$ http://www.wsws.org/articles/2002/mar2002/lec2-m15.shtml

${ }^{21}$ Simon T, "Banking industry faces widespread failure", Washington Post, 17 December 1990

${ }^{22}$ Vartanig G., "Utility, Bank Stocks up in 5th-heaviest Trading", The New York Times, 19 December 1980
} 


\section{Real Estate Portfolio:}

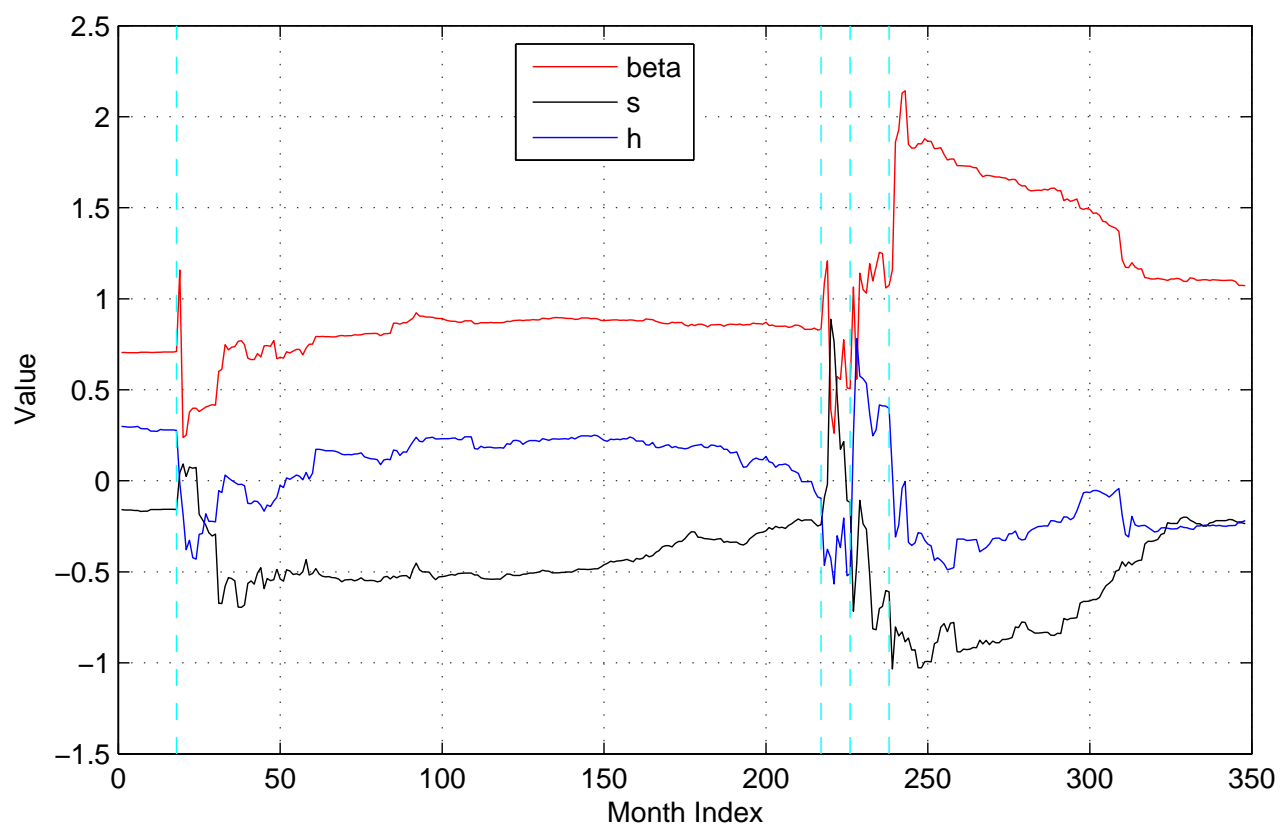

Figure 4.6: FF-PC: abnormal changes in multifactor systematic risk of real estate portfolio

Figure 4.6 displays the significant changes in the three-factor systematic risk of the real estate portfolio. The detected month indexes are 198, 397, 406, and 418 which corresponds to Nov. 2002, Feb. 2001, Nov. 2001, and Jul. 1984.

\section{November 2002}

Figure 4.6 shows the rise in the "market risk" and the decrease in the "value risk" and "size risk". According to analysis, November 2002 was when sale of previously owned houses jumped to their highest level in six months. Low interest rates helped boost the purchase of pre-owned homes by $6.1 \%$. Rates for 30-year fixed mortgages were below $6.5 \%$ - the lowest in at least 31 years ${ }^{23}$. However, this caused people to worry that increased housing sales and housing prices caused by low interest rates could lead to a housing bubble in the midst of popping. The public was concerned with the growing distance between the increasing home prices and income, which did not increase fast enough to keep pace with the rising costs of homes. It was feared that as soon as interest rates started rising again then the

${ }^{23}$ Barbara H., USA Today, 26 November 2002 
bubble would pop. This caused market risk to go up as people lost confidence and were not certain about the housing market due to the oversupply of housing and a worry that as soon as there is weak income growth, job losses, and a decrease in consumer confidence, the buble would pop. People did not buy homes as their fear surpassed the low interest rates ${ }^{24}$.

\section{November 2001}

November 2001 indicates an increase in "market risk" and "value risk". Even though the housing market had begun to rebound after a miserable September, consumer confidence increasingly weakened. This was due to the rising unemployment and continued layoff announcements. In November, $23 \%$ of consumers said jobs were hard to get, up from $20.6 \%$ in October. The decline in consumer confidence pushed stocks lower. Even with the previous month rebound, sales were still weaker than they were late summer of 2001, when sales of existing homes had hit a record pace of 5.54 million units. The inventory of available homes fell $10.1 \%$ to a total of 1.95 million homes. That drop suggested that fewer homeowners were putting their houses up for sale, possibly because they viewed the market as weakening. "If people are not listing their homes to sell, those are the same people that would have bought a trade-up house and now won't”, said David Lereah, the NAR's chief economist ${ }^{25}$.

\section{February 2001}

The "market risk" is up according to our analysis. The Dow index dropped down to 106.8 from 115.7 in January for the fifth straight month due to an uncertainty in employment and declining economic conditions. Consumer confidence was low and was indicated by a decrease in consumer spending, which accounts for two-thirds of U.S. economic activity. New home buyers hit the lowest level in 11 years, dropping 10.9\% even with falling mortgage rates. Existing-home sales plunged 6.6 percent in January, to an annual rate of 4.65 million units. It was the slowest sales rate since the 4.54 million in January 2000 and well below the 4.98 million level forecasted by economists ${ }^{26}$. Pre-owned home sale, which made up $80 \%$ of the overall US housing market declined by $6.6 \%$ to an annual rate of 4.65 million units; indicating the slowest sales rate since January 2000. "Given the fears of layoffs and an

\footnotetext{
${ }^{24}$ Nena G., "Is housing market a bubble that's waiting to burst", The Boston Globe, 24 November 2002 ${ }^{25}$ Patrick \&Greg, The Wall Street Journal, 28 November 2001

${ }^{26}$ Reuters News, 27 February 2001
} 
economic recession, more and more people are starting to sit on the sidelines, and take a wait-and-see attitude" before buying a home, said Sung Won Sohn, chief economist at Wells Fargo \& Co. He said his bank, one of the largest mortgage lenders in the country, was seeing a particularly noticeable drop-off in sales of high-end homes ${ }^{27}$. Thus, the real estate industry was performing poorly because of the low sales of homes causing the market risk to rise as people were uncertain about the economic condtions.

\section{July 1984}

"Market risk" and "size risk" increase strongly while "value risk" is down based on our analysis. The Deficit Reduction Act of 1984, now called the Tax Reform Act, was signed into law by the President on July 18, 1984 to help cut the federal deficit by $\$ 50$ billion over a three-year time span and proved to be a very controversial piece of legislation. Many American taxpayers were unfavourably affected by this new tax law, but especially real estate investors. The new law consisted of tax implications on real estate sellers who helped buyers in the financing of investment property. Prior to the act taking effect, sellers of investment property had to charge buyers on mortgages offered by sellers at least $9 \%$ interest. After the act, an interest rate of no less than $10 \%$ of the prevailing rate on Treasury notes of similar maturity must be charged by sellers . The real estate investors perceives this Act to be bad news because real estate companies would face a harder time selling property, thus market risk and size risk would go up. As stated by investment advisor Arnold G Rudoff. of California-based Spectrum Financial Group, "A real killer in the new act, especially for real estate transactions, was the provision requiring that all depreciation recaptured be taken into account in the year of the installment sale regardless of the amount of cash or other consideration receive at that time" ${ }^{28}$.

\subsection{Summary}

In this chapter, the PCM used to determine the changes in the market risk in [69], [70] is applied to detect the significant changes in the multi-factor beta. Accordingly, the multi-

\footnotetext{
${ }^{27}$ Patrick B., The Wall Street Journal, 27 February 2001

28 "Real estate investors may feel bite of Deficit Reduction Act", Gary S.Meyers, Herald Journal, 8-Oct1984
} 
variate modified Kalman filter is also presented in order to track the "market risk", "size risk" and "value risk" simultaneously. The empirical test results and event-study indicates the great application of the multi-factor beta PCM in detecting the significant events. The economic events in the case studies also explain the sudden changes in the multi-factor beta. By analyzing the abnormal changes in the multi-factor systematic risks based on the signal processing modeling technique and the economic events, we prove that the signal processing technique is a promising method for financial market analysts. 


\section{Chapter 5}

\section{Piecewise Mean Reverting Multi-factor Beta Model}

\subsection{Introduction}

In chapter III, the availability of the time-varying multi-factor beta models used to describe the market models are tested and show great improvement in the betas estimation. These results confirm the time-varying characteristic of the multi-factor beta. Moreover, chapter IV indicates the reliability of the jump process in detecting the abnormal changes in the multi-factor beta while still maintaining an accurate estimation. The Piecewise Constant Model (PCM) introduced in chapter IV, is in fact the Random Walk Model (RWM) with a jump process because it assumes beta follows the random walk process if there is no jump. Alternatively, this chapter introduces a new way of detecting sudden changes in the multifactor beta by modeling beta as a mean reverting process after each jump, called Piecewise Mean Reverting (PMR) model. This model is based on the observation seen in the previous two chapters that the "market risk", "size risk" and "value risk" tend to revert around their means and incur sudden jumps when there are important events. Different to the PCM in chapter IV, which the multi-factor beta stay almost constant after each jump, the PMR model allows the three betas to revert to their means after each jump with different reverting speeds depending on the model's parameters.

Our simulations and empirical tests demonstrate that the proposed model outperforms the traditional PC and RW model based on the RMSE criteria. It also does well in explaining the effects of different type of events on the market risk. 


\subsection{Piecewise Mean Reverting Model}

Assuming that the "market risk", "size risk" and "value risk" follow a jump-reverting process. That is, the three betas will jump when a significant event occurs and then revert to their means depending on a reverting factor. This mean reverting process will continue until another jump occurs. The reverting factor is denoted by $\phi_{t}$ and the means are denoted by $\bar{\beta}, \bar{s}$ and $\bar{h}$. The piecewise jump process $\left(z_{t}\right)$, the error terms $\left(u_{t}, \zeta_{t}\right)$, and other parameters are assumed to be the same as described in chapter IV for the PCM. This model becomes an original PCM if the reverting factor is set to be one. The PMR model is formulated as follow for the "market risk":

$$
\beta_{t}=\left(1-\phi_{\beta, t}\right) \bar{\beta}+\phi_{\beta, t} \beta_{t-1}+z_{\beta, t} u_{\beta, t}+\zeta_{\beta, t}, \quad \zeta_{\beta, t} \sim N\left(0, \sigma_{\zeta_{\beta}}^{2}\right)
$$

In contrast to the traditional MR model, the $\phi_{\beta, t}$ in this model is time variance. The parameter $\phi_{\beta, t}$ changes when a jump occurs and stay the same until the next jump occurs. In order to estimate $\phi_{\beta, t}$ for each jump, we use the maximum likelihood estimation algorithm in chapter III. The details of the $\phi_{t}$ estimation can be found in the Algorithm 5.

Based on the observation from chapter III and IV, the "size risk" and "value risk" are not significant as compared to the "market risk", we focus on tracking the "market risk" in this model. The "size risk" and "value risk" are assumed to follow the PCM which is a specific case of the PMR when $\phi_{s}$ and $\phi_{h}$ are set to one. The $s$ and $h$ are modeled below:

$$
\begin{array}{cc}
s_{t}=\left(1-\phi_{s}\right) \bar{s}+\phi_{s} s_{t-1}+z_{s, t} u_{s, t}+\zeta_{s, t}, & \zeta_{s, t} \sim N\left(0, \sigma_{\zeta_{s}}^{2}\right), \quad \phi_{s}=1 . \\
h_{t}=\left(1-\phi_{h}\right) \bar{h}+\phi_{h} h_{t-1}+z_{h, t} u_{h, t}+\zeta_{h, t}, & \zeta_{h, t} \sim N\left(0, \sigma_{\zeta_{h}}^{2}\right), \quad \phi_{h}=1 .
\end{array}
$$

For ease in applying the modified Kalman filter in chapter IV, the above equations can be rewritten in the matrix form:

$$
\mathbf{X}_{t}=\left(\mathbf{I}-\mathbf{F}_{t}\right) * \overline{\mathbf{X}}+\mathbf{F}_{t} * \mathbf{X}_{t-1}+\mathbf{z}_{t} * \mathbf{u}_{t}+\boldsymbol{\zeta}_{t}
$$

where $\mathbf{X}_{t}=\left[\begin{array}{lll}\beta_{t} & s_{t} & h_{t}\end{array}\right]^{\prime}, \overline{\mathbf{X}}=\left[\begin{array}{lll}\bar{\beta} & \bar{s} & \bar{h}\end{array}\right]^{\prime}, \mathbf{z}_{t}=\left[\begin{array}{lll}z_{\beta, t} & z_{s, t} & z_{h, t}\end{array}\right]^{\prime}, \mathbf{u}_{t}=\left[\begin{array}{lll}u_{\beta, t} & u_{s, t} & u_{h, t}\end{array}\right]^{\prime}$, $\boldsymbol{\zeta}_{t}=\left[\begin{array}{lll}\zeta_{\beta, t} & \zeta_{s, t} & \zeta_{h, t}\end{array}\right]^{\prime}, \mathbf{u}_{t} \sim N(0, \mathbf{U})$, and $\boldsymbol{\zeta}_{t} \sim N(0, \mathbf{Q})$.

The error terms $\mathbf{u}_{t}, \boldsymbol{\zeta}_{t}$ are assumed to have normal distributions and uncorrelated. The other multi-factor model parameters matrix, such as $\mathbf{F}_{\mathbf{t}}, \mathbf{Q}$, and $\mathbf{U}$ definition can be found 
in chapter IV. Notice that $\mathbf{F}_{t}(1,1)=\phi_{\beta, t}$ while $\mathbf{F}_{t}(2,2)=\mathbf{F}_{t}(3,3)=1$. The algorithm 4 in chapter IV can now be applied to track the multi-factor beta, following the PMR model, by replacing the "prediction step" (calculate $\hat{\mathbf{X}}_{t \mid t-1}$ ) with the following equation:

$$
\hat{\mathbf{X}}_{t \mid t-1}=\left(\mathbf{I}-\mathbf{F}_{t}\right) * \overline{\mathbf{X}}+\mathbf{F}_{t} * \hat{\mathbf{X}}_{t-1 \mid t-1} \text {. }
$$

Figure 5.1 displays a simulated 500-sample of the model with the standard derivations $\sigma_{\epsilon}$ $=0.01, \sigma_{u_{\beta}}=1, \sigma_{u_{s}}=\sigma_{u_{h}}=0.2$ and $\sigma_{\zeta_{\beta}}=\sigma_{\zeta_{s}}=\sigma_{\zeta_{h}}=0.1$. The jumps $\left(z_{t}\right)$ are set to one

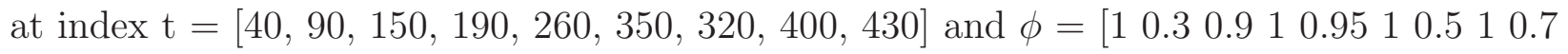
0.6] accordingly at jump intervals. We can see how the model behaves before and after each jump occurs. The beta fluctuates around their means, jump significantly and then revert to their means like an exponential function while $\mathrm{s}$ and $\mathrm{h}$ behave as in the PC model. In this model, the parameter $\phi$ decides the sharpness of the reverting process and is assumed to be in the range of [0:1]. The larger $\phi$ is, the slower the reverting process is after each jump.

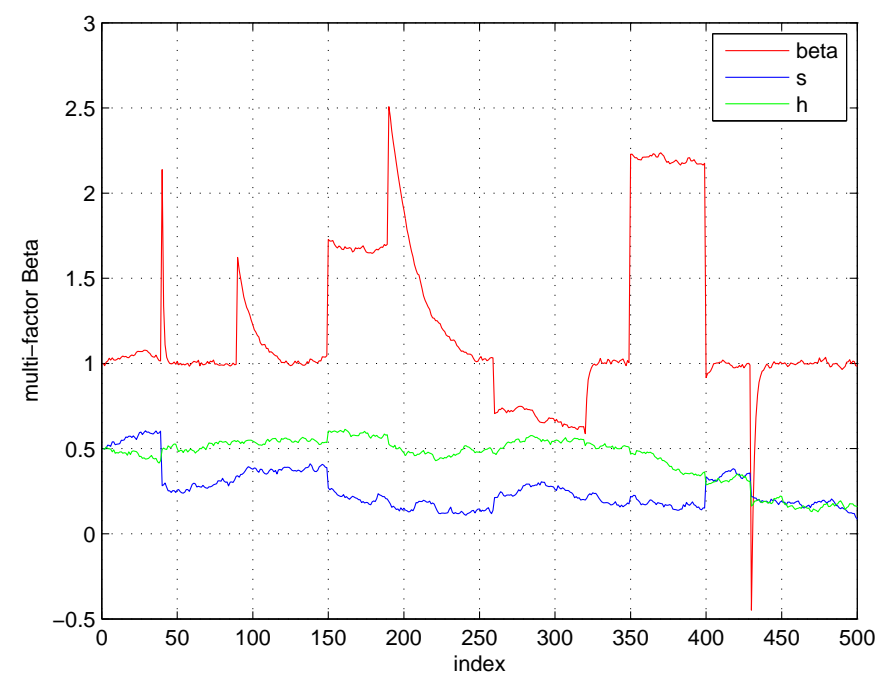

Figure 5.1: A simulated sample of PMRM

\subsection{Modified Kalman Filter Algorithm for PMR Beta Tracking}

In this model, we assume that the parameter $\phi$ changes over each jump. In finance, this means that the effect of each event to the market risk is different. Some events could make 
the risk go up suddenly but it can also recover very quickly while the others could cause long term recovery. Thus, assuming $\phi$ is constant over the whole time series, may increase the error in the estimation and reduce the ability in expressing the type of event of the market risk.

In order to estimate the parameter $\phi$, an algorithm based on the log likelihood function is constructed. Similar to the idea of estimating the model's parameters in the previous chapter, the chosen $\phi$ satisfies the maximum likelihood function in each jump interval. Algorithm 6 shows the complete procedure in estimating the PMR multi-factor beta. At first, the jumps are detected by using the modified Kalman filter in chapter IV with an additional modification mentioned in the above section for this model. The model parameters (except $\phi)$ are also optimized using the maximum likelihood method. Then, the parameter $\phi$ is estimated for each jump interval based on the optimized parameters from the previous step. Finally, the multi-factor beta is estimated based on these parameters.

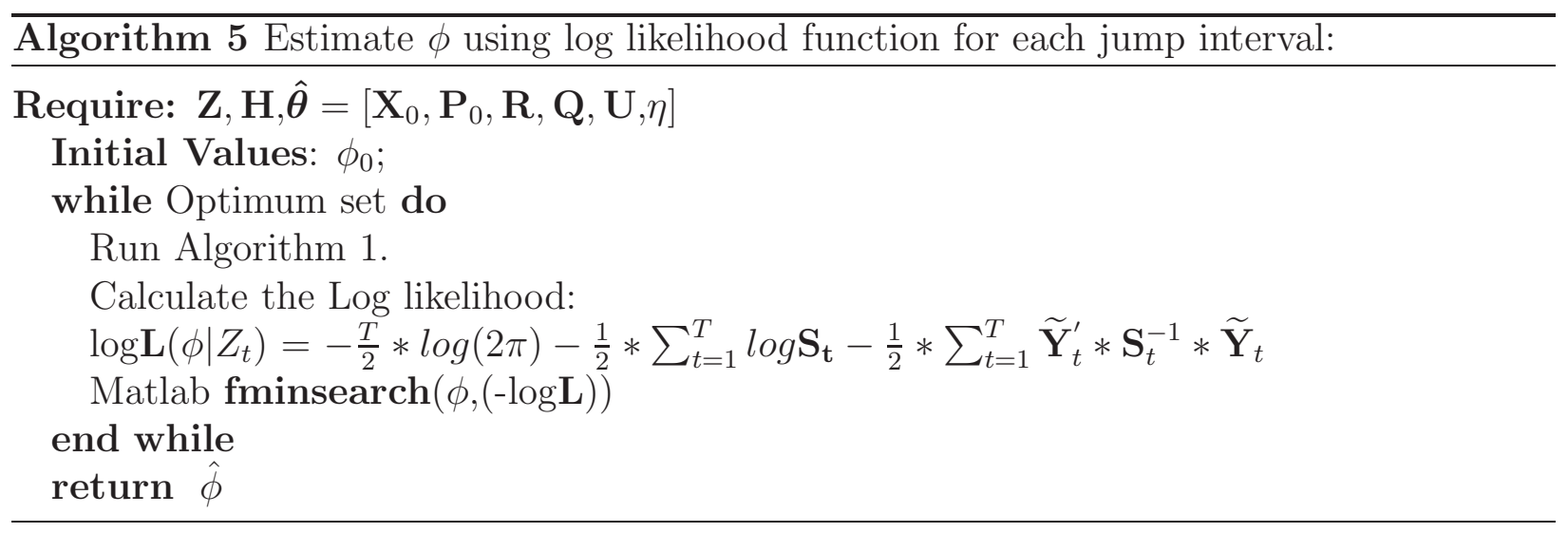

\subsection{Simulations}

The simulation procedure includes the following steps:

- Create the multi-factor beta signals ( $\beta$, s and h) using the PMR Model as described in the previous section.

- Create the random market return, SMB and HML signals. 


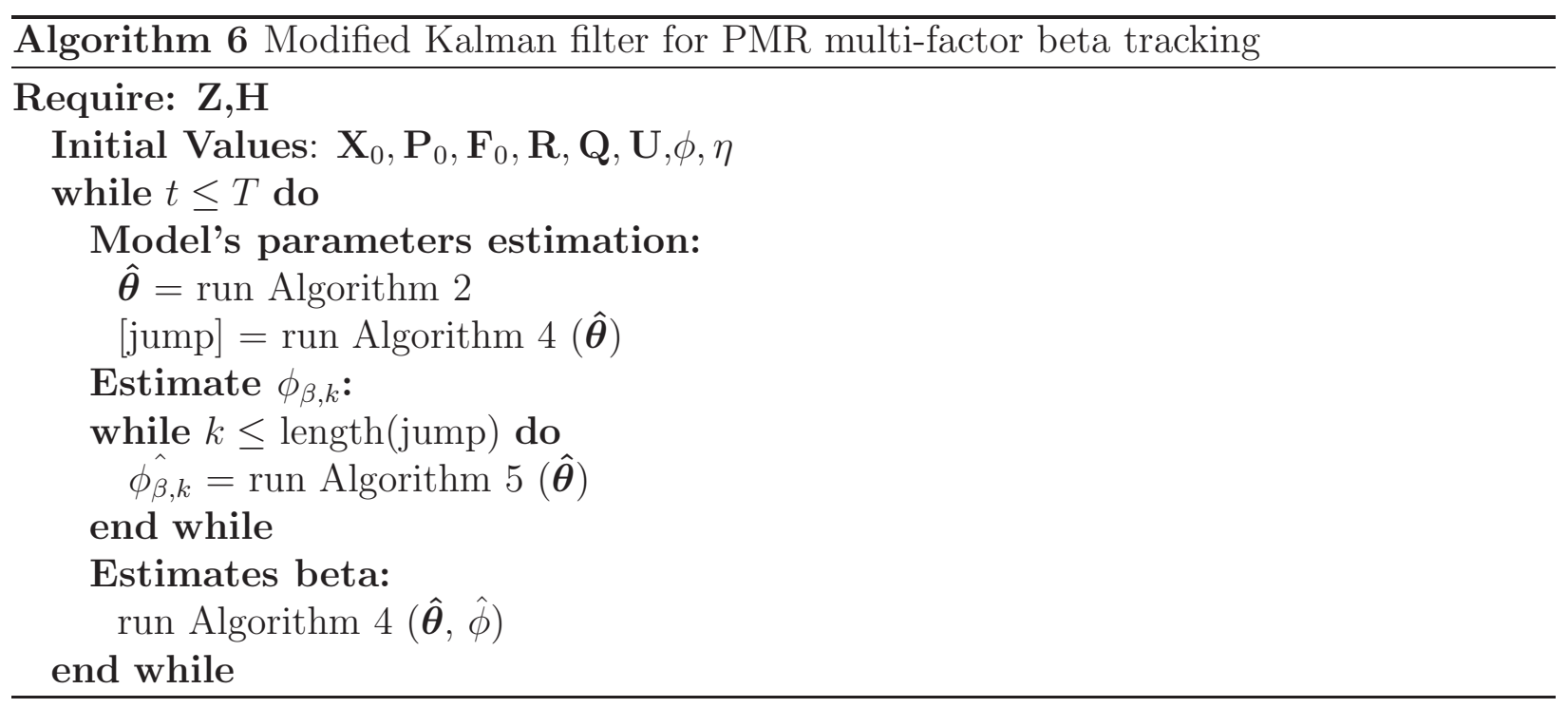

- Calculate the asset return signal based on the Fama-French model using the simulated market return, SMB, HML signals and multi-factor beta signals.

- Using the modified Kalman filter Algorithm 6 to track the $\beta, \mathrm{s}$ and $\mathrm{h}$ using the simulated asset return, market return, SMB, and HML signals.

- Compare the tracking result to the original simulated multi-factor beta signal based on the RMSE.

- Vary the $\phi, \sigma_{\epsilon}^{2}, \sigma_{\eta}^{2}$ parameters to test the tracking performance when the noise variance changes.

Monte-Carlo simulations are performed one hundred times to evaluate the estimation performance based on the average RMSE of the multi-factor beta and errors in the asset's return. The effects of changing the noise standard deviation in the observation model $\sigma_{\epsilon}$ and the noise standard deviation in the state model $\sigma_{\eta}$, are determined by the simulation results shown below.

Simulation 1: Testing the efficiency of the tracking method assuming that the multifactor beta follows the PMR model.

Figure 5.2 and 5.3 display the multi-factor beta tracking results using the simulated signals with 500 samples. The set of noise's variance and model's parameter are the same as described in Section 5.2. The estimates of $\beta$ in Figure 5.2, $\mathrm{s}$ and $\mathrm{h}$ in Figure 5.3 detected all 
the jumps accurately and very closely to the original signals as compared to the PCM. This shows the modified Kalman filter is efficient in tracking the multi-factor PMR beta in the Fama-French three factors model, if the multi-factor beta is following the PMR Model.

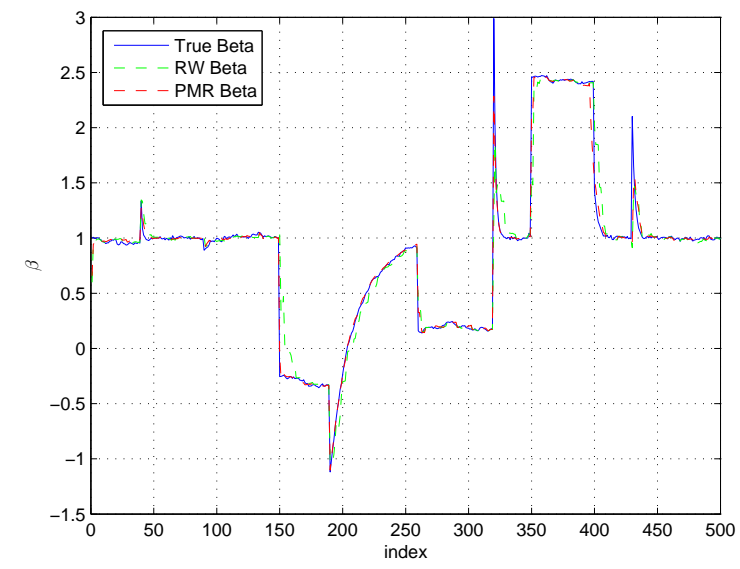

Figure 5.2: An example of PMR multi-factor beta tracking for $\beta$
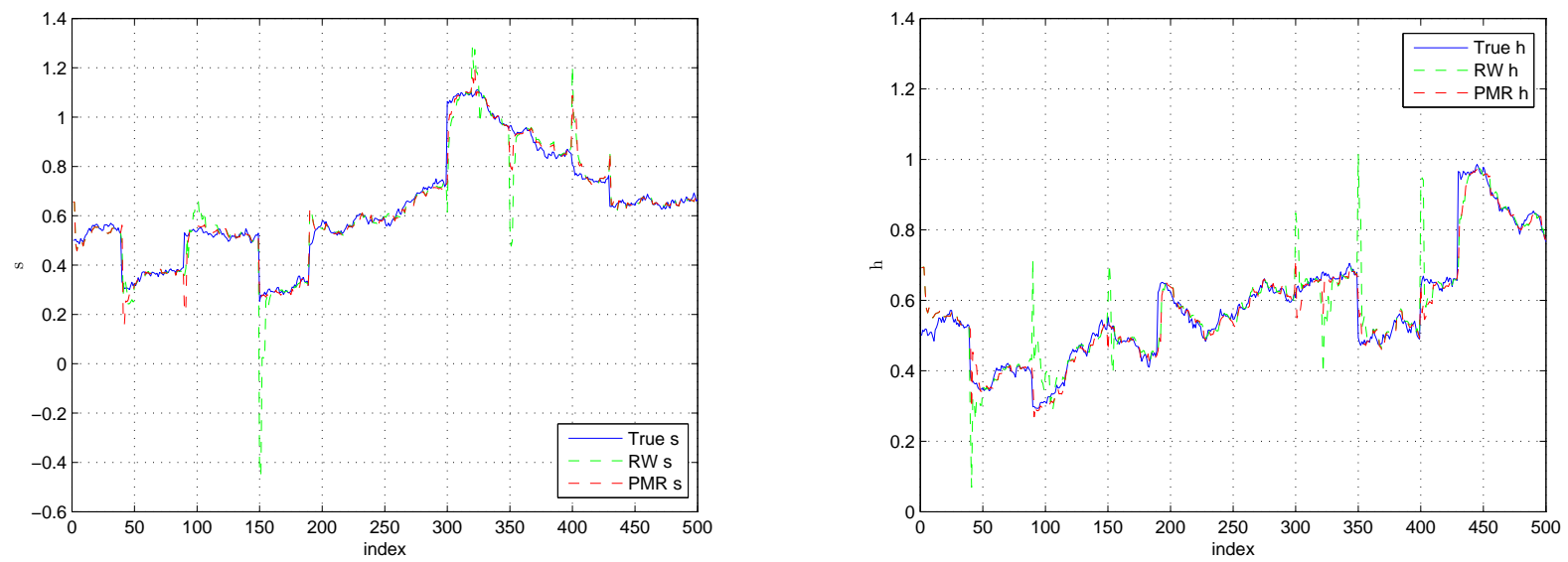

Figure 5.3: An example of PMR multi-factor beta tracking for $\beta_{S M B}$ and $\beta_{H M L}$

Simulation 2: The effect of noise in the Fama-French observation model.

The standard deviation of noise $\sigma_{\epsilon}$ from the observation model is set in the range of [0.025:0.25]. The other parameters are set as follow: $\sigma_{u_{\beta}}=1, \sigma_{u_{s}}=\sigma_{u_{h}}=0.2, \sigma_{\zeta_{\beta}}=\sigma_{\zeta_{s}}=\sigma_{\zeta_{h}}=0.1$, $\phi_{\beta, 0}=0.7$. Figure 5.4 indicates that when the noise in the observation model increases, the accuracy in multi-factor beta estimation decreases implied by the increase in RMSE. Figure 5.4(a) displays the RMSE of the calculated asset return from the estimated multi-factor beta 
as compared to the generated asset return. Figure 5.4(b)(c)(d) show the RMSE of estimated $\beta, \mathrm{s}$, and $\mathrm{h}$ in comparison to the generated signals. In all cases, the modified Kalman filter with PMR state model and the Fama-French observation model results in a better estimation of time-varying $\beta, \mathrm{s}$, and $\mathrm{h}$ as compared to traditional $\mathrm{PC}$ and $\mathrm{RW}$ models.
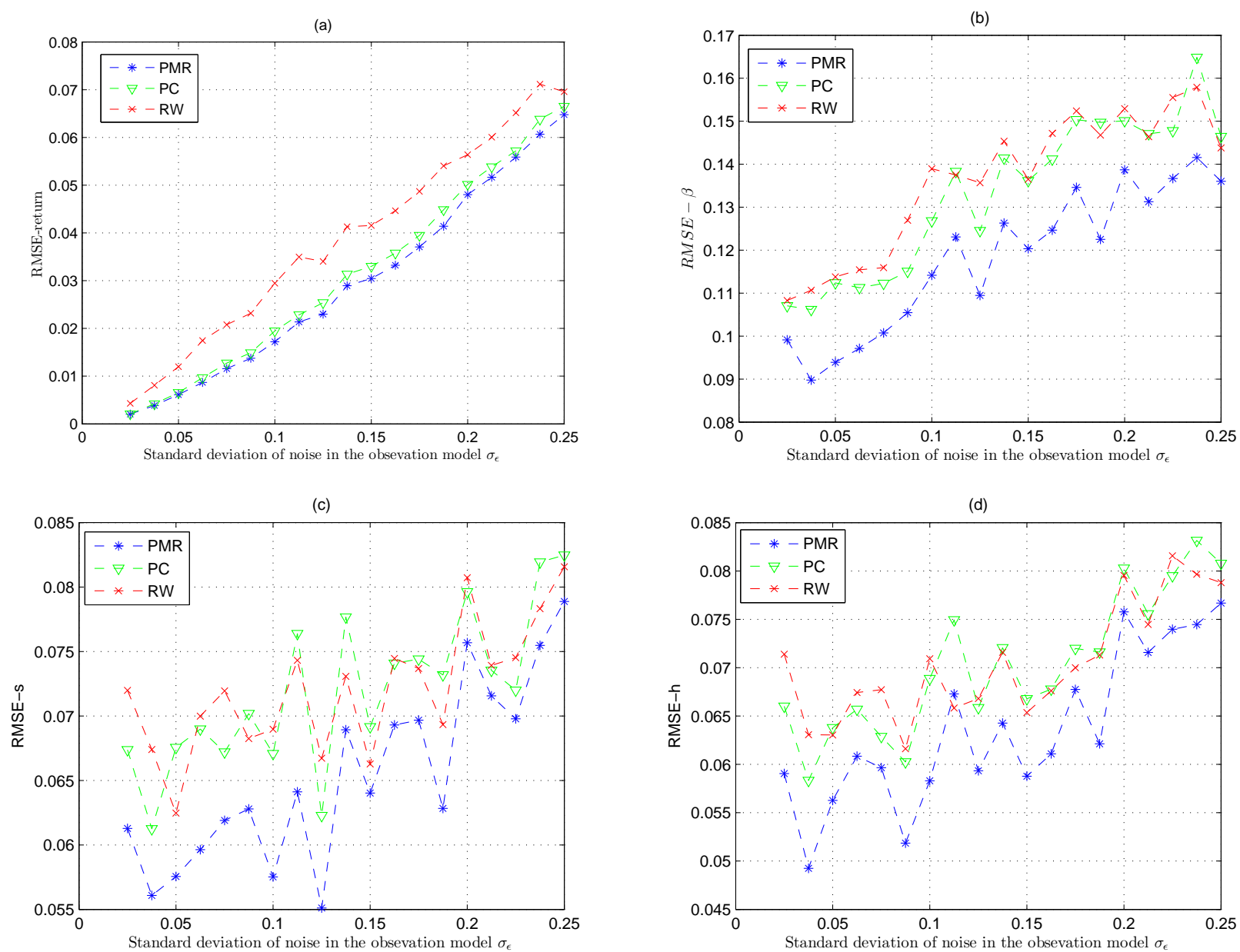

Figure 5.4: Effect of noise in the observation model on the PMR beta tracking

Simulation 3: The effect of noise in the PMR state model.

The variance of the noise $\sigma_{\zeta}$ from the state model is set in the range of [0.05:0.20]. The other parameters are set the same as the simulation 2 except $\sigma_{\epsilon}=0.025$. The results in Figure 5.5 and Figure 5.6 indicate a great improvement in the estimation of $\beta$, s, and $\mathrm{h}$ using the PMR model in comparison to the RW and PC, based on the assumption that the multi-factor risk follows a PMR hold. 


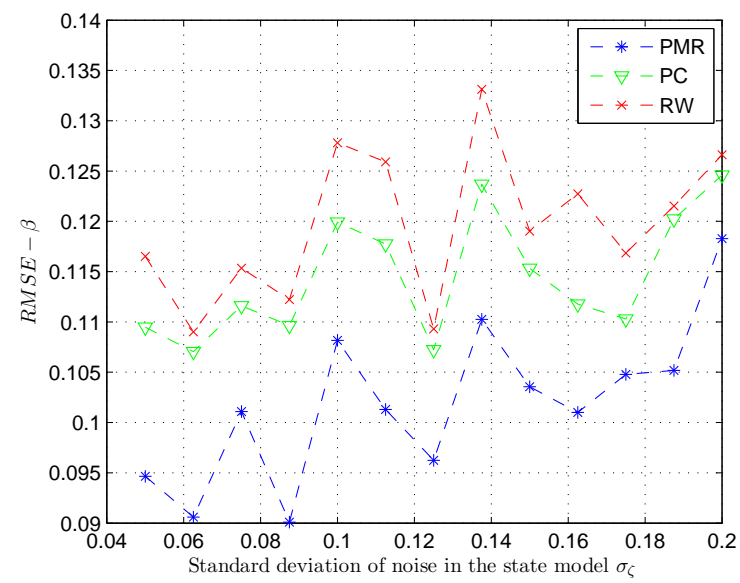

Figure 5.5: Effect of noise in the state model on the PMR $\beta$ tracking
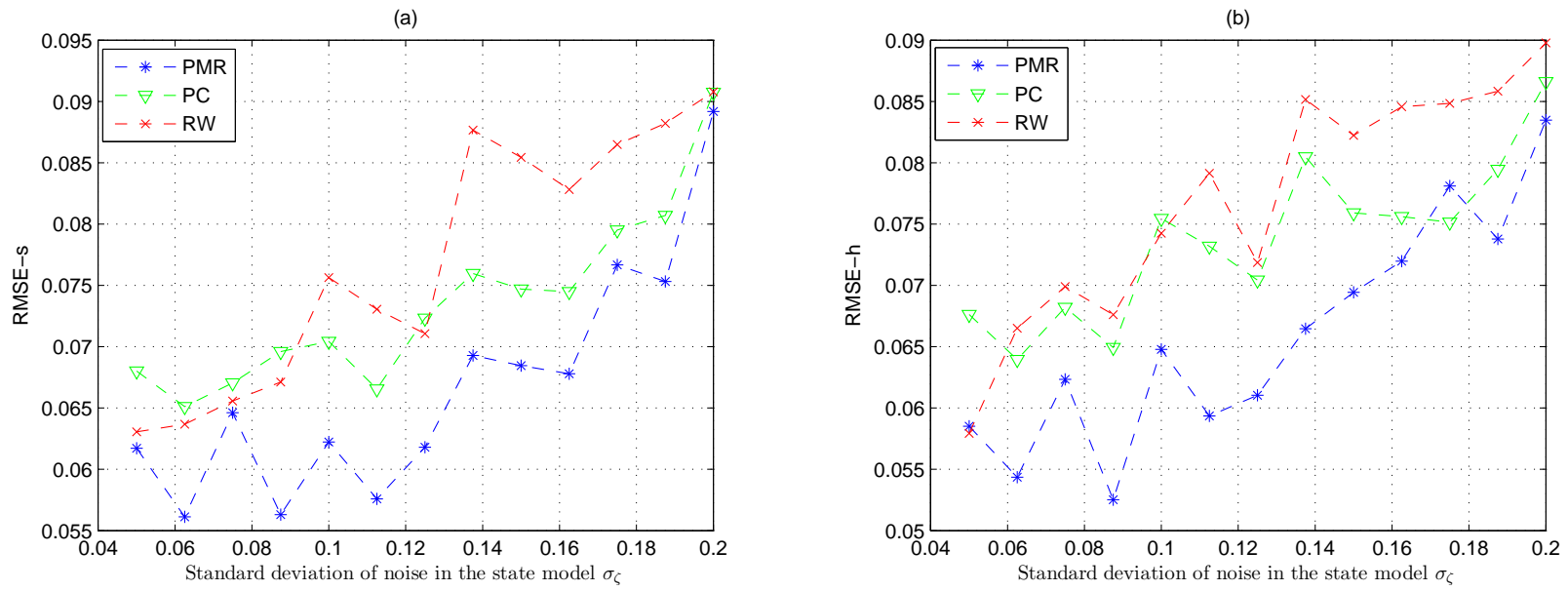

Figure 5.6: Effect of noise in the state model on the PMR $\beta_{S M B}$ and $\beta_{H M L}$ tracking

\subsection{Empirical Tests}

In this empirical test, we use the same data set of individual stocks and portfolios in chapter IV. The RMSE and AIC criteria are calculated to evaluate the performance of the modified Kalman filter in tracking the PMR multi-factor beta. The test results are displayed in Table 5.1 and 5.2 .

The following are case studies that indicate the abnormal changes in market risk and the time variance in the mean reverting factor $\phi$; the manner in which it adapts to the different type of events and how the stocks or portfolios perform after significant events.

\section{Cisco System Inc. (CSCO)}


Table 5.1: FF-PMR test results for individual stocks

\begin{tabular}{|c|c|c|c|}
\hline \hline Ticker & RMSE & AIC & Max-loglikelihood \\
\hline AAPL & 0.1144 & -1.3252 & 213.7317 \\
IBM & 0.0498 & -3.0169 & 1464.2 \\
GE & 0.0419 & -3.3103 & 1605.9 \\
XOM & 0.0335 & -3.5985 & 1745.1 \\
CSCO & 0.0778 & -1.8676 & 196.5568 \\
MSFT & 0.0680 & -2.0869 & 266.8225 \\
RIMM & 0.1299 & -0.3899 & 25.3264 \\
\hline
\end{tabular}

Table 5.2: FF-PMR test results for portfolios

\begin{tabular}{|c|c|c|c|}
\hline \hline Portfolio & RMSE & AIC & Max-loglikelihood \\
\hline Oil & 0.0318 & -3.8096 & 1847.0 \\
Autos & 0.0362 & -3.5530 & 1723.1 \\
Banking & 0.0329 & -3.5615 & 1727.2 \\
Real Estate & 0.0587 & -2.6856 & 1304.1 \\
Computers & 0.0354 & -3.6751 & 1782.1 \\
\hline
\end{tabular}

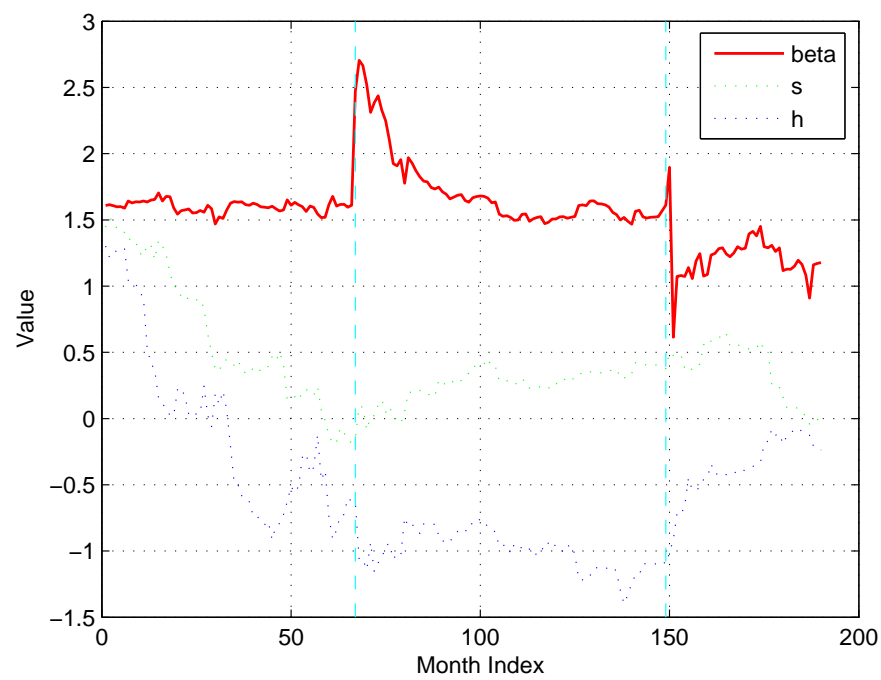

Figure 5.7: PMR multi-factor $\beta$ tracking of CSCO

Figure 5.7 displays the multifactor beta estimation results for CSCO based on the PMR model. There are two significant jumps at index 67th and index 149th in the "market risk" $(\beta)$, which corresponds to September 2001 and July 2008. In CSCO history, there was an important announcement made by Daniel Scheinman, the Senior Vice President, on 
September 13th that "its board of directors has authorized a stock repurchase program of up to $\$ 3$ billion over the next two years. The program is effective immediately" 1 . During a stock repurchase program, a company asks stockholders to tender their shares for repurchase by the company. Although stockholders who offer their shares for repurchase may be at a disadvantage if they are not fully aware of all the details. As such, an investor may file a lawsuit with the company, which is seen as a risk ${ }^{2}$. In July 2008, our analysis show that the market risk suddenly went up, then dropped down and reverted slowly to its mean. CSCO shares slipped to a new 52-week low in the first week of July 2008 after a pair of Wall Street analysts voiced concerns about the high-tech giant's upcoming quarter, which may be pressured by a slowing U.S. economy. The stock has lost about one-third of its value since hitting a 7-year high in November of 2007, the Wall Street Journal reports. Wednesday's drop came after analysts for UBS and RBC Capital Markets issued reports that suggested the company's outlook for the fourth fiscal quarter (end of July) would be soft ${ }^{3}$. However, the official quarter report announced that the company's profit and growth still increased ${ }^{4}$. With low prices and a promising future for the company, investors would be more confident to invest in the stock considering the risk was going down. The two different $\phi$ values were estimated for the two events which are 0.9162 for September 2001 and 0.9728 for July 2008. The larger $\phi$ indicates the effect of the events in the long term investment.

\section{Research In Motion Limited (RIMM)}

Figure 5.8 displays the multifactor beta analysis of RIMM. Focussing on the market risk, there is a jump and it slowly reverts to its previous risk as estimated $\phi=0.847$ at index 67th which corresponds to October 2010. This jump can be explained as an important announcement was made on September 27, 2010. RIMM unveiled the long rumoured BlackBerry PlayBook tablet that will compete with Apple's iPad. With all fancy features such as uncompromised web browsing, true multitasking and high performance multimedia, the new product was expected to bring RIMM back to being a leader in technology. This good

\footnotetext{
${ }^{1}$ http://www.sec.gov/Archives/edgar/data/858877/000109581101504917/0001095811-01-504917.txt

${ }^{2}$ http://www.investopedia.com/exam-guide/cfa-level-1/corporate-finance/stock-dividendsrepurchases.asp\#axzz1yLISDwNT

${ }^{3} \mathrm{http}: / /$ www.marketwatch.com/story/correct-cisco-hits-new-low-on-worries-about-it-spending-economy

${ }^{4}$ http://www.financial-gauges.com/2008/08/csco-financial-analysis-through-july.html
} 


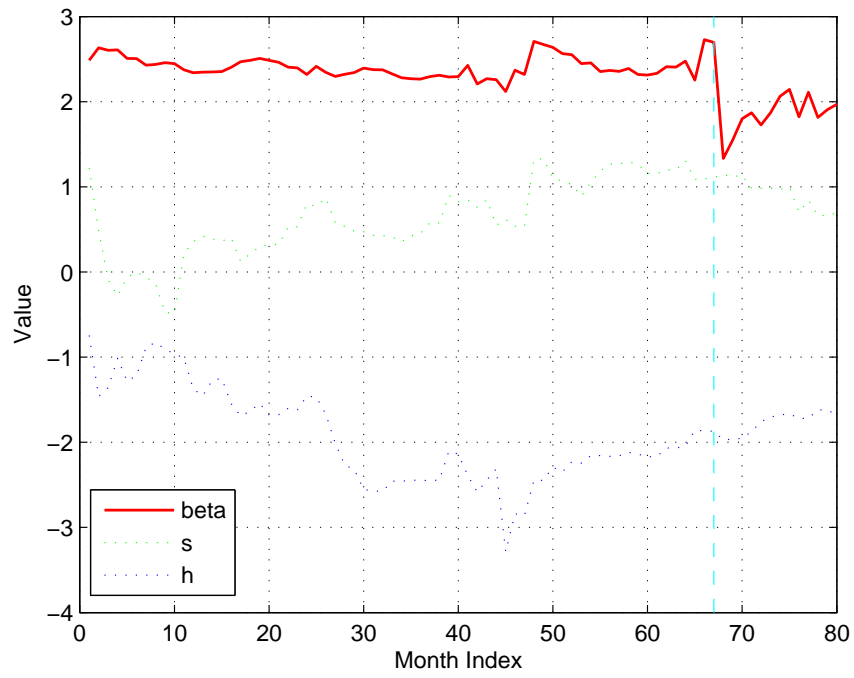

Figure 5.8: PMR multi-factor $\beta$ tracking of RIMM

news gave investors a higher confidence level to invest in RIMM stock, causing a reduction in risk ${ }^{5}$. The BlackBerry PlayBook was officially released to US and Canadian consumers on April 19, 2011.

\section{Microsoft Corp. (MSFT)}

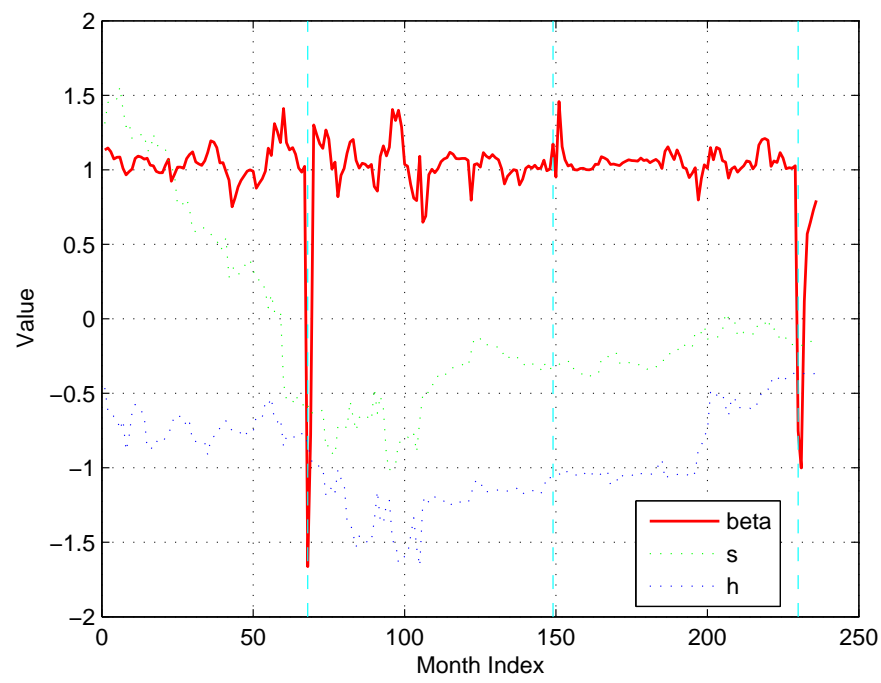

Figure 5.9: PMR multi-factor $\beta$ tracking of MSFT

Figure 5.9 indicates the multifactor beta risk of MFST. There are two significant drops in

\footnotetext{
${ }^{5}$ http://wallstreetpit.com/46020-rim-unveils-its-long-rumored-blackberry-playbook-tablet
} 
the market risk at index 68th and index 230th which corresponds to May 2011 and October 1997. The reverting after the jumps are also very quick as the estimated $\phi=0.109$ and $\phi=0.23$, respectively. In October 1997, the Department of Justice (DOJ) filed a motion in the Federal District Court, stating that Microsoft violated an agreement signed in 1994 and asked the court to stop the bundling of Internet Explorer with Windows ${ }^{6}$. Microsoft filed its response to the DOJ petition by producing numerous documents demonstrating that the company had planned to incorporate Web browsing functionality into the Microsoft Windows 95 operating system (code-named "Chicago") as early as 1993, and that the DOJ knew of Microsoft's intent prior to the signing of the 1994 consent decree ${ }^{7}$. Through all of their efforts, Microsoft launched Windows 98 on schedule on June 25, 1998 and earned profit after that. This would explain why the risk recovered so quickly after the bad news as the risk jumped down to -1.5 .

In May 10, 2011, Microsoft confirmed that they had bought Skype for $\$ 8.5$ billion. This is one of the biggest acquisitions Microsoft has ever made up to date ${ }^{8}$. Buying Skype, the leading brand within VoIP technologies with 60 million registered users globally, Microsoft has a significant advantage to compete with both Google and Apple as these companies are in the process of developing their own VoIP technologies: Apple (FaceTime) and Google (Voice). This move could help Microsoft recover its loss in online communication. However, on the investors side, they were concerned about this high price purchase. Michael Clendenin, director of consulting firm RedTech Advisors, implied that "Microsoft has a high wall to climb to prove to investors that Skype is a necessary linchpin for the company's online and mobile strategy". Ben Woods, head of research group of CCS Insight, also concerned with "how do Skype assets work for Microsoft... how do you justify the price?" 9 .

\section{Automobile Industry Portfolio}

Figure 5.10 displays the abnormal changes in market risk of the automobile industry portfolio. Using the PMR model, the four significant jumps are detected at index 84 (Aug1989), 182 (Nov-1997), 281 (Feb-2006), and 319 (Apr-2009). The abnormal change in beta in

\footnotetext{
${ }^{6}$ http://news.bbc.co.uk/2/hi/in_depth/business/2000/microsoft/637808.stm

${ }^{7}$ http://www.microsoft.com/en-us/news/press/1997/nov97/dojpetpr.aspx

${ }^{8}$ http://www.bbc.co.uk/news/business- 13343600

${ }^{9}$ http://online.wsj.com/article/SB10001424052748703730804576313932659388852.html?ru=yahoo
} 


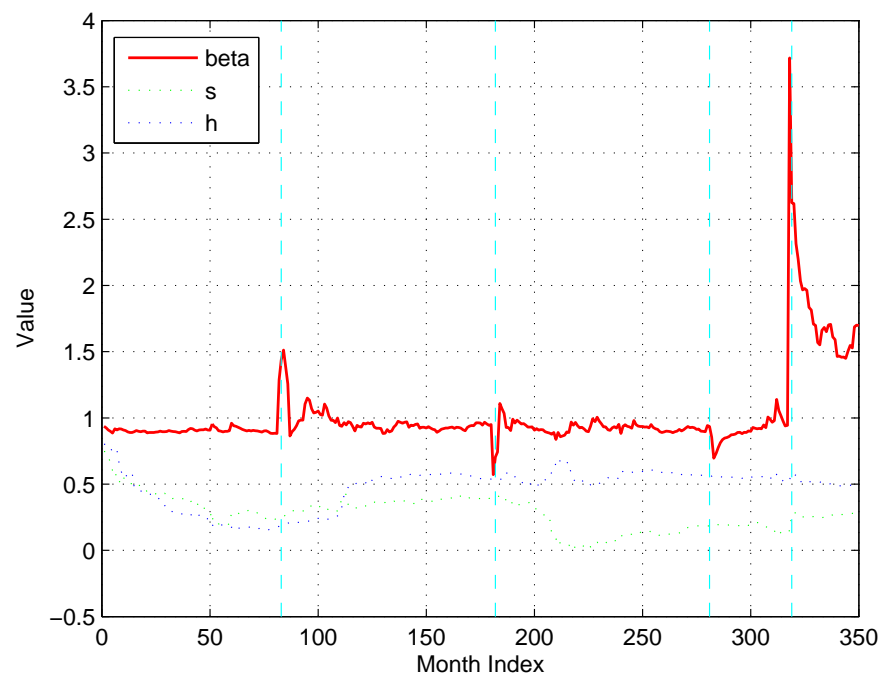

Figure 5.10: PMR multi-factor $\beta$ tracking of automobile industrial portfolio.

November 1997 is due to the global mini market crash on 27 October, caused by the economic crisis in Asia ${ }^{10}$. Risk went down and quickly reverted to the equilibrium with estimated $\phi=$ 0.2943. Recovery was fast since the market recovered the following day. In the U.S., the Dow Jones Industrial Average gained a record of 337.17 points, closing at 7,498.32. One billion shares were traded on the New York Stock Exchange for the first time ever. In February 2006, the foreign carmakers were expanding, hiring, and stoking local growth brought upon good news about America's auto industry ${ }^{11}$. Nissan (NSANY), Toyota (TM), Honda (HMC), and Mercedes (DCX), opened assembly plants and made investors believe that there would be growth in the auto industrial portfolio in the market since many companies expanded their production. The market risk went down and slowly reverted to one with the estimated reverting factor $\phi=1$ according to our analysis.

In April 2009, the effect of the automotive industry crisis of 2008-2010, a part of the global financial downturn, to US automobile industry peaked. The two out of American "Big Three" automakers (General Motors, Ford, and Chrysler) faced bankruptcy. On April 30, Chrysler filed for Chapter 11 bankruptcy protection from its current creditors. The U.S. government had described Chrysler's action as a "pre-packaged surgical bankruptcy"

\footnotetext{
${ }^{10}$ http://money.cnn.com/1997/10/27/markets/marketwrap/

${ }^{11}$ http://www.businessweek.com/magazine/content/06_07/b3971057.htm
} 
through which it hopes the company will be able to exit the bankruptcy process within 30 to 60 days $^{12}$. GM also announced that it would cut 21,000 jobs and close 13 factories. GM had until the end of May to convince the government it had a viable business plan to restructure outside the Chapter 11 reorganization ${ }^{13}$. GM then filed for Chapter 11 in June. The crises involving the two typical examples above of US automobile industry causes the portfolio's market risk to go up significantly. Fortunately, due to the US and Canadian government's bailout, the industry slowly recovered indicated by the slow reversion in risk at estimated $\phi$ $=0.9998{ }^{14}$

\subsection{Summary}

In this chapter, the PMR model is proposed to express the market risk behaviour based on the Fama-French model. The model allows beta to change according to the significant events and revert to its mean with different reverting rates. The empirical test cases indicated that the RMSE reduces by using the PMR for our selected stocks and portfolios. The sudden

changes in beta and the variance in the reverting rate can also be explained efficiently through the economic events in our case studies. By simulation and empirical test, we prove that the model is efficient in tracking multifactor beta of stocks and portfolios in the market.

\footnotetext{
${ }^{12}$ http://www.thestar.com/business/article/626832-chrysler-files-for-bankruptcy

${ }^{13}$ http://money.cnn.com/2009/06/01/news/companies/gm_bankruptcy/

${ }^{14}$ http://www.thestar.com/business/article/626832-chrysler-files-for-bankruptcy
} 


\section{Chapter 6}

\section{Conclusion and Future Works}

In this thesis, the performance of the Fama-French model in estimating the systematic risk is tested in comparison to the CAMP model. The better performance of the Fama-French model over the CAPM in estimating the systematic risk observed in our analysis, indicates that not only "market risk" but other risk factors such as "value risk" and "size risk" are also important for investors to look at. We face the challenges in finding the optimal interval and data frequency for the multi-factor beta using the traditional OLS estimation. The variance in the performance criteria of the empirical test confirms the previous research in a sense that there is no particular method in finding the best time interval for the constant betas assumption. Although this assumption has been used broadly in practice, economists need to consider the time-varying issues of risks.

The constant multifactor beta analysis results lead us to explore the time-varying characteristic of the multi-factor beta. By applying the time-varying MR, RW and RC models to the multi-factor beta analysis using the Kalman filter, great improvement is shown in the multi-factor beta estimation as compared to the OLS method. The time-varying multifactor beta empirical test is conducted on both selected individual stocks and industrial portfolios. Our tests prove the validity of the time-varying signal processing models in analyzing the multifactor systematic risk in the Fama-Fench model for both individual stocks and portfolios.

Based on the observation from the time-varying multi-factor beta analysis, there are significant jumps in the multi-factor systematic risk. The PCM and modified Kalman filter are used for the purpose of making these observations more clear. Our empirical test indicates 
that the "market risk", "value risk", and "size risk" can be tracked using the PCM and the modified multivariate Kalman filter. Through multiple case studies, the abnormal changes in the multi-factor beta are explained by economic events. This study demonstrates the important effects of events on the sudden changes in the multifactor systematic risk.

The economic events found in our case studies are able to explain the abnormal changes in the multifactor beta for both individual stocks and portfolios. The types of events we found on the testing stocks and portfolios are very diverse such as stock split, changing in company management, government control, war, financial crisis, industry bubble and bust, recession, and etc. An event could affect not only one of the multi-factor risk but it can also affect all the factor risks. By building the beta tracking framework using the modified multivariate Kalman filter based on the PCM and Fama-French model, we provide a new tool which hopefully helps financial analysts to have a more in depth look into the business performance of firms or industries in order to analyze and predict the risk of their invested securities.

The MR, RW, RC and PC models bring us a new idea of modeling the multi-factor systematic risk based on the observation that beta tends to jump when there is a significant event then reverts to its mean. The proposed PMR model expresses that beta is affected by economic events on the market and the investments in different scenarios. The model not only captures the event but also considers the effect of the event afterwards, given the time varying reverting parameter $\phi$. Some events could cause a sudden jump in beta and quickly revert it to the mean value while other events could take a long time to recover after its sudden change. Our new model outperforms the traditional RW and PCM in tracking the multifactor beta based on the simulations. Our case studies indicate that the model does convey the behaviour of the market risk during the event period while still maintaining minimal errors in beta estimation. This model shows potential in becoming one of the efficient time-varying beta models to analyze the systematic risk in stock markets.

In summary, our research verifies that the time-varying characteristic of multifactor systematic risk exists and needs to be considered when investing in stocks. The time-varying signal processing models are more efficient in tracking the multifactor beta as compared to the traditional regression method. The new piecewise mean reverting model implies the 
significant impacts of different types of events on beta. The beta behaviour varies depending on the type of economic event. Our multifactor systematic risk analysis based on the signal processing models framework indicates the connection between signal processing principles and financial manner.

In the future, we would like to continue researching the following matters:

- The model's parameters estimation.

In the thesis, the models' parameters are estimated based on the traditional maximum log likelihood function. However, in the empirical test, sometimes the estimated set of parameters fail to describe the model and the initial parameter needs to change manually to reestimate the model's parameters. We would also like to build a more accurate estimation algorithm that is not only based on the log likelihood but also on other criteria such as RMSE or AIC.

- Apply the multi-factor piecewise mean-reverting model in a more flexible way. In chapter $\mathrm{V}$, because of limited time, we were only able to test the effect of the model on the market risk. However, we believe that if applied correctly and a satisfactory estimation algorithm for $\phi$ is achieved, the PMR could also work well in analyzing the "size risk" and "value risk". An empirical test needs to be done to explore this.

- An alternative algorithm to detect the jump process.

In chapter IV and V, the modified Kalman filter with Bayes' criteria is used to detect the jumps in beta. However, there may be an alternative method that could perform better. Tracking jump processes using particle filtering has been paid more attention to recently [69]. It would be a great candidate in building a new multi-factor beta tracking and used to compare the performance to our current algorithm. In addition, the Markov Switching model with the two states one and zero can also be used to test.

- Try different models for each risk factor and evaluate the performance.

Our empirical test done on the multi-factor beta assumes that all risks follow the same model such as MR, RW or PMR. However, we could perform an empirical test on a larger amount of stocks or portfolios to evaluate if there is a different set of models for 
the multi-factor beta. For example, is it possible for the "market risk" to follow the PMR model while the "size risk" follows the RWM and the "value risk" follows the PCM?

- Carhart's four-factors model.

The model is similar to the Fama-French three-factor model, with an additional factor "PR1YR" to capture momentum. According to Carhart, the model can be thought of as a performance attribution model, where the coefficients of the factor-mimicking portfolios indicate the proportion of mean return explained by the four factors [26]. It can be applied to our framework to test the performance of this multi-factor model in comparison to the Fama-French model. 


\section{Bibliography}

[1] R.S. Tay, Analysis of Financial Time Series, 3rd Edition, Wiley, 2010.

[2] E. Jay, P. Duvaut, S. Darolles, and A. Chretien, "Multifactor Models", IEEE Signal Processing Magazine, vol. 28, no. 5, pp. 37-48, 2011.

[3] E. Fama and K. French, "Multifactor Explanations of Asset Pricing Anomalies", The Journal of Finance, vol. 51, no. 1, 1996.

[4] N. Groenewold and P. Fraser, "Time-varying Estimates of CAPM Betas", Mathematics and Computers in Simulation, vol. 48, pp. 531-539, 1999.

[5] R.E. Kalman, "A New Approach to Linear Filtering and Prediction Problems", Journal of Basic Engineering, vol. 82, pp. 35-45, 1960.

[6] E. Fama and K. French, "The Cross-Section of Expected Stock Returns", The Journal of Finance, vol. 17, no. 2, pp. 427-465, 1992.

[7] H.W. Sorenson, "Least-squares Estimation: from Gauss to Kalman", IEEE Spectrum, vol. 7 , no. 7 , pp. 63-68, 1970.

[8] G. Fusai and A. Roncoroni, Implementing Models in Quantitative Finance: Methods and Cases, Springer Finance, Springer, 2008.

[9] A. Das and T.K. Ghosal, "Market Risk Beta Estimation Using Adaptive Kalman Filter", International Journal of Engineering Science and Technology, vol. 2, no. 6, pp. 1923-1934, 2010.

[10] M.S. Grewal, A.P. Andrews, Kalman Filtering: Theory and Practice Using MATLAB, Second Edition, John Wiley \& Sons, Inc., ISBNs: 0-471-39254-5, 2001. 
[11] H. Akaike, "A New Look at the Statistical Model Identification", IEEE Transactions on Automatic Control, vol. 19, no. 6, pp. 716-723, 1974.

[12] J.P. Huelsenbeck, K.A. Crandall, "Phylogeny Estimation and Hypothesis Testing Using Maximum Likelihood", Annual Review of Ecology and Systematics, vol. 28, pp. 437-466, 1997.

[13] J.D. Hamilton, Time Series Analysis. Princeton, NJ: Princeton University Press, 1994.

[14] R.W. Faff and R.D. Brooks, "Time-varying Beta Risk for Australian Industry Portfolios: A Comparison of Modelling Techniques", Australian Journal of Management, vol. 23, no. 1, pp.1-22, 1998.

[15] R.D. Brooks, R.W. Faff, and J.H.H. Lee, "The Form of Time Variation of Systematic Risk: Some Australian evidence", Applied Financial Economics, vol. 2, pp. 191-198, 1992.

[16] R.W. Faff, D. Hillier, and J. Hillier, "Time Varying Beta Risk: An Analysis of Alternative Modelling Techniques", Journal of Business Finance Accounting, vol. 27, no. 5\&6, pp. 523-554, 2000.

[17] R.D. Brooks, R.W. Faff, and J.H.H. Lee, "Beta Stability and Portfolio Formation", Pacific Basin Finance Journal, vol. 2, pp. 463-79, 1994.

[18] V. Fernandez, "The CAPM and Value at Risk at Different Time-scales", International Review of Financial Analysis, vol. 15, no. 3, pp. 203-19, 2006.

[19] R. Gencay, F. Selcuk, and B. Whitcher, "Systematic Risk and Timescales", Quantitative Finance, vol. 3, no. 2, pp. 108-16, 2003.

[20] R. Gencay, F. Selcuk, and B. Whitcher, "Multiscale Systematic Risk", Journal of International Money and Finance, vol. 24, no.1, pp. 55-70, 2005.

[21] J. Yao, J. Gao, "Computer-Intensive Time-Varying Model, Approach to the Systematic Risk of Australian Industrial Stock Return", Australian Journal of Management, vol. 29, no. 1, pp. 121-145, 2004. 
[22] G.N. Gregoriou and R. Pascalau, Financial Econometrics Modeling, Palgrave Macmillan, 2011.

[23] E. Fama, "Random Walks in Stock Market Prices", Financial Analysts Journal, vol. 21, no. 5, pp. 55-59, 1965.

[24] E. Fama and K. French, "The Capital Asset Pricing Model: Theory and Evidence", The Journal of Economics Perspectives, vol. 18, no. 3, pp. 25-46, 2004.

[25] Y. Wang and Y. Gao, "Extension on F-F 3 Factors Asset Pricing Model and Related Empirical Researches", Information Management, Innovation Management and Industrial Engineering (ICIII), pp. 361-365, 2010.

[26] M.M. Carhart, "On Persistence in Mutual Fund Performance", Journal of Finance, vol. 52, pp. 57-82, 1997.

[27] O. Hu, "Applicability of the Fama-French Three-factor Model in Forecasting Portfolio Returns", The Journal of Financial Research, vol. 30, no. 1, pp. 111-127, 2007.

[28] S.J. Brown and J.B. Warner, "Using Daily Stock Returns - The Case of Event Study", Journal of Financial Economic, vol. 14, pp. 3-31, 1985.

[29] M.R. Gibbons, "Multivariate Tests of Financial Models - A New Approach", Journal of Financial Economic, vol. 10, pp. 3-27, 1982.

[30] C. Tofallis, "Investment Volatility: A Critique of Standard Beta Estimation and a Simple Way Forward", European Journal of Operational Research, vol. 187, pp. 13581367, 2008.

[31] C. Wells, The Kalman Filter in Finance, Kluwer Academic Publishers, Dordrecht, 1996.

[32] D. Kim, "The Extent of Non-stationarity of Beta", Review of Quantitative Finance and Accounting, vol. 3, pp. 241-254, 1993.

[33] F.J. Fabozzi and J.C. Francis, "Beta as Random Coefficient", Journal of Financial and Quantitative Analysis, vol. 13, no. 1, pp. 106-116, 1978. 
[34] G.J. Alexander and P.G. Benson, "More on Beta as a Random Coefficient", Journal of Financial and Quantitative Analysis, vol. 17, no. 1, pp. 27-36, 1982.

[35] T. Bos and T.A. Ferson, "Nonstationarity of the Market Model, Outliers, and the Choice of Market Rate of Return", Advances in Pacific-Basin Financial Markets, vol. 1, JAI Press, Greenwich, 1995.

[36] D.E. Allen, A.K. Singh, and R.J. Powell, "Asset Pricing, the Fama-French Factor Model and the Implications of Quantile Regression Analysis", FEMARC Working Paper Series, Edith Cowan University, 2009.

[37] F. Hayashi, Econometrics, Princeton University Press, ISBN 0-691-01018-8, 2000.

[38] Y.T. Chan, "A Kalman Filter Based Tracking Scheme with Input Estimation", IEEE Transactions on Aerospace and Electronic Systems, vol. 15, no. 2, pp. 237-244, 1979.

[39] J. Ohlson and B. Rosenberg, "Systematic Risk of the CRSP Equal-Weighted Common Stock Index: A History Estimated by Stochastic Parameter Regression", Journal of Business, vol. 55, no. 1, pp. 121-145, 1982.

[40] S. Sunder, "Stationarity of Market Risk: Random Coefficients Tests for Individual Stocks", Journal of Finance, vol. 35, no. 4, pp. 883-896, 1980.

[41] R. Simonds, L. LaMotte, and A. McWhorter, "Testing for Nonstationarity of Market Risk: An Exact Test and Power Considerations", Journal of Financial and Quantitative Analysis, vol. 21, no. 2, pp. 209-220, 1986.

[42] C. Wells, "Variable Betas on the Stockholm Exchange 1971-1989", Applied Financial Economics, vol. 4, no. 1, 1994.

[43] J.W. Cheng, "A Switching Regression Approach to the Stationarity of Systematic and Nonsystematic Risks: The Hong Kong Experience", Applied Financial Economics, vol. 7, no. 1, pp. 45-58, 1997.

[44] M. Blume, "On The Assessment of Risk", Journal of Finance, vol. 26, pp.177-181, 1971. 
[45] M. Blume, "Betas and Their Regression Tendencies", Journal of Finance, vol. 3, pp. 785-795, 1975.

[46] W.F. Sharpe, "Capital Asset Prices: A Theory of Market Equilibrium Under Conditions of Risk", The Journal of Finance, vol. 19, no. 3, pp. 425-442, 1964.

[47] H.M. Markowitz, "Portfolio Selection", Journal of Finance, vol. 7 , pp. 77-91, 1952.

[48] P.A.V.B. Swamy, G.S. Tavlas, "Random Coefficient Models: Theory and Applications", Journal of Economic Surveys, vol. 9, no. 2, pp. 165-196, 1995.

[49] W.F.M. De Bondt and R.H. Thaler, "A Mean-Reverting Walk Down Wall Street", The Journal of Economic Perspectives, vol. 3, no. 1, pp. 189-202, 1989.

[50] J.B. Berk, R.C. Green, and V. Naik, "Optimal Investment, Growth Options, and Security Returns", Journal of Finance, vol. 54, no. 5, pp. 1553-1607, 1999.

[51] G. Joao, L. Kogan, and L. Zhang, "Equilibrium Cross-Section of Returns", Journal of Political Economy, vol. 111(4), pp. 693-732, 2003.

[52] L. Zhang, "The Value Premium", Journal of Finance, vol. 60, no. 1, pp. 67-103, 2004.

[53] A. Ang and J. Chen, CAPM Over the Long-Run: 1926-2001, Working Paper, Columbia University and University of Southern California, 2003.

[54] G.E. Schwarz, "Estimating the Dimension of a Model", Annals of Statistics, vol. 6, no. 2, 461-464, 1978.

[55] L.J. Lockwood and K.R. Kadiyala, "Risk Measurement for Event-Dependent Security Returns", Journal of Business \&6 Economic Statistics, vol. 6, no. 1, pp. 43-49, 1988.

[56] G.V. Henderson Jr., "Problems and Solutions in Conducting Event Studies", The Journal of Risk and Insurance, vol. 57, no. 2, pp. 282-306, 1990.

[57] M. Scholes and J. Williams, "Estimating Betas from Nonsynchronous Data", Journal of Financial Economics, vol. 5, no. 3, pp. 309-327, 1977. 
[58] R.P. DeGennaro, K.B. Cyree, "A Generalized Method for Detecting Abnormal Returns and Changes in Systematic Risk", FRB of Atlanta Working Paper, no. 8, 2001.

[59] C. MacKinlay, "Event Studies in Economics and Finance", Journal of Economic Literature, vol. 35, no. 1, pp. 13-39, 1997.

[60] A. McWilliams and D. Siegel, "Event Studies in Management Research: Theoretical and Empirical Issues", The Academy of Management Journal, vol. 40, no. 3, 1997.

[61] W.T. Carleton and J. Lakonishok, "Risk and Return on Equity: The Use and Misuse of Historical Estimates", Financial Analysts Journal, vol. 41, no.1, pp. 38-47, 1985.

[62] F.K. Reilly and D.J. Wright, "A Comparison of Published Betas", The Journal of Portfolio Management, vol. 14, no. 3, pp. 64-69, 1988.

[63] S.P. Kothari, J.Shanken, and R.G. Sloan, "Another Look at the Cross-Section of Expected Stock Returns", The Journal of Finance, vol. 50, no. 1, pp. 185-224, 1995.

[64] D. Kent and S. Titman, "Evidence on the Characteristics of Cross-Sectional Variation in Stock Returns", Journal of Finance, vol. 52, pp. 1-33, 1997.

[65] B.M. Barber and J.D. Lyon, "Firm Size, Book-to-Market Ratio, and Security Returns: A Holdout Sample of Financial Firms", Journal of Finance, vol. 52, pp. 875-883, 1997.

[66] P.R. Daves, M.C. Ehrhardt, R.A. Kunkel, "Estimating Systematic Risk: The Choice of Return Interval and Estimation Period", Journal of Financial and Strategic Decisions, vol. 13 , no. $1,2000$.

[67] J. Bartholdy and P. Peare, "Estimation of Expected Return: CAPM vs. Fama and French", International Review of Financial Analysis, vol. 14, no. 4, pp. 407-427, 2005.

[68] B. Hansson and B. Nilsson, Are Time-Varying Betas Predictable?, Working Paper, Department of Economics, Lund University, 2007.

[69] M.A. Sebghati and H. Amindavar, "Tracking Jump Processes Using Particle Filtering", IEEE-Sensor Array and Multichannel Signal Processing Workshop, vol. 5, pp. 409, 2008. 
[70] T. Rajbhandary, "Piecewise Constant Modeling and Tracking of Systematic Risk in Financial Market", Master of Applied Science Thesis, Department of Electrical \& Computer Engineering, Ryerson University, 2011. 


\section{VITA}

NAME:

Luan Vo

PLACE OF BIRTH:

Vietnam

YEAR OF BIRTH:

1984

POST-SECONDARY EDUCATION

Vietnam National University of Technology

AND DEGREES:

Ho Chi Minh City, Vietnam, 2002-2007,

Bachelor of Engineering (Electrical Engineering).

HONORS AND AWARDS: D Deans List, Ryerson University 2008-2010.

Natural Science and Engineering Research

Council of Canada award 2010.

Ryerson Graduate Scholarship 2010-2012.

Academic Achievement Award from Ontario

University Athletics 2009.

RELATED WORK EXPERIENCE: Chip Designer

Arrive Technologies, Inc.

2007

Publications:

Vo, L., Zhang, X.P., "Multifactor Systematic Risk Analysis based on Piecewise Mean Reverting Modeling and Multivariate Kalman Filter ", Journal of Financial and Quantitative Analysis. (To be submitted) 